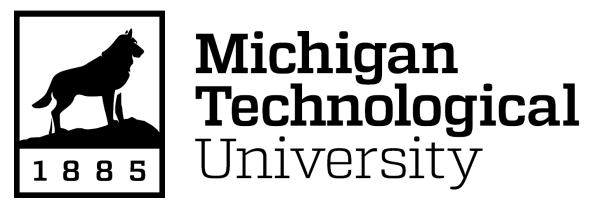

Michigan Technological University Digital Commons @ Michigan Tech

Dissertations, Master's Theses and Master's Reports

2018

\title{
GROUND DEFORMATION STUDIES AND EVACUATION BEHAVIOR DURING ERUPTIONS AT GUATEMALAN VOLCANOES
}

Hans Lechner

Michigan Technological University, hnlechne@mtu.edu

Copyright 2018 Hans Lechner

Recommended Citation

Lechner, Hans, "GROUND DEFORMATION STUDIES AND EVACUATION BEHAVIOR DURING ERUPTIONS AT GUATEMALAN VOLCANOES", Open Access Dissertation, Michigan Technological University, 2018.

https://doi.org/10.37099/mtu.dc.etdr/764

Follow this and additional works at: https://digitalcommons.mtu.edu/etdr

Part of the Applied Behavior Analysis Commons, Geology Commons, Nature and Society Relations Commons, and the Volcanology Commons 


\title{
GROUND DEFORMATION STUDIES AND EVACUATION BEHAVIOR DURING ERUPTIONS AT GUATEMALAN VOLCANOES
}

By

Hans Nicholas Lechner

\section{A DISSERTATION}

Submitted in partial fulfillment of the requirements for the degree of DOCTOR OF PHILOSOPHY

In Geology

MICHIGAN TECHNOLOGICAL UNIVERSITY 2018

\author{
(C)2018 Hans N. Lechner
}


This dissertation has been approved in partial fulfillment of the requirements for the Degree of DOCTOR OF PHILOSOPHY in Geology.

Department of Geological and Mining Engineering and Sciences
Dissertation Co-Advisor:
Gregory P. Waite
Dissertation Co-Advisor:
Bradley Baltensperger
Committee Member: $\quad$ Rudiger Escobar-Wolf
Committee Member: $\quad$ Mark D. Rouleau
Department Chair: John S. Gierke 


\section{Dedication:}

To the memory of Dr. Carl Lough "Sandy" Hansen. A geographer, geomorphologist, and inspiration. 


\section{Table of Contents}

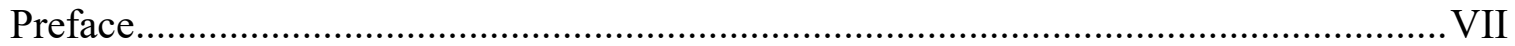

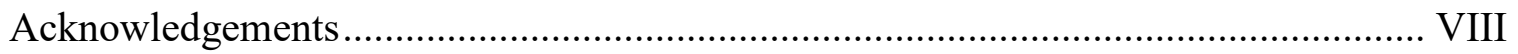

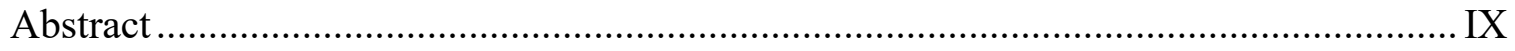

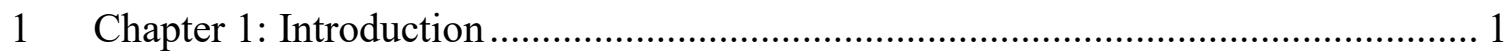

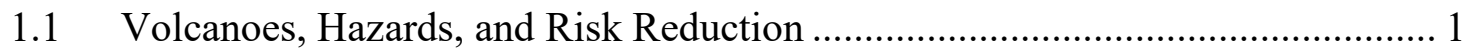

1.2 Natural Hazards Research and Social Volcanology .......................................... 5

1.3 Volcanoes and other natural hazards in Guatemalan .......................................... 7

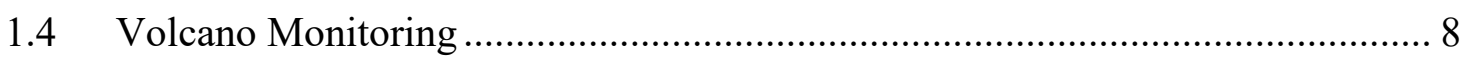

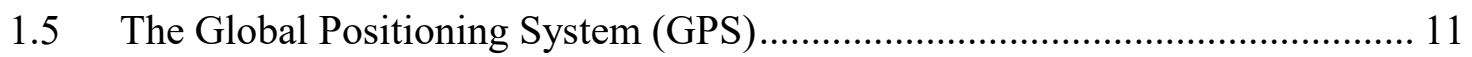

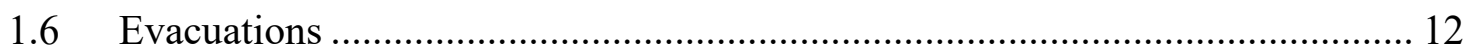

1.7 Motivation, problem statement and research objectives ................................... 12

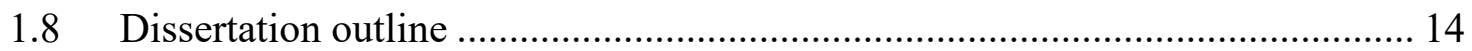

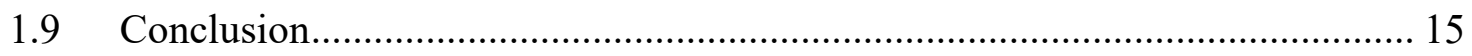

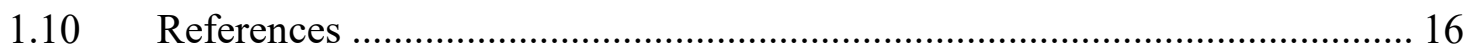

2 Chapter 2: Magma storage and diking revealed by GPS and InSAR geodesy at

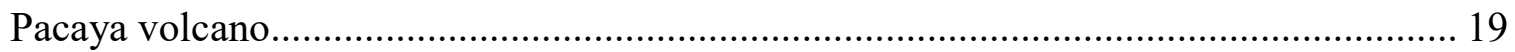

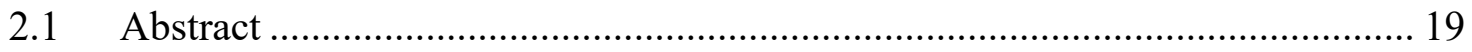

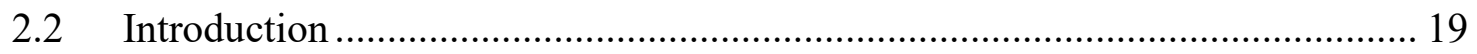

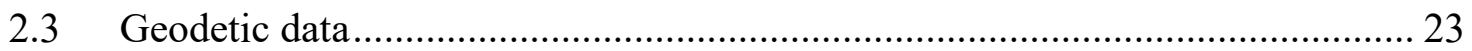



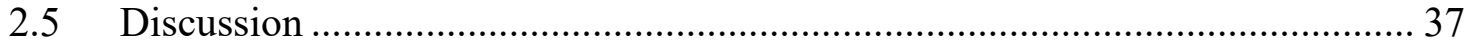



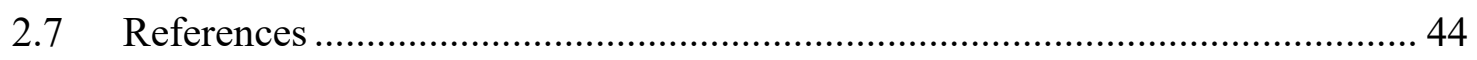

3 Chapter 3: Should we stay or should we go now? Factors affecting evacuation decisions at Pacaya volcano, Guatemala …………………........................................ 48





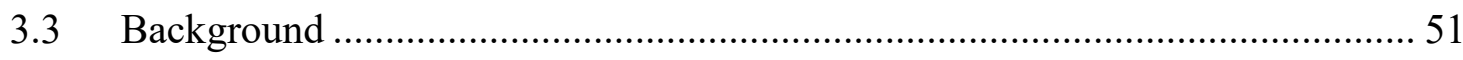

3.3.1 Pacaya volcano................................................................................... 51

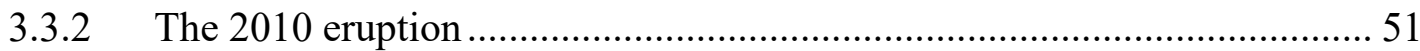

3.3.3 Evacuation decision-making and risk perception .................................... 52 


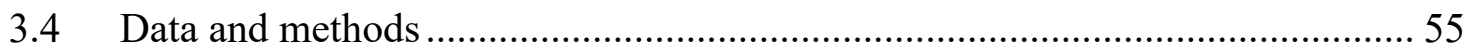



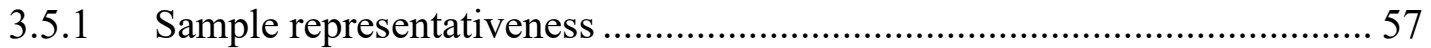

3.5.2 Characteristics of our respondents as a whole ...................................... 61

3.5.3 Observed differences in evacuation experience, behavior, and intentions . 62

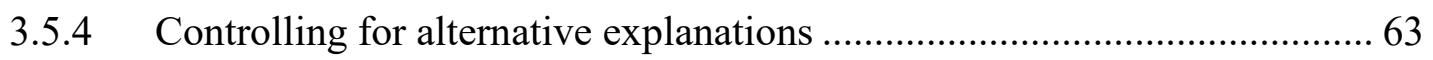

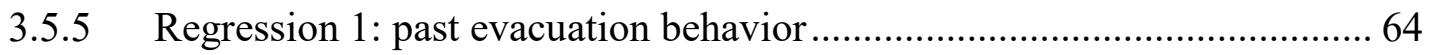

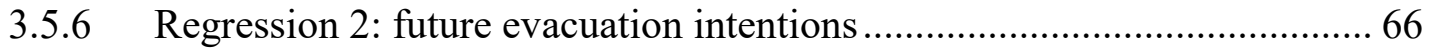

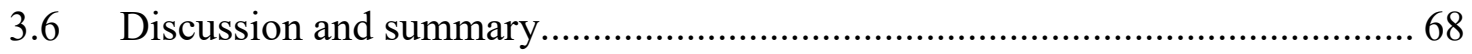

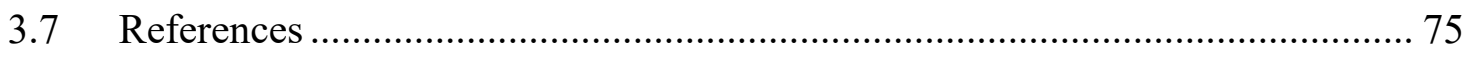

4 Chapter 4: An experiment using high-rate GPS (HRGPS) to monitor inflation and deflation at Santiaguito volcano, Guatemala ............................................................ 79

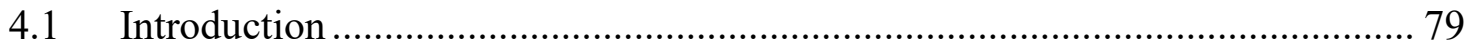

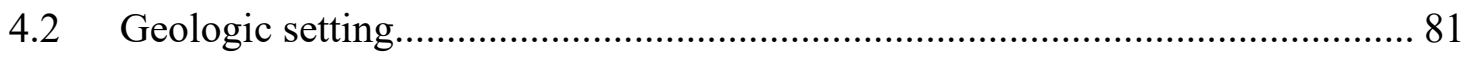

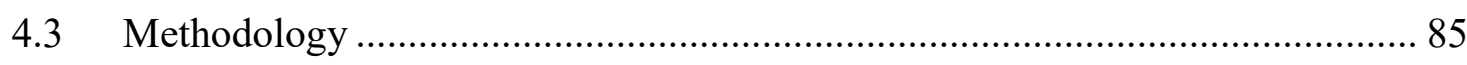

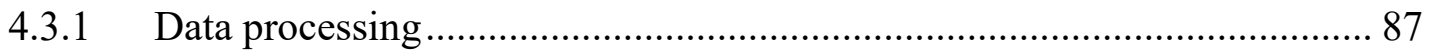

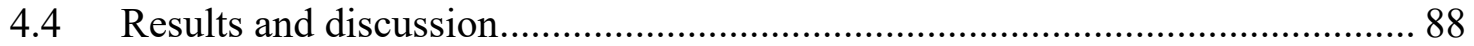

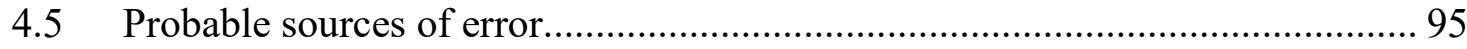

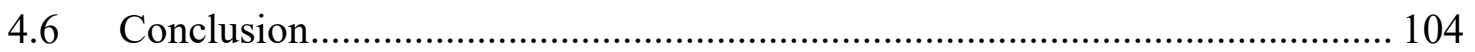

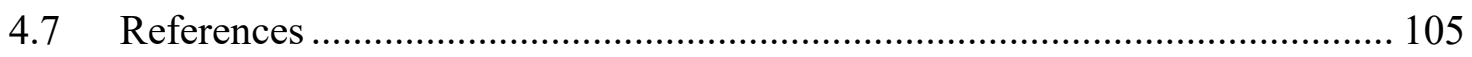

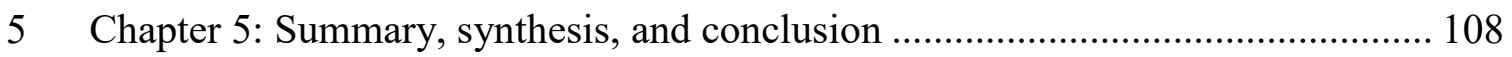

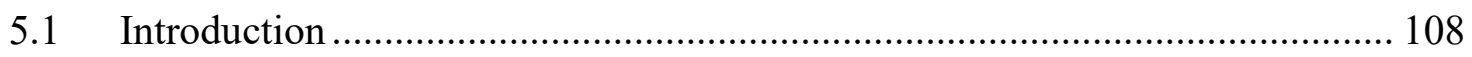

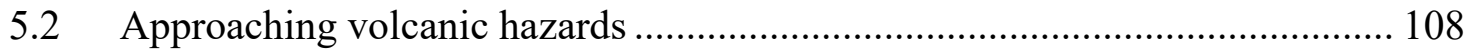





5.5 Physical dimensions of Pacaya hazards research ....................................... 111

5.6 Social dimensions of Pacaya hazards research .......................................... 112

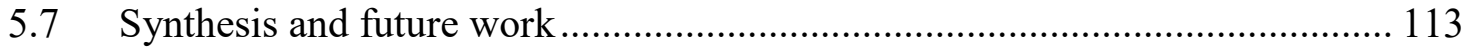

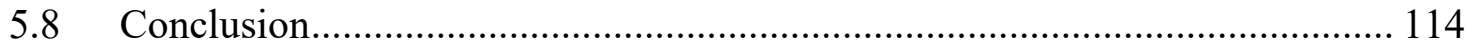

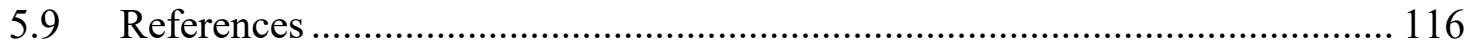

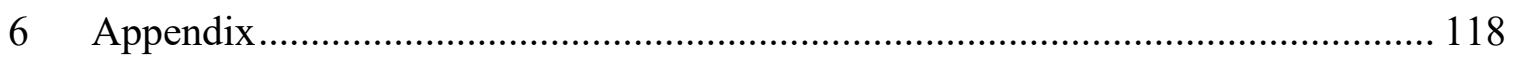

6.1 Chapter 2 supplemental material ............................................................... 118 




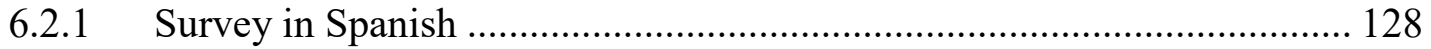

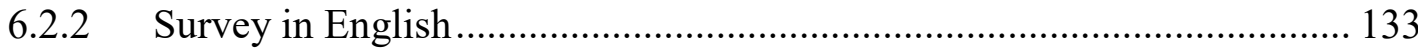




\section{Preface}

- Chapter 2. Magma Storage and diking revealed by GPS and InSAR geodesy at Pacaya volcano, Guatemala

This chapter has been submitted to the Bulletin of Volcanology as a research article and at the time of preparing this dissertation is considered "under revision." As this manuscript has previously been submitted, revised and rejected two previous times it now incorporates edits from six external peer reviewers. C. Wauthier helped with the development and analysis of the InSAR data helped with the production of the non-linear inverse modeling, contributed to the organization, and editing of the content. G. Waite helped develop the thesis of this research, organize, and edit the written content. R. Escobar-Wolf provided help developing Matlab scripts that we used to analyze data produce plots and figures. All authors have read and approved of the final version of this manuscript.

- Chapter 3. Should we stay or should we go now? Factors affecting evacuation decisions at Pacaya volcano, Guatemala

This chapter, authored by H.N. Lechner and M.D. Rouleau, has been submitted to the International Journal of Disaster Risk Reduction and is currently in review. Both authors developed the survey questionnaire. H.N. Lechner supervised a team of master's students in Guatemala to administer surveys to participants and record responses. H.N. Lechner also conducted all open-ended interviews and participant observations. H.N. Lechner held a focus group session consisting of Spanish speaking faculty and students from MTU to translate and assess the survey questions. M.D. Rouleau helped with the research design as well as the manuscript organization, thesis development, data processing and interpretation, and the writing and revision of text. All authors read and approved the final manuscript.

- Chapter 4. An experiment using High-rate GPS (HRGPS) to monitor inflation and deflation at Santiaguito volcano, Guatemala.

This chapter is a report on the results of an experiment that was conducted at Santiaguito volcano, Guatemala. H.N. Lechner organized logistics for the experiment, conducted fieldwork with the assistance of other MTU colleagues, processed the bulk of the data and wrote the interpretations of the results. Dr. Greg P. Waite also aided in the processing of some of these data and the interpretation of results. 


\section{Acknowledgements}

I would like to thank my advisors Dr. Greg Waite and Dr. Brad Baltensperger for their support, guidance, flexibility, and most importantly their patience in these projects. Thanks also to my committee members Dr. Rudiger Escobar-Wolf and Dr. Mark Rouleau for the uncountable hours spent helping with project design, analysis and writing. Thank you Dr. John Gierke for looking out for funding and teaching opportunities, a little support from you goes a long way. Thanks to Dr. Wayne Pennington for your support from the very beginning of this endeavor. Thanks to Dr. Bill Rose for introducing me to idea of "social volcanology" and for being a good friend.

Chapter 2: The authors would like to thank Dr. Chuck Demets at University Wisconsin Madison for his advice and suggestions in all things GPS related. We acknowledge Brianna Lopez Hetland, for collecting some of these data. UNAVCO provided equipment and resources in the field; UNAVCO/COCONet grant EAR-1042906 for partial support during this research and NSF grants 0530109 and 1053794 for partial support of this research. We also appreciate the support in field from INSIVUMEH, Park Police and local park guides and the rest of our friends and support network in Guatemala.

Chapter 3: Support for fieldwork was funded in part by Michigan Tech GMES from the Bill Rose Geoscience Student Travel Fund. Special thanks to Edgar Roberto Mérida Boogher, Roberto Cauhtémoc Armijo, Monica Castro-Escobar for their tireless work in the field during data collection. Thanks to Michael K Lindell for sharing examples of evacuation survey questionnaires. Thanks to Erika Grunert, Ezequiel Medici, Hugo Gordillo, and Kyle Brill and the others for focus grouping and translations. Special thanks to personnel at INSIVUMEH, CONRED and Pacaya National Park for taking the time to answer questions critical to understanding what happened during the 2010 eruption.

Chapter 4: Thanks to Greg Waite, John Lyons, Federica Lanza, and Felix von Aulock who risked life and limb climbing up that canyon to deploy the GPS and other instruments. I'm glad we didn't die. Thanks to Max Guettinger for carrying the other GPS up Santa Maria and setting it up. I know it was heavy. Thanks to Baldur Bergsson for sacrificing your shoelaces in the name of science.

Thanks to my friends here in Houghton/Hancock, you guys made the long, cold winters fun and bearable. Thank you to my family and friends in California and Michigan for your unconditional love and enduring support. Special thanks to my Mom for everything.

Lastly, thanks to my wife Emily who literally got me here, and to my son Roland for that last push of motivation. I love you both. 


\section{Abstract}

Volcanic eruptions can be an especially problematic hazard when considering the uncertainty in eruption timing and magnitude coupled with challenges associated with delivering warnings to remote areas and facilitating effective evacuations. The hazards presented by Guatemala's active volcanoes demand enhanced monitoring capabilities and instrumentation infrastructure. Strengthening the link between the physical and social sciences should lead to more accurate, reliable, and timely hazard information to the people living in proximity to the volcano and facilitate rational decisions and actions that reduce their level of risk.

While there is no one single technique that can provide unambiguous diagnostics about the timing, behavior, and outcome of a volcanic eruption, the use of GPS geodesy can provide valuable insight into the internal dynamics of a volcano allowing for enhanced interpretation of unrest signals that can be relayed to crisis management officials. The 2010 eruption of Pacaya lead to evacuations of more than 2500 people and resulted in damage and destruction to hundreds of homes. During this period of unrest, Pacaya was a poorly monitored volcano with little available quantitative geophysical data. However, despite a pronounced increase in activity prior to the eruption, and the heightened threat of injury or death during the eruption, many residents in communities surrounding the volcano chose to stay in their home throughout the eruptive crisis.

Part of this research presents measurements from a campaign GPS network at Pacaya volcano, combined with InSAR data that reveals a large downward vertical and outward horizontal deformation signal at several locations around the volcano associated with two eruptive periods. We invert the available geodetic data to model the magma plumbing system and produce analytical models, which suggest that deformation was dominated by inflation of a sub-vertical dike high within the edifice while deflation of one or two deeper, spherical sources embedded below the edifice occurred during part of the observation period.

The second part of this research seeks to understand why some chose to stay in harm's way. Using data obtained from a door-to-door survey we found that evacuation behavior was strongly influenced by one's exposure to and perception of the hazards as well as their perception of readiness. We also found that future intention to evacuate is strongly influenced by prior evacuation experience, perception of home vulnerability and warning messages.

The research presented in this dissertation integrates geophysics and social vulnerability research with the aim to better understand magmatic system dynamics and associated hazards in volcanic regions in an effort to improve warning messages and evacuation behavior. 


\section{Chapter 1: Introduction}

\subsection{Volcanoes, Hazards, and Risk Reduction}

Geophysical hazards and natural disasters causing death, destruction, and disruption to society are easily perceived as increasing in frequency and global distribution (Figure 1.1). Of course, the idea of "naturalness" in the concept of hazards and disasters is somewhat of a misconception as it is the interaction of humans with natural systems that truly creates a hazard. Additionally, social vulnerability coupled with exposure to a hazard exacerbate risk and influence people's perception of it. When vulnerability and risk become intertwined with the physical phenomenon, detrimental results occur and turn natural events into hazards or disasters. While there is a broad range of geophysical events that we have come to define as natural hazards however, the topics discussed in this dissertation will focus on volcanoes.

It is estimated that there are over 450 densely populated volcanoes, 222 of which are historically active and have a population greater than 1 million people within $100 \mathrm{~km}$ radius (Small and Naumann 2001). In other words, roughly a quarter billion people live within striking distance of an active volcano. In the last 300 years volcanic disasters have killed more than 300,000 people and caused millions of dollars in damages (Tilling 2008), and while the number of active volcanoes around the world remains fairly consistent year-to-year - between 50 on average (Sigurdsson et al. 2015) - the interaction between humans and volcanic hazards seems to be increasing as well (Figure 1.2). This is undoubtedly the result of growing population densities along continental margins near subduction volcanoes (Figure 1.3). As populations grow they often push into the more hazardous regions on the flanks of active volcanoes increasing exposure, vulnerability and ultimately risk. The interface of humans and volcanoes is most stark in the developing world (Chester et al. 2000, Small and Naumann 2001, Witham 2005), particularly in Central America and Southeast Asia (Figure 1.3). With increasing population and urban migration, the number of communities and people that are exposed to volcanic hazards continues to rise. Beyond the geographical situation of many developing nations, economic, social and political development also contribute to a heightened degree of vulnerability (Alcántara-Ayala 2002) and ultimately greater risk. This dilemma creates a need for an interdisciplinary approach to volcanic hazards that melds the natural and social sciences to deal with hazard, risk, and vulnerability jointly (Bankoff et al. 2004). 


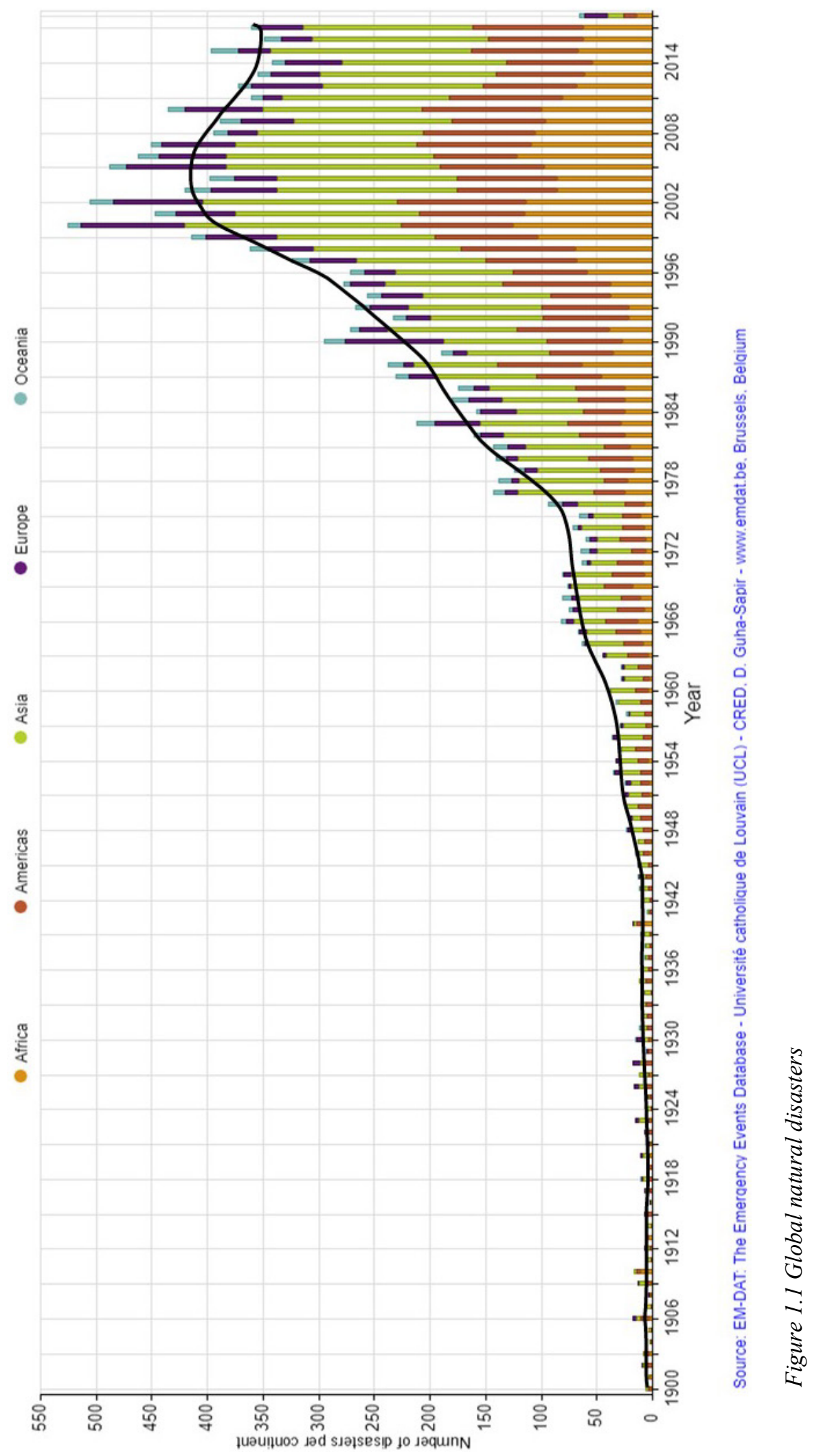




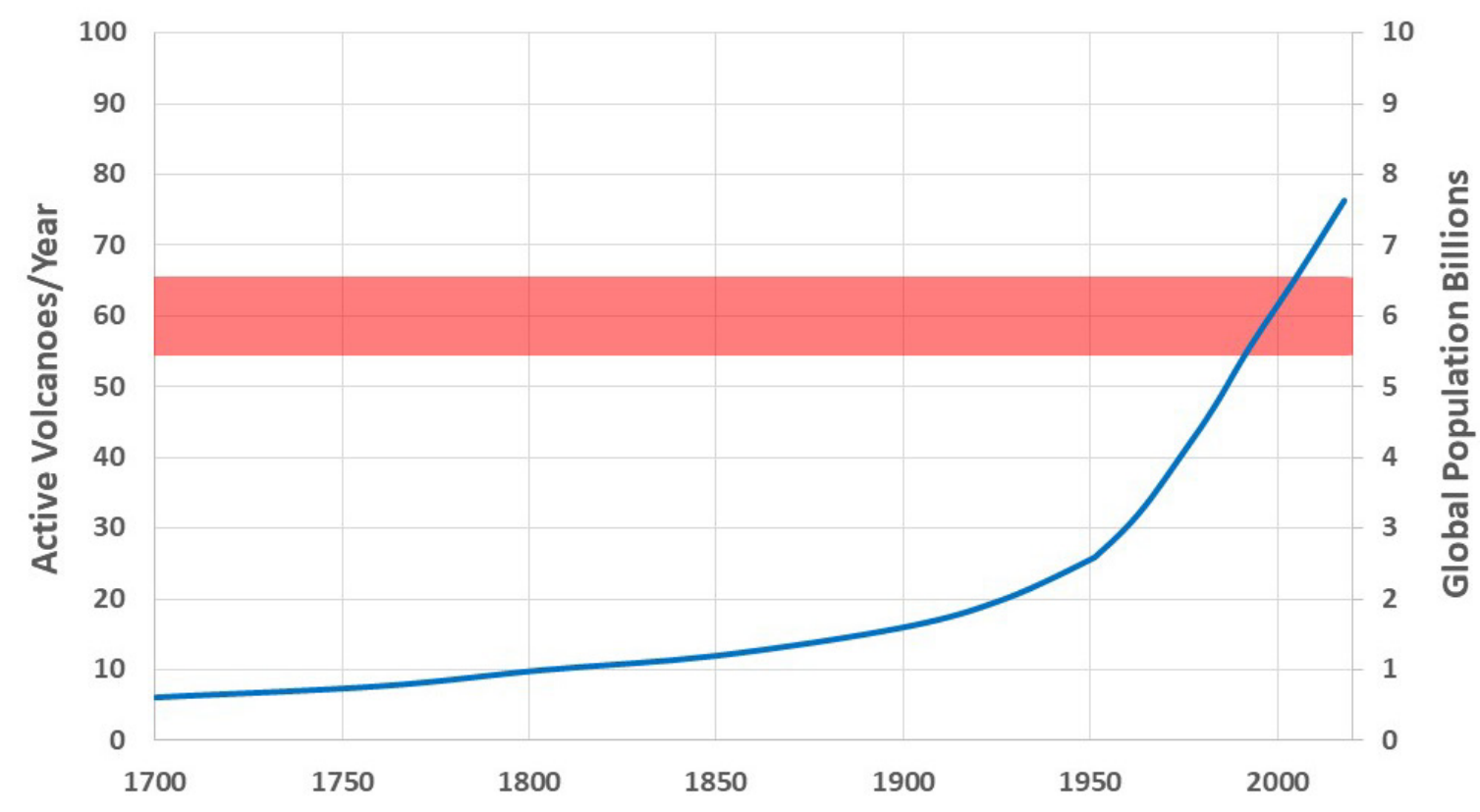

Figure 1.2 Actively erupting volcanoes per year (red bar) and global population growth since 1700. Modified from Tilling (2008).

To be clear, the questions and concerns expressed by the "at-risk" public during a volcanic crisis are not always based in scientific or geologic principles, but often are more reflective of concerns regarding livelihoods and their personal safety. However, geoscientists are constrained in their answers by the bounds of their knowledge and research interests (Donovan et al. 2012b). Therefore, volcanic hazards risk reduction research must provide the link that binds together the geophysical understanding of the natural processes with the people and places vulnerable to those phenomena.

Often those engaged in physical science of volcanoes - geophysics, geochemistry, seismology, geodesy, remote sensing, fluid dynamics, petrology, sedimentology and stratigraphy, geomorphology, etc. - produce impactful research on the natural phenomena and then at the end, haphazardly introduce the "social implications" or "broader impacts" of their work. Conversely, there seems to be a deficit of social scientists engaged in research related to physical phenomena of volcanoes. However, human behavior is central to most aspects of natural hazards and the contribution of social science is not just important but necessary when considering the complications associated with hazards and disasters caused by volcanoes. It is therefore essential that social science play more than just a sideline role in its relationship to volcanic hazards and disaster reduction. The scientific disciplines that focus on volcanic phenomena must not settle for simply coexisting, or occasionally interacting with social scientists, but they must intertwine themselves as a single, interdisciplinary specialization. 
While it is impossible to prevent or reduce volcanic eruptions, we can reduce risk. When a volcanic crisis begins to unfold, geoscientists are charged with the task of analyzing available data and interpreting what the signals mean in terms of eruption potential. This information and uncertainty must be relayed to emergency management authorities and citizens at risk so they may determine how to manage the situation and what action to take. Providing pertinent and timely scientific information to vulnerable populations allows people the opportunity to make informed decisions about evacuations and mitigation strategies. The research presented in this dissertation endeavors to address the importance of incorporating the geophysical research of volcanic processes into risk reduction strategies, as well as incorporating an understanding of social behavior into the study of volcanology.



Figure 1.3 Holocene volcanoes around the world and global population densities. From Small and Nauman (2001). 


\subsection{Natural Hazards Research and Social Volcanology}

The link between the physical and social sciences relative to natural hazards research has been gaining traction in the past several decades. However, during the early days of natural hazards research the Behavioral paradigm was the prevailing theory. It grew from the work by Gilbert White in the 1940's and his research on flood control and loss in the United States (White 1945). White and other colleagues led the way in hazards research for several decades by focusing on human adjustments to hazardous events (White 1945, Burton et al. 1968, Kates 1971). This approach employed scientific, engineering, monitoring, and early warning systems to provide a range of adjustments to mitigate natural hazards. It was assumed that people chose to occupy hazardous regions because they found some attached benefit, and in the event of extreme environmental conditions people will make rational choices and appropriate behavioral adjustments based on their individual or societal perceptions of risk. The dominant paradigm understands that societal factors such socio-economic status, past experience, and perception of risk play role in the behavioral adjustments of an individual or social group and that the choice of adjustment relies on how a people perceive a threat and the associated risk - individuals or a social group with a heightened perception of risk will make appropriate adjustments, conversely those with lower perception of risk will adjust poorly (Gaillard 2008). However, the idea of appropriate adjustments within the behavioral paradigm is hinged upon the range of available adjustments to an individual or society that can be used to mitigate an environmental extreme (Chester 1999). To expand the range of adjustments and reduce loss, policy initiatives aimed at modifying the hazard were implemented throughout the US and many other developed nations throughout the world. The focus of these initiatives was commonly on the physical characteristics and processes of the hazard and its triggers. Understanding and controlling nature then became the responsibility of earth scientists and engineers with the primary objective of reducing the magnitude and frequency of extreme events.

This approach dominated the field for several decades until the 1970s and 1980s when natural hazards research began shifting from a more quantitative investigation of the physical processes to include a greater focus on society and the human component. In a radical response to the dominant paradigm emerged a new understanding of natural hazards that incorporated the social component of human vulnerability as a factor in people's behavior and response to natural hazard events (O'Keefe et al. 1976, Hewitt 1983, Wisner and Luce 1993). Critics of the dominant paradigm argued that the range of available adjustments is limited, especially in the economically developing world where individual and social response to extreme events is inhibited by political, social and economic constraints beyond their control (Gaillard 2008). It was further argued that individual and societal perceptions of risk to natural hazards are also strongly influenced by social structure and conditions more than the geophysical event itself (Hewitt 1983, Gaillard and Dibben 2008a). Of fundamental importance to the radical approach is that poverty, deprivation, marginalization, as well as limited access to resources, or political 
and social capital have more to do with disasters than the extremes of nature (Chester 1999). This approach emphasizes people's social vulnerability to loss and suffering. Victims of natural hazards are disproportionality found in marginalized social groups such as women, children, elderly, poor, and disenfranchised. Therefore, groups with limited access to social protections such as insurance, or government protection and oversight are more likely to be negatively affected and less likely to rapidly recover.

This paradigm shift gained even more traction with the United Nations designation of the 1990-2000 as the International Decade for Natural Disaster Reduction (IDNDR), which called for increased collaboration and communication between social and physical scientists and vulnerable communities. The goal was to put more energy into the study and reduction of natural hazards in vulnerable societies and the developing world. The study of volcanic hazards also benefitted from the IDNDR when the International Association of Volcanology and Chemistry of the Earth's Interior (IAVCEI) identified 16 volcanoes as worthy of increased research efforts, several of which are found in developing nations. However, both the IDNDR and IAVCEI defined the approach to natural and volcanic hazards primarily on a transfer of technology and experience from areas where hazard responses and adjustments were considered successful to areas where they were unsuccessful or non-existent (Annen and Wagner 2003).

In the decades to follow there has been a steady stream of publications focused on social vulnerability, human impacts, and risk perception of volcanic eruptions (Chester 1993, Lirer and Vitelli 1998, McGuire 1998, Chester 1999, Dibben and Chester 1999, Blong 2000, Annen and Wagner 2003, Cashman and Cronin 2008, Gaillard and Dibben 2008a). This momentum was followed in 2005 with the United Nations International Strategy for Disaster Risk Reduction, which was implemented as part of the Hyogo Framework for Action (HFA) with the holistic goal of reducing loss and growing resiliency to natural disasters by 2015. This push for an interdisciplinary approach to natural hazards also spurned a boom in publications of volcanic hazards research, which employ social science frameworks and methodologies (Barberi et al. 2008, Barclay et al. 2008, Cashman and Cronin 2008, Gaillard and Dibben 2008b, Haynes et al. 2008, Ikeda et al. 2008, Donovan 2010). One area of particular interest in natural (volcanic) hazards research is people's behavior during an eruptive crisis. This dissertation tries to further the interdisciplinary approach to volcanic hazards and vulnerability by examining volcanoes in Guatemala and focusing specifically on understanding the relationship between surface deformation and eruptions, and eruptions and evacuations. 


\subsection{Volcanoes and other natural hazards in Guatemalan}

Guatemala is a country faced with a variety of natural phenomena and its political history, physical geography, and socioeconomic evolution have fostered the growth of a significant population of communities vulnerable to natural disasters. Since $1902 \sim 500$ disasters associated with natural events have claimed $\sim 160,000$ lives and affected tens of millions (Alcántara-Ayala 2009) drought, earthquake, flooding, mass-movement, storms and volcanic eruptions. The country is situated in a subtropical setting on the tectonic triple junction at the boundary between the North America, Caribbean, and Cocos plates. The country is frequently hit by destructive earthquakes and powerful tropical storms (Ortega-Obregón et al. 2008, Brocard et al. 2014) and is home to three very active openvent volcanoes that are part of the Central American volcanic arc.

The hazards presented by Guatemala's active volcanoes demand enhanced monitoring capabilities and instrumentation infrastructure, and in response to volcanic hazards risk reduction, major societal changes are needed to improve the distribution, dissemination of information, education and a greater understanding of geophysical processes. One very important step in reducing risk is providing accurate, reliable, and timely information to the people living in proximity to the volcano about the potential hazards, which can allow for rational decisions and actions that reduce their level of risk.

Strategically, the reduction and prevention of disasters is a universal concept, yet the application needs to account for the specific characteristics of the hazard and the population at risk (Alcántara-Ayala 2002). This dissertation draws from two recent eruptions at Pacaya volcano and an experimental monitoring strategy at Santiaguito volcano. The research provides insight into volcano monitoring and volcano dynamics through the application of GPS geodesy as well as the evacuation decision making process during a volcanic crisis. 


\subsection{Volcano Monitoring}

Most volcanoes provide precursory signals of unrest days or months prior to an eruption (Dzurisin 2000, Siebert et al. 2011). This precursory activity allows volcanologist an opportunity to assess the nature of the activity, develop short-term forecasts, and provide information and early warnings to at-risk communities. However, this is only possible when there is a balance between instrumentation, effective monitoring, and volcanic activity (Loughlin et al. 2015). Active monitoring efforts can detect signals that may indicate an impending eruption and provide community members and civil authorities the opportunity for critical decision making and mitigation strategies (Newhall and Punongbayan 1996).

While there is no one single technique that can provide clear-cut information about the timing, behavior and outcome of a volcanic eruption, a combination of monitoring tools such as seismology, geodesy, gas geochemistry, and other techniques can give valuable insight into the interpretation of unrest signals that can be relayed to crisis management officials. Providing a degree of scientific certainty related to the complex and often uncertain variety of volcanic processes can reduce risk by reducing ambiguity and increasing awareness by presenting the best available information and understanding about the current situation (Donovan et al. 2012a).

In many cases, monitoring of volcanoes starts with geologic mapping to gain an understanding of past behavior, eruption style, ages, extent, and distribution of eruptive material from past eruptions to establish a baseline understanding of the volcano. This is followed by regular observations and instrumentation to detect changes within the volcano. Knowledge of a volcano's past behavior correlated with current activity allows for the anticipation of future behavior. Effective volcano monitoring is most often the integrated system of disciplines, instruments, and methodologies.

Volcanic unrest, often defined as a deviation from the background/baseline behavior of a volcano towards a behavior or state which is a cause for concern in the short-term (hoursmonths), is often preceded by increased seismicity and detecting the ascent of magma towards the surface of the earth is of critical interest to those monitoring volcanoes (Phillipson et al. 2013). In times of volcanic unrest, volcano scientists are concerned with the prospect of magma reaching the service and causing an eruption. The challenge is to understand the signals within the data deviant from baseline that may indicate an eruption. Of course the biggest limiting factor is the inability to directly observe magma movement; therefore interpretations are based on information from secondary signals associated with those processes (Gottsmann et al. 2017).

Seismic monitoring is the single most important method in detecting change in a volcanic system and is considered the most useful and reliable tool in providing indications of possible eruptive activity. However, volcano seismology varies from one volcano to the next and often benefits from a network of seismic instruments. The dynamic interaction 
of gas, liquid, and solids along complex magma pathways manifests itself as a seismic signal (Chouet 1996, Chouet and Matoza 2013). Seismic signals that originate in the magmatic or hydrothermal fluids are typically detected as Long-Period (LP) events and/or tremor. When the sheer strength of the surrounding rock is exceeded by the stresses created by magma movement, or gas pressurization the rock fractures generating an acoustic wave that can be detected or felt as an earthquake (Lockwood and Hazlett 2013). There are several challenges associated with volcano seismology: volcanic earthquakes often occur in swarms; volcanic earthquakes are much smaller than tectonic earthquakes - the largest magnitudes are often less than M 5.0 (Lockwood and Hazlett 2013) and can only be detected instrumentally; and they can be difficult to locate without multiple instruments. However, despite these challenges, the abundancy, frequency distribution, overall seismic energy, onset, and location of events can provide invaluable clues about the magma movement, conduit dynamics and eruption potential or activity.

In addition to increased seismicity, volcanic eruptions may also be preceded by ground deformation often caused by internal pressure changes, magma migration, or changes to a magma chamber. While deformation at the surface may be imperceptible to humans it can be detected with precision instrumentation. Deformation measurements can be achieved with the use of tilt meters, electronic distance measurements (EDM) and more recently with the space-based platforms of the Global Positioning System (GPS) and Interferometric synthetic aperture radar (InSAR). Before an eruption a volcano may exhibit inflation as magma rises toward the surface or as pressure builds and magma vesiculates within a magma chamber. During and following eruptive activity a volcano may exhibit deflation as the magma chamber is vacated and pressure released. Studying deformation at the surface on or near a volcanic edifice provides input to accurately model the location, shape, and volume of a subsurface magma system. Mathematical models of observed deformation can allow scientists to calculate depths, volumes, and pressure changes to magma bodies and the sources of deformation. These types of analyses allow volcanologists to improve their understanding of surface deformation and the subsurface dynamics. In many cases deformation models assume a point source (Mogi 1958, McTigue 1987) or a rectangular dislocation source (Okada 1985) with simple geometry and attempt to fit it to the observed deformation. In turn, these models can be used to improve future monitoring efforts prior to an eruption.

Gas geochemistry is also a valuable application in the volcano-monitoring toolkit. Gas monitoring can provide information on the nature of the magma including depth and volume changes. Samples and data can be collected in-situ or, more commonly, through remote sensing methodologies. SO2 is the most commonly monitored species of volcanic gas considering its abundance at active volcanoes and its more minute presence in the atmosphere. While $\mathrm{SO} 2$ spectroscopy and that of other gas species $(\mathrm{HCl}, \mathrm{Hf}$ and $\mathrm{H} 2 \mathrm{~S})$ are becoming a more common and promising technique, data processing is time consuming, labor intensive, and subject to high error (Donovan et al. 2012a). 
Infrasound, thermal emissions, petrologic investigations, and gravity measurements are other techniques used in volcano monitoring. However, often these methodologies require a great deal of expertise and training to understand and are therefore, difficult to apply in real-time or near real-time monitoring. Furthermore, communicating results and interpretations of these methodologies can be complex across disciplines and to emergency management decision makers (Donovan et al. 2012a).

Adequate instrumentation combined with seismic and geodetic observations is a sophisticated and promising technique in volcano monitoring, and GPS, coupled with seismology has proven time and again to be a robust, and favorite, monitoring and diagnostic tool in the field of volcanology (Donovan et al. 2012a). Any one or any combination of these methodologies that allow for a greater understanding of the interplay between magmatic systems, eruptive cycles, and morphology at specific volcanoes such as Pacaya can greatly advance our detection of hazard triggers and our ability to forecast eruptions. However, for the purposes of my research and this dissertation I have chosen GPS as my tool and will therefore discuss its application to volcano monitoring and analysis and its role in providing timely information to emergency management officials before, during and after a volcanic eruption crisis. 


\subsection{The Global Positioning System (GPS)}

In 1978 the U.S. Department of Defense began the installation of a constellation of Navigation Satellite Time and Ranging (NAVSTAR) satellites to create a system of global positioning and timing information - primarily for military applications, available 24-hours per day, under any weather conditions at any point in the world - now commonly referred to as the Global Positioning System or GPS (Leick 2004). GPS along with other satellite positioning systems, such as Russia's GLONASS, the European Galileo system and China's Beidou system (both still in development at the time of writing) are collectively known as the Global Navigation Satellite System (GNSS). For the purposes of this document, I will discuss the applications of the NAVSTAR GPS, and refer to it simply as GPS. GPS is well known among surveyors and geodesists as one of the most versatile positioning and navigation tools ever developed for use in terrestrial, marine and air navigation as well as surveying, mapping and GIS support.

Of course, the role of GPS in measuring and monitoring ground surface displacements is well accepted; however, its application to volcanology being fairly recent is gaining popularity as it provides valuable information for the assessment of volcanic hazards and eruption forecasting. While volcanic unrest is often preceded by days to months of deformation that is measurable using GPS the position estimates will not be very useful for hazard mitigation unless they can be visualized in near real-time and at the very minimum with sub-daily or daily positions.

GPS based geodesy is capable of producing sub-centimeter precision of position estimates and therefore position changes over time. This is a useful tool when applied to measuring and monitoring changes of volcanoes. As the goals of this project relate to surface deformation at volcanoes, two types of GPS data is presented here: 1) short, static observations (3-9 hours) from repeated campaigns over a span of several months to several years; 2) high-rate kinematic GPS data (HRGPS), defined here as $>1 \mathrm{~Hz}$ sample rate, is collected and processed in an effort solve instantaneous position estimates and observe short term, rapid volcanic deformation.

Campaign GPS allows GPS receivers to remain static for several hours to several weeks. The receivers record data from the same benchmarks on a regular basis to detect surface changes over time. The large-scale changes can be used to characterize eruptive and inter-eruptive behavior from one occupation to the next, and develop models of what is happening beneath the volcano. HRGPS can detect and reveal - in real-time or near realtime - episodes of transient surface displacement and strong ground motion that may be related to magmatic fluid displacements thus indicating possible precursors of eruptive activity (Mattia et al. 2008).

Well-developed monitoring strategies employing GPS technology can enhance near realtime eruption forecasting, as well as improve hazard warnings and risk communication, which may ultimately safeguard lives, livelihoods, and the economic stability of a region. 


\subsection{Evacuations}

During a volcanic crisis, one of the most appropriate and effective hazard adjustments is to relocate to a safer location (Chester 1993, Blong 2000), and given sufficient warning individuals living within hazard zones face the choice to evacuate or remain in a high-risk area. Of course, these individuals may perceive social or environmental cues differently when making their decision. To stay or to go is a decision often based on perception of risk versus the perception of an evacuation. While it has been shown that high perception of risk can influence behavior it is not a significant predictor of hazard adjustment (Perry and Lindell 2008). When considering this conundrum it therefore becomes necessary to examine what factors contribute to the decision process that may or may not lead to action. While evacuation behavior is one of the most perplexing facets of natural hazards research and there is no shortage of literature about this subject in the context of other natural hazards. Evacuation decision making in response to volcanic eruptions is an underexplored topic in this field of study (Chester et al. 2002, Barclay et al. 2008).

\subsection{Motivation, problem statement and research objectives}

My research interests in volcanoes, stems from an interest in the use of GPS geodesy for volcano deformation, risk perception, and hazard communication. It straddles the interface of geophysics and social vulnerability with the aim to better understand magmatic system dynamics, associated hazards, and adjustment behavior in volcanic regions. Using GPS as a monitoring strategy, I have endeavored to enhance the abilities of hazard management authorities to communicate risk and volcano status during an eruption crisis. It has long been my goal to integrate two interconnected research interests: 1) the use of GPS to monitor volcano deformation, and 2) the desire to reduce risk to vulnerable communities.

I first came to Michigan Technological University in 2005 as a student in the Peace Corps Masters International (PCMI) program. As a PCMI student, I had the opportunity to design, implement, and install a GPS network at Santa Ana volcano in El Salvador. This work included all aspects of the project from network design, to hardware installation, to data acquisition and processing. For over a year I deployed GPS receivers at 12 stations around the volcano during monthly campaigns and acquired high quality data for differential processing. This work ultimately became my master's thesis but also proved valuable as pilot project to measure the inter-eruptive behavior at a sub-tropical volcano.

In May of 2010, several months before I finished my masters, Pacaya volcano in Guatemala erupted. Initial reports from the media and colleagues about the eruption suggested misdirected or missing warning messages and evacuation orders, poorly prepared communities and disorganized evacuation measures. In September of 2011, I visited several communities around Pacaya to help improve an existing GPS network that had been established by MTU researchers in 2009. During this visit I had the opportunity 
to see first-hand the lingering impacts from that eruption on surrounding communities. I listened to anecdotes from community members about the terror of red-hot bombs raining down and igniting homes, the chaos of the disorganized evacuations, and the poor communication and mistrust of emergency officials.

During the last 50 years of activity at Pacaya, the central vent on the Mackenney cone has produced eruptive products that have typically forced evacuations and affected communities to the south of the volcano. The 2010 eruption was atypical for Pacaya in that the explosive paroxysm was a directed blast to the north from a rift opening on the northwestern flank of the edifice. In this way, the eruption came as a surprise to the volcanologists charged with monitoring Pacaya, emergency management agencies charged with providing warning messages and evacuation orders, and the communities surrounding Pacaya volcano who had grown accustomed to southward-directed eruptions. To me, the problem of poor warning messages, evacuation orders, and the communication of hazard information was the result of inadequate instrumentation, insufficient monitoring, and low-level baseline understanding of the internal structure of the volcano. After my 2011 visit to Pacaya, I decided to make an effort to incorporate a social volcanology theme into my Ph.D. research. I felt that I could integrate the technical skills and geophysical understanding that I had gained during my masters to better understand Pacaya volcano and the social problems that occurred at during the 2010 eruption.

While my master's research was a scientific and quantitative study of a volcano and provided insight into the mechanics of volcanic cycles, it came up short in providing qualitative information to the communities most likely to be affected during a volcanic eruption. Furthermore, while scientific observations are important, the ultimate goals of a volcano scientist should be to provide information in a format that will help save lives of people living near volcanoes. Therefore, the goals of this study are as follows:

1. Development of analytical models of the internal magmatic structure of Pacaya volcano through the use of geodetic data.

2. Understand the factors that influenced household decisions to evacuate or not during the 2010 eruption and their intention to evacuate during future eruptive crises.

3. Develop geodetic monitoring strategies using high-rate GPS in real-time or near real-time in an effort to detect and characterize transient deformation signals associated with explosive eruptions that can improve short-term eruption forecasting and hazard communication information between emergency management agencies and the public in need. 


\subsection{Dissertation outline}

This dissertation is divided into four chapters, including this introductory chapter. This first chapter endeavors to highlight the need for improved volcano monitoring, especially through the use of GPS and to interconnect the geophysical understanding of volcanoes with the social implications of hazard risk reduction.

Chapter two provides the first glimpse of GPS data collected at Pacaya dating back to 2009 combined with InSAR data to develop two analytical models of deformation sources for two eruptive periods in May 2010 and 2013-2014. The results corroborate previous hypotheses and models suggesting a subvertical dike seated high within the volcanic edifice being fed by a deeper spherical source below the NW flank of the volcano. Considering the lack of previous geodetic studies at Pacaya, and Central American volcanoes in general, this research is important as it presents greater insight into the magmatic plumbing system at Pacaya. Furthermore, it bolsters GPS research as a monitoring tool, especially when combined with InSAR data. Lastly, considering the recent eruptions and volcanic hazard implications at Pacaya, this work is significant because it provides valuable information to at-risk communities in Guatemala.

Chapter three is an examination of factors that affect evacuation decisions at communities surrounding Pacaya volcano. The study focuses on evacuations during the eruption in May of 2010 and resident's intention to evacuate in the likely event of future eruptions. Our findings suggest that evacuation behavior during the 2010 eruption was most influenced by one's exposure to the hazard, perception of the hazard and perception of readiness. We also found one's intention to evacuate during a future eruption is most influenced by their experience from the 2010 eruption, their perception of home vulnerability and warning messages. Considering the many challenges, complications and uncertainty associated with evacuations during a volcanic crisis, especially in developing nations, this research is important as it is one of the few studies that presents a systematic examination of the process of intention to behavior during an eruption. This research also, provides greater insight into people's risk reduction behavior at Pacaya and in Guatemala. Furthermore, considering the recent tragedy at Fuego volcano and similar evacuation complications related to the eruption of Kilauea, this work is relevant and significant to social scientists, physical scientists, and vulnerable communities living in the shadow of an active volcano.

The fourth and final chapter reports on a 2016 geodetic experiment that was conducted at Santiaguito volcano, Guatemala. Using high rate GPS I attempted to capture a deformation signal that is associated with the frequent eruptions that occur at the active Caliente dome. This report discuss rationale, methodology, expected results and actual results, and then discusses possible sources of data error and future recommendations for improvements in this experiment. 


\subsection{Conclusion}

Guatemala is a country faced with a variety of natural hazards, which are exacerbated by social inequities manifested as inadequate monitoring, poor communication, and poor preparation. Humankind is not (generally) capable of reducing the geophysical nature of a natural hazard; however, we are capable of reducing risk to such hazards. While geoscientists are typically trained for research on the geophysical event they are not always proficient at how to communicate those results to emergency management decision-makers and the public at risk. Communicating volcanic hazards during an eruption crisis can be especially problematic when considering the uncertainty in eruption timing, magnitude, forecasting. The uncharacteristic nature of the 2010 eruption of Pacaya demonstrated that insufficient instrumentation and monitoring led to an inadequate baseline understanding of the volcanic system, which resulted a dubious eruption forecast, an inequitable hazard warning, and a misdirected evacuation order. The use of GPS as a monitoring instrument is excellent tool to augment geophysical observations and provide timely information during future volcanic unrest situations that may be used to inform at risk citizens living in the shadow of Pacaya and other volcanoes in Guatemala. 


\subsection{References}

Alcántara-Ayala, I. (2002) Geomorphology, natural hazards, vulnerability and prevention of natural disasters in developing countries. Geomorphology, 47, 107-124.

Alcántara-Ayala, I. (2009) Disasters in Mexico and Central America: a little bit more than a century of natural hazards. Developments in Earth Surface Processes, 13, 7597.

Annen, C. \& J. J. Wagner (2003) The impact of volcanic eruptions during the 1990s. Natural Hazards Review, 4, 169.

Bankoff, G., G. Frerks \& D. Hilhorst. 2004. Mapping vulnerability: disasters, development, and people. Earthscan/James \& James.

Barberi, F., M. Davis, R. Isaia, R. Nave \& T. Ricci (2008) Volcanic risk perception in the Vesuvius population. Journal of Volcanology and Geothermal Research, 172, 244258.

Barclay, J., K. Haynes, T. Mitchell, C. Solana, R. Teeuw, A. Darnell, H. S. Crosweller, P. Cole, D. Pyle \& C. Lowe (2008) Framing volcanic risk communication within disaster risk reduction: finding ways for the social and physical sciences to work together. Geological Society, London, Special Publications, 305, 163-177.

Blong, R. (2000) Volcanic hazards and risk management. Encyclopedia of volcanoes. Academic Press, Orlando, Florida.

Brocard, G., T. Adatte, O. Magand, H.-R. Pfeifer, A. Bettini, F. Arnaud, F. S. Anselmetti \& S. Moran-Ical (2014) The recording of floods and earthquakes in Lake Chichój, Guatemala during the twentieth century. Journal of paleolimnology, 52, 155-169.

Burton, I., R. W. Kates \& G. F. White. 1968. The human ecology of extreme geophysical events. Department of Geography, University of Toronto.

Cashman, K. V. \& S. J. Cronin (2008) Welcoming a monster to the world: Myths, oral tradition, and modern societal response to volcanic disasters. Journal of Volcanology and Geothermal Research, 176, 407-418.

Chester, D. K. 1993. Volcanoes and society. E. Arnold.

Chester, D. K., M. Degg, A. M. Duncan \& J. Guest (2000) The increasing exposure of cities to the effects of volcanic eruptions: a global survey. Global Environmental Change Part B: Environmental Hazards, 2, 89-103.

Chester, D. K., C. J. Dibben \& A. M. Duncan (2002) Volcanic hazard assessment in western Europe. Journal of Volcanology and Geothermal Research, 115, 411-435.

Chester, D. K., Dibben, C., Coutinho R., Duncan, A.M., Cole, P.D., Guest, J.E., Baxter, P.J. (1999) Human adjustments and social vulnerability to volcanic hazards: the case of Furnas Volcano, Sao Miguel, Azores. Volcanoes in the quaternary. Geological Society of London, Special Publications, 169, 189-207.

Chouet, B. A. (1996) Long-period volcano seismicity: its source and use in eruption forecasting. Nature, 380, 309-316.

Chouet, B. A. \& R. S. Matoza (2013) A multi-decadal view of seismic methods for detecting precursors of magma movement and eruption. Journal of Volcanology and Geothermal Research, 252, 108-175.

Dibben, C. \& D. K. Chester (1999) Human vulnerability in volcanic environments: the case of Furnas, São Miguel, Azores. Journal of Volcanology and Geothermal Research, 92, 133-150. 
Donovan, A., C. Oppenheimer \& M. Bravo (2012a) Science at the policy interface: volcano-monitoring technologies and volcanic hazard management. Bulletin of Volcanology, 74, 1005-1022.

Donovan, A., C. Oppenheimer \& M. Bravo (2012b) Social studies of volcanology: knowledge generation and expert advice on active volcanoes. Bulletin of Volcanology, 74, 677-689.

Donovan, K. (2010) Doing social volcanology: exploring volcanic culture in Indonesia. Area, 42, 117-126.

Dzurisin, D. (2000) Volcano geodesy: challenges and opportunities for the 21st century. Phil. Trans. R. Soc. Lond., A, 1547-1566.

Gaillard, J.-C. (2008) Alternative paradigms of volcanic risk perception: The case of Mt. Pinatubo in the Philippines. Journal of Volcanology and Geothermal Research, 172, 315-328.

Gaillard, J.-C. \& C. Dibben (2008a) Editorial: Volcanic risk perception and beyond. Journal of Volcanology and Geothermal Research, 172, 163-169.

Gaillard, J.-C. \& C. J. Dibben (2008b) Volcanic risk perception and beyond. Journal of Volcanology and Geothermal Research, 172, 163-169.

Gottsmann, J., J.-C. Komorowski \& J. Barclay (2017) Volcanic Unrest and Pre-eruptive Processes: A Hazard and Risk Perspective.

Haynes, K., J. Barclay \& N. Pidgeon (2008) Whose reality counts? Factors affecting the perception of volcanic risk. Journal of Volcanology and Geothermal Research, 172, 259-272.

Hewitt, K. 1983. Interpretations of calamity: From the viewpoint of human ecology. Unwin Hyman.

Ikeda, S., T. Sato \& T. Fukuzono (2008) Towards an integrated management framework for emerging disaster risks in Japan. Natural Hazards, 44, 267-280.

Kates, R. W. (1971) Natural hazard in human ecological perspective: hypotheses and models. Economic Geography, 47, 438-451.

Leick, A. 2004. GPS satellite surveying. John Wiley \& Sons.

Lirer, L. \& L. Vitelli (1998) Volcanic risk assessment and mapping in the Vesuvian area using GIS. Natural Hazards, 17, 1-15.

Lockwood, J. P. \& R. W. Hazlett. 2013. Volcanoes: global perspectives. John Wiley \& Sons.

Loughlin, S. C., R. S. J. Sparks, S. K. Brown, S. F. Jenkins \& C. Vye-Brown. 2015. Global volcanic hazards and risk. Cambridge University Press.

Mattia, M., M. Palano, M. Aloisi, V. Bruno \& Y. Bock (2008) High rate GPS data on active volcanoes: an application to the 2005-2006 Mt. Augustine (Alaska, USA) eruption. Terra Nova, 20, 134-140.

McGuire, W. (1998) Volcanic hazards and their mitigation. Geological Society, London, Engineering Geology Special Publications, 15, 79-95.

McTigue, D. F. (1987) Elastic stress and deformation near a finite spherical magma body: Resolution of the point source paradox. Journal of Geophysical Research: Solid Earth, 92, 12931-12940. 
Mogi, K. (1958) Relations Between the Eruptions of Various Volcanoes and the Deformations of the Ground Surfaces around them. Bulletin of the Earthquake Resezarch Institute, 36, 99-134.

Newhall, C. G. \& R. Punongbayan. 1996. Fire and mud: eruptions and lahars of Mount Pinatubo, Philippines. Philippine Institute of Volcanology and Seismology Quezon City.

O'Keefe, P., K. Westgate \& B. Wisner. 1976. Taking the Naturalness Out of Natural Disaster. In Enviromental Risks and Hazards, ed. S. Cutter, 94-96. New Jersey: Prentice Hall.

Okada, Y. (1985) Surface deformation due to shear and tensile faults in a half-space: Okada, Y Bull Seismol Soc AmV75, N4, Aug 1985, P1135-1154. International Journal of Rock Mechanics and Mining Sciences \& Geomechanics Abstracts, 23, 128.

Ortega-Obregón, C., L. Solari, J. Keppie, F. Ortega-Gutiérrez, J. Solé \& S. Morán-Ical (2008) Middle-Late Ordovician magmatism and Late Cretaceous collision in the southern Maya block, Rabinal-Salamá area, central Guatemala: implications for North America-Caribbean plate tectonics. Geological Society of America Bulletin, 120, 556570.

Perry, R. W. \& M. K. Lindell (2008) Volcanic risk perception and adjustment in a multihazard environment. Journal of Volcanology and Geothermal Research, 172, 170-178.

Phillipson, G., R. Sobradelo \& J. Gottsmann (2013) Global volcanic unrest in the 21st century: an analysis of the first decade. Journal of Volcanology and Geothermal Research, 264, 183-196.

Siebert, L., T. Simkin \& P. Kimberly. 2011. Volcanoes of the World. Univ of California Press.

Sigurdsson, H., B. Houghton, S. McNutt, H. Rymer \& J. Stix. 2015. The encyclopedia of volcanoes. Elsevier.

Small, C. \& T. Naumann (2001) The global distribution of human population and recent volcanism. Global Environmental Change Part B: Environmental Hazards, 3, 93-109.

Tilling, R. (2008) The critical role of volcano monitoring in risk reduction. Advances in Geosciences, 14, 3-11.

White, G. F. 1945. Human adjustment to floods: a geographical approach to the flood problem in the United States. University of Chicago Chicago.

Wisner, B. \& H. R. Luce (1993) Disaster vulnerability: Scale, power and daily life. GeoJournal, 30, 127-140.

Witham, C. S. (2005) Volcanic disasters and incidents: A new database. Journal of Volcanology and Geothermal Research, 148, 191-233. 


\section{Chapter 2: Magma storage and diking revealed by GPS and InSAR geodesy at Pacaya volcano}

\subsection{Abstract}

GPS measurements from a campaign network at Pacaya volcano, Guatemala occupied from 2009-2015 were combined with InSAR data from 2013-2014 to model deformation sources for two eruptive time-periods: 2009-2011 and 2013-2014. The GPS data for both of these time-periods show downward vertical and outward horizontal deformation greater than $25 \mathrm{~cm}$ at several stations surrounding the volcano, while InSAR data shows up to $15 \mathrm{~cm}$ line-of-sight displacement. To better understand the dynamics of the magma storage system and sources of deformation, we invert available geodetic data for those two periods. Our analytical modeling suggests that horizontal deformation was dominated by inflation of a shallow, subvertical dike, high within the volcanic edifice, while deflation of a deeper, spherical source embedded below the NW flank of the volcano occurred during at least part of the observation period. The source parameters for the dike feature are in good agreement with observed orientation of recent vent emplacement while parameters for the deeper, spherical source accommodate the downward vertical deformation observed at stations on and around the volcano.

\subsection{Introduction}

Geodetic measurements at active volcanoes enables the modeling of subsurface deformation sources and can enhance eruption forecasts and hazard warnings that are crucial to decision makers and individuals during a volcanic crisis (Sparks 2003). It is commonly understood that most volcanoes produce some degree of surface deformation associated with pressurization of magma reservoirs and upward migration of magma prior to an eruption (Dzurisin 2003). Detailed geodetic surveys allow us to track the ascent and extrusion of magma, and improves our understanding of the geophysical process and internal structure of volcanoes, which is critical to minimizing risk associated with volcanic hazards (Sparks 2003, Acocella and Neri 2009, Ebmeier et al. 2018). While geodetic surveys using GPS networks seem plentiful at volcanoes found throughout North America (Dixon et al. 1997, Cabral-Cano et al. 2008, Dzurisin et al. 2009, Biggs et al. 2010, Grapenthin et al. 2013, Poland et al. 2017), deformation studies at Central American volcanoes often rely on InSAR (Fournier et al. 2010, Schaefer et al. 2017, Wnuk and Wauthier 2017, Pritchard et al. 2018, Stephens and Wauthier 2018); those that use GPS are less common (Lechner et al. 2013, Saballos et al. 2014). Even though GPS research has proven to be a robust monitoring and diagnostic tool (Dzurisin 2006); equipment costs, access to field sites, and vulnerability to observers can produce logistical challenges that may deter researchers from implementing GPS as a methodology particularly in countries with limited scientific resources. 
Pacaya volcano, in Guatemala, produces a variety of hazards including ash-fall, ballistics, lava flows, lahars, and debris avalanches (Kitamura and Matías 1995, Vallance et al. 1995, Matías 2009, Escobar-Wolf 2010, Rose et al. 2013), and poses significant risk to a population ca. 3 million within $40 \mathrm{~km}$. Since 1961, eruptions at Pacaya have prompted at least 12 evacuations from nearby communities, damaged property, infrastructure and disrupted air traffic (Matías 2009, Escobar-Wolf 2010, Wardman et al. 2012, Rose et al. 2013). Considering its accessibility and moderate topography, Pacaya offers excellent conditions for the study of magmatic systems and volcano dynamics through geodetic field observations; however, few geodetic surveys have ever been implemented there (Eggers 1983, Schaefer et al. 2015, 2017, Wnuk and Wauthier 2017). While it has been hypothesized that the linear alignment of eruptive vents and the fissure-like collapse structure formed during the 2010 eruption are indicative of a shallow dike residing high in the volcanic cone that is likely fed by a magma reservoir somewhere below the volcanic edifice (Eggers 1983, Matías 2009, Rose et al. 2013), the deficiency in geodetic studies at Pacaya has left a gap in our understanding of the magmatic plumbing system. Recent GPS observations dating back to 2009 show a deformation signal - associated with eruptive episodes - that is moving down and away from the edifice at several benchmarks surrounding the volcano. This paper provides a first glimpse of these GPS observations, proposes two analytical models of deformation sources associated with eruptive periods in 2010 and 2013-2014, and provides new insights into the shallow plumbing system at Pacaya volcano that may ultimately improve monitoring efforts and advanced warning messages to vulnerable populations living in close proximity.

Pacaya is a $2550 \mathrm{~m}$ high basaltic stratovolcano and one of three open-vent volcanoes located within the Central American volcanic arc in southwestern Guatemala. The volcanic arc runs roughly parallel to the convergent boundary where the Cocos Plate subducts beneath the Caribbean plate. The Pacaya volcanic complex, composed of several ancestral cones, is located on the southern rim of the Amatitlán caldera, which is itself situated at the intersection of the N-S trending Guatemala City Graben (GCG) (Kitamura and Matías 1995, Rose et al. 2013) and the Jalpatagua Fault Zone (JFZ) - a trench-parallel, right-lateral, strike-slip fault (Figure 2.1 inset) that could indicate the inland boundary of the forearc sliver and reflects $6 \pm 2 \mathrm{~mm} \mathrm{yr}^{-1}$ of $\mathrm{NW}$, counterclockwise motion (DeMets 2001, Correa-Mora et al. 2009)

Pacaya's episodic eruptive record dates back several thousand years and in its current phase has been persistently active since 1961 (Rose et al. 2013). Geologic and petrologic studies generally divide the eruptive history into three (Eggers 1971, Kitamura and Matías 1995) or four (Bardintzeff and Deniel 1992) eruptive phases: 1) development of a much older Pacaya edifice, now heavily eroded, faulted and covered in pyroclastic deposits; 2) emplacement of the initial cone comprised of large lava flows circa $0.5 \mathrm{Ma}$; 3 ) growth of several andesitic-dacitic cones emplaced during an extrusive phase dating back to approximately $0.16 \mathrm{Ma}$; and 4) growth and evolution of the currently active Mackenney cone (Figure 2.1), composed predominately of interbedded lava, breccia, 
tephra, ash and spatter (Schaefer et al. 2013). Additionally, a massive debris avalanche and associated lateral pyroclastic surges occurred sometime between 600 and 1500 years before present (Kitamura and Matías 1995, Vallance et al. 1995).

Pacaya entered its current active phase in 1961 after $\sim 200$ years of quiescence (Rose et al. 2013 ) and is now one of Guatemala's most active volcanoes. During this time, a network of eruptive vents produced the volume of volcanic material forming Mackenney cone on the western flank of the ancient Pacaya edifice (Pacaya Viejo), within the ancestral collapse scar. The Mackenney cone has grown asymmetrically within the collapse amphitheater through a series of small and moderate lava flows coupled with tephra producing events. Pacaya's eruptive style over the last 50-years is generally characterized by strombolian eruptions, intermittent lava flows, and persistent degassing (Kitamura and Matías 1995, Dalton et al. 2010, Rose et al. 2013). Rose et al. (2013) identified and delineated Pacaya's eruptive episodes during this time and noted several significant tephra-producing events in the 1980s-1990's, which culminated in two larger eruptions in 2000 and 2010. Prior to the 2010 eruption a series of lateral vents on the western flank of the Mackenney cone produced sporadic lava flows lasting for several days to months at a time. Contemporary background activity is characterized as strombolian with observations of a nearly constant white-and-blue plume, low-frequency tremor, and weak infrasound events indicative of small bubble bursting events (Dalton et al. 2010). Notable events significant for this research include the explosive eruption in May 2010 and two smaller explosive and effusive events in August 2013 and from January - March 2014.

While this type of eruptive behavior is the most common for Pacaya, it is the asymmetrical growth of the modern Mackenney cone within the ancestral collapse scarp on the western flank that presents potential risk to nearby communities. Recent work by Schaefer et al. (2017) suggests that a large section of the Mackenney cone (approx. $7 \mathrm{~km}^{2}$ and estimated volume between $0.65>1 \mathrm{~km}^{3}$ ) slipped as much as $4 \mathrm{~m}$ to the southwest during the 2010 eruption. The 2010 eruption is also notable following a significant change in the morphology of the cone in the form of a NW-SE trending trough that extends approximately $600 \mathrm{~m}$ from the $2500 \mathrm{~m}$ high summit of Mackenney down $300 \mathrm{~m}$ lower to the base of the cone (Figure 2.2). Considering the rapid growth of the unbalanced Mackenney cone upon a weak basal layer, coupled with the interaction of gravity, regional tectonic activity, dike intrusions and magmatic deformation, a sector collapse of the western flank is realistic possibility (Rose et al. 2013, Schaefer et al. 2015, Schaefer et al. 2017) and should be monitored closely with ground-based and satellite geodetic techniques. 




Figure 2.1 Map showing Pacaya volcano and the GPS network. Inset shows Guatemala and Pacaya (blue triangle) relative to Guatemala City Graben (GCG) and the Jalpatagua Fault Zone (JFZ). The 7-station GPS network is indicated by red squares. The Mackenney cone hosts the current active crater. GPS station CRAK was located within the fissure-like trough that formed during the 2010 eruption. This trough is oriented in line with Cerro Chino - an older parasitic vent - and a 2010 flank vent on the SE face of Pacaya Viejo. This linear alignment of eruptive vents suggest a shallow dike within the cone. The hashed line shows the ancestral collapse scarp. 


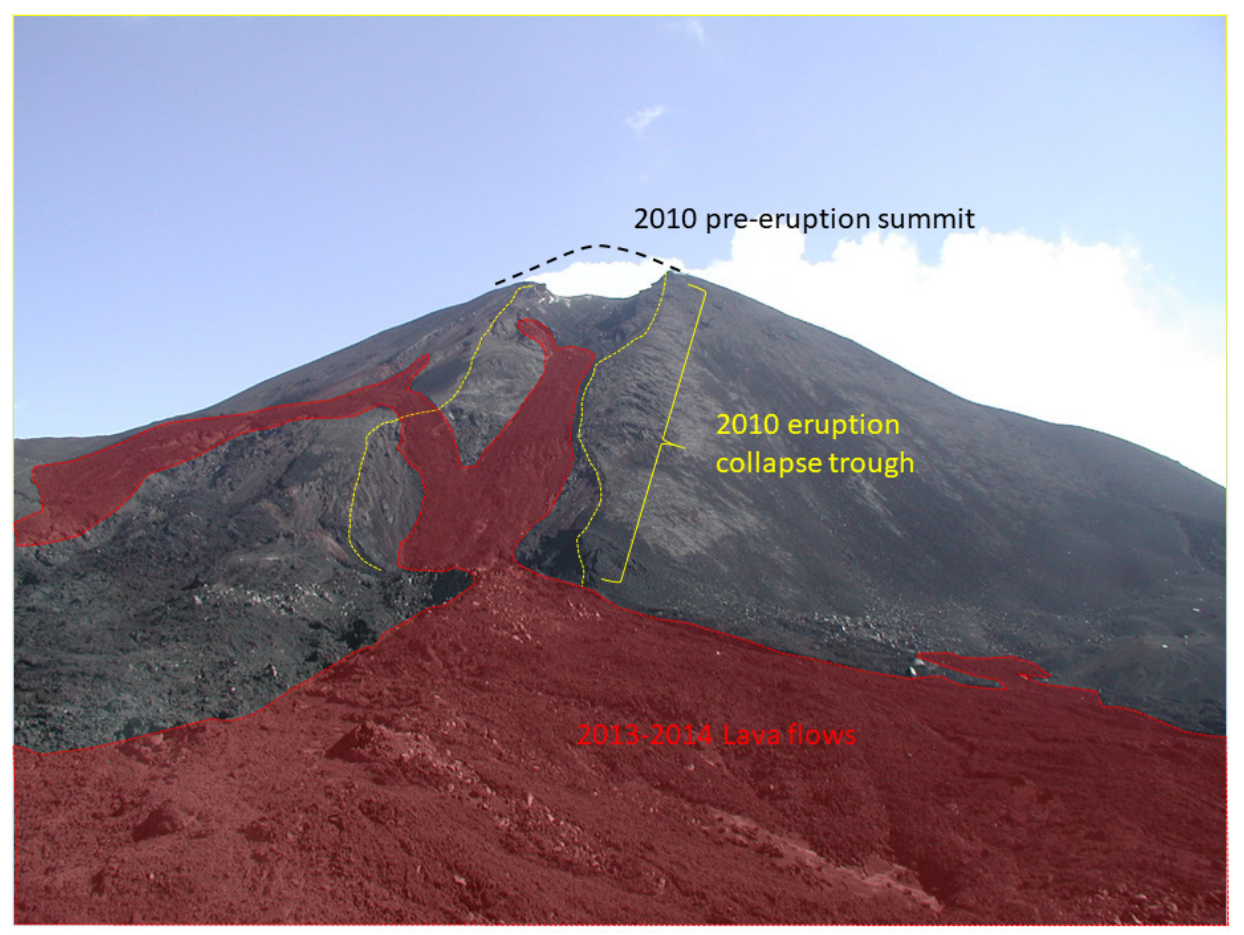

Figure 2.2 During the May 2010 eruption a large trough, with a NW-SE orientation, opened from the summit and extended to the base of Mackenney cone. During the 2013-2014 eruptive phase, a series of lava flows partially filled the collapse trough and destroyed GPS station CRAK.

\subsection{Geodetic data}

Repeated GPS measurements from a network of 5-7 benchmarks (Figure 2.1) were collected during twelve campaigns between 2009 -2015 (Table 6-1 appendix). GPS monuments were installed based on proximity, ground stability, ease of access, security, and azimuthal distribution around the Mackenney cone. Benchmarks consist of a threaded steel pin, drilled and epoxied into rock or a buried concrete monument, which accommodates a $0.61 \mathrm{~m}$ fixed-height, threaded, steel antenna-mast, and allows for rapid installation of the GPS antenna and eliminates errors associated with centering and instrument height calibration.

GPS receivers were deployed between 3 and 9 hours during each campaign. Survey equipment consisted of Trimble dual-frequency receivers (NetRS, R7 and 5700 series) and Zephyr-Geodetic antennas. All data were processed using GISPY/OASIS software, version GOA 6.3 which incorporates single-receiver, phase ambiguity resolution (Bertiger et al. 2010) and precise clock and orbit determinations provided by JPL (Zumberge et al. 1997). Each campaign measurement provides a non-fiducial position estimate (in Cartesian coordinates) that is calculated in the Earth-Centered-Earth-Fixed (ECEF) reference and then translated into the International Terrestrial Reference Frame 2008 (ITRF08). 
Table 2-1 Measured displacements and $2 \sigma$ error for station data used in this study from time-periods between 2009-2011 and 2013-2014 (TPA and TPB) respectively.

\begin{tabular}{|l|c|c|c|c|c|c|}
\hline 2009-2011 & $\begin{array}{c}\text { Easting } \\
\mathrm{mm}\end{array}$ & $\begin{array}{c}2 \sigma \\
\mathrm{mm}\end{array}$ & $\begin{array}{c}\text { Northing } \\
\mathrm{mm}\end{array}$ & $\begin{array}{c}2 \sigma \\
\mathrm{mm}\end{array}$ & $\begin{array}{c}\text { Vertical } \\
\mathrm{mm}\end{array}$ & $\begin{array}{c}2 \sigma \\
\mathrm{mm}\end{array}$ \\
\hline BVIS & -65 & 6 & -5 & 2 & -39 & 8 \\
CHNO & -59 & 6 & -259 & 2 & -184 & 9 \\
CHQO & 2 & 5 & -3 & 2 & -9 & 8 \\
CHUP & -20 & 6 & -33 & 3 & -21 & 10 \\
LBLK & -105 & 5 & -220 & 2 & -189 & 9 \\
\hline & Easting & $2 \sigma$ & Northing & $2 \sigma$ & Vertical & $2 \sigma$ \\
2013-2014 & $\mathrm{mm}$ & $\mathrm{mm}$ & $\mathrm{mm}$ & $\mathrm{mm}$ & $\mathrm{mm}$ & $\mathrm{mm}$ \\
\hline BVIS & -15 & 11 & -11 & 4 & -80 & 16 \\
CHNO & 16 & 13 & 4 & 5 & -129 & 19 \\
CHQO & 21 & 10 & 14 & 4 & -49 & 16 \\
CHUP & -12 & 8 & 8 & 3 & -93 & 13 \\
LBLK & -16 & 9 & -8 & 4 & -63 & 15 \\
LVES & 250 & 14 & 111 & 5 & -121 & 19 \\
\hline
\end{tabular}

Our data acquisition strategy and processing approach were based on an earlier study at Santa Ana volcano, El Salvador (Lechner et al. 2013) in a similar subtropical setting. The study investigated the reliability of short 1 to 3 -hour acquisition periods for absolute positioning compared to differential processing errors as a function of baseline length. That study found that single station ambiguity resolution produced $95 \%$ repeatabilities of $+/-10-12 \mathrm{~mm}$ in horizontal and $+/-33 \mathrm{~mm}$ in vertical for 3-hour measurement sessions. The study also compared differential processing of baselines with varying lengths and found that differential techniques limit maximum baseline distances to $\sim 10 \mathrm{~km}$, after which tropospheric wet delay and other sources of error at both ends of the baseline become increasingly decorrelated leading to a breakdown in precision. Considering the distance between Pacaya and the nearest CORS station GUAT is $\sim 24 \mathrm{~km}$ with an elevation difference of $\sim 1000 \mathrm{~m}$, differential processing would likely not provide a significant advantage over precise point positioning.

A time-series of all Pacaya station absolute-position estimates with $2 \sigma$ error bars from 2009 to 2015 is shown in Figure 2.3; calculated displacements and error estimates are given in Table 2-1. The time series reflects a dynamic deformation history Figure 2.4 that is difficult to constrain with our limited spatial and temporal sampling. However, there appear to be displacement trends at all stations in the three directional components 
associated with eruptive activity - the most obvious being downward vertical- which we infer as deflation related to eruptive events in May 2010, 2013-2014. The inter-eruptive period between 2011 through 2013 is represented by a temporally dense GPS data set; however, the signal-to-noise ratio is rather low to interpret reliably small deformation signals that may have occurred during this time-period. Therefore, we decided to focus our modeling efforts on the two co-eruptive time periods in which the highest deformation signals were successfully observed at all benchmarks with a high signal-tonoise ratio and span the eruptions noted above: 1) January 2009 - January 2011, which includes the May 2010 eruption; and 2) March 2013 - November 2014, which includes eruptions in late 2013 and early 2014. These two periods will hence be referred to as Time-Period-A and Time-Period-B (TPA and TPB), respectively. General trends for both TPA and TPB show all station's displacements moving downward and some outward away from the cone, which we assume as primarily elastic deformation related to eruptive events.

Total horizontal displacements during TPA range from $2 \mathrm{~mm}$ to $105 \mathrm{~mm} \mathrm{E}$ and $-3 \mathrm{~mm}$ to $-259 \mathrm{~mm} \mathrm{~N}$, while during TPB horizontal displacement range from $-15 \mathrm{~mm}$ to $250 \mathrm{~mm} \mathrm{E}$ and $-11 \mathrm{~mm}$ to $111 \mathrm{~mm} \mathrm{~N}$. Both time-periods show downward vertical displacements, with between $-9 \mathrm{~mm}$ to $-189 \mathrm{~mm}$ and $-49 \mathrm{~mm}$ to $-129 \mathrm{~mm}$ during TPA and TPB, respectively. While all stations during TPB show significant downward displacements, vertical motion during TPA at stations CHNO and LBLK is $\sim 60 \mathrm{~mm}$ greater with a much smaller signal-to-noise ratio. This small margin of error is consistent with the longer duration observations during TPA. This is also consistent with the greater magnitude of the 2010 eruption relative to the 2013 and 2014 events.

The possibility that some of the displacement signal is associated with flank motion was considered before beginning elastic modeling efforts. Recent deformation studies at Pacaya, using InSAR (2013, Schaefer et al. 2015, 2016) revealed that the flank displacement associated with the 2010 eruption was localized to the SW flank of the Mackenney cone, with the majority occurring high on the cone. InSAR analysis by Wnuk and Wauthier (2017) suggests a minimum of $\sim 900 \mathrm{~mm}$ of line of sight (LOS) subsidence on the southwest flank of the edifice between April 2013 through April 2014, consistent with the large vertical displacements in TPB. Within the spatial extent of the 2010 slope motion identified by Schaefer et al. (2015) and the 2013-2014 LOS subsidence identified by Wnuk and Wauthier (2017), there is no GPS data available. However, some motion observed at station LBLK may be attributed to this flank motion and is discussed in more detail in the discussion section.

For TPA, there is no available InSAR data coincident in time with the GPS campaign measurements (Schaefer et al. 2015, 2016, 2017). For TPB however, we used a RADARSAT-2 descending dataset presented in (Wnuk and Wauthier 2017). Conventional InSAR is challenging at Pacaya, with temporal InSAR signal decorrelation preventing us from obtaining useful measurements for long temporal baseline interferograms. Therefore, the following strategy is used to create an InSAR-derived 
dataset coincident in time with TPB and the campaign GPS measurements: to increase the signal to noise ratio and mitigate atmospheric effects (Massonnet and Feigl 1998), we have stacked consecutive interferograms in time to match time-period-B (TPB). All interferograms were first processed using the GAMMA software (Werner et al. 2000), with topographic phase contributions removed by using a $12 \mathrm{~m}$ TanDEM-X digital elevation model. Second, interferograms were filtered using a Goldstein filter (Goldstein and Werner 1998), then unwrapped using the minimum cost flow technique and a triangular irregular network (Costantini 1998). Finally, 17 consecutive unwrapped interferograms (Wnuk and Wauthier 2017) were stacked spanning 26 March 2013 - 16 November 2014, therefore closely matching TPB (Table 6-2 appendix, for acquisition dates).

The InSAR data for TPB (Figure 2.4, bottom) shows two distinct signals: $\sim 15 \mathrm{~cm}$ of range increase (positive phase change: motion away from the satellite) encompassing the lower western and southwestern portion of Mackenney cone, and $\sim 10 \mathrm{~cm}$ of range decrease (negative phase change: motion towards the satellite) east-southeast of the summit (Figure 2.4, bottom). The InSAR stacked dataset was then subsampled to 478 points in coherent areas (Figure 2.4, bottom) and inverted simultaneously with the GPS data in all TPB inversions (see following sections). 


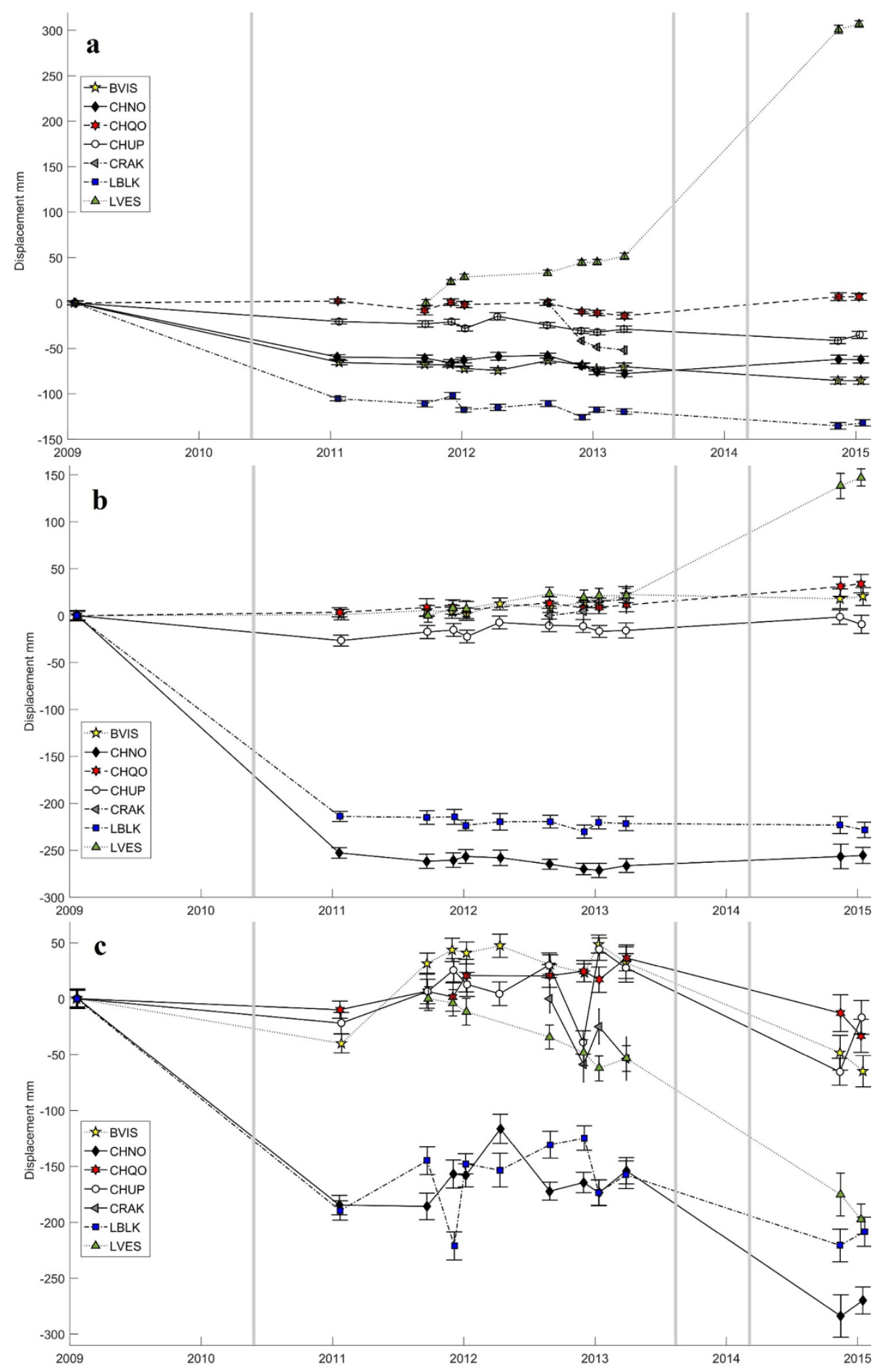

Figure 2.3 Time series of positions for each geodetic component (a) easting, (b) northing, (c) vertical. Gray vertical lines indicate eruptive events. Error bars are 2- $\sigma$ outputs from GIPSY v6.3. 

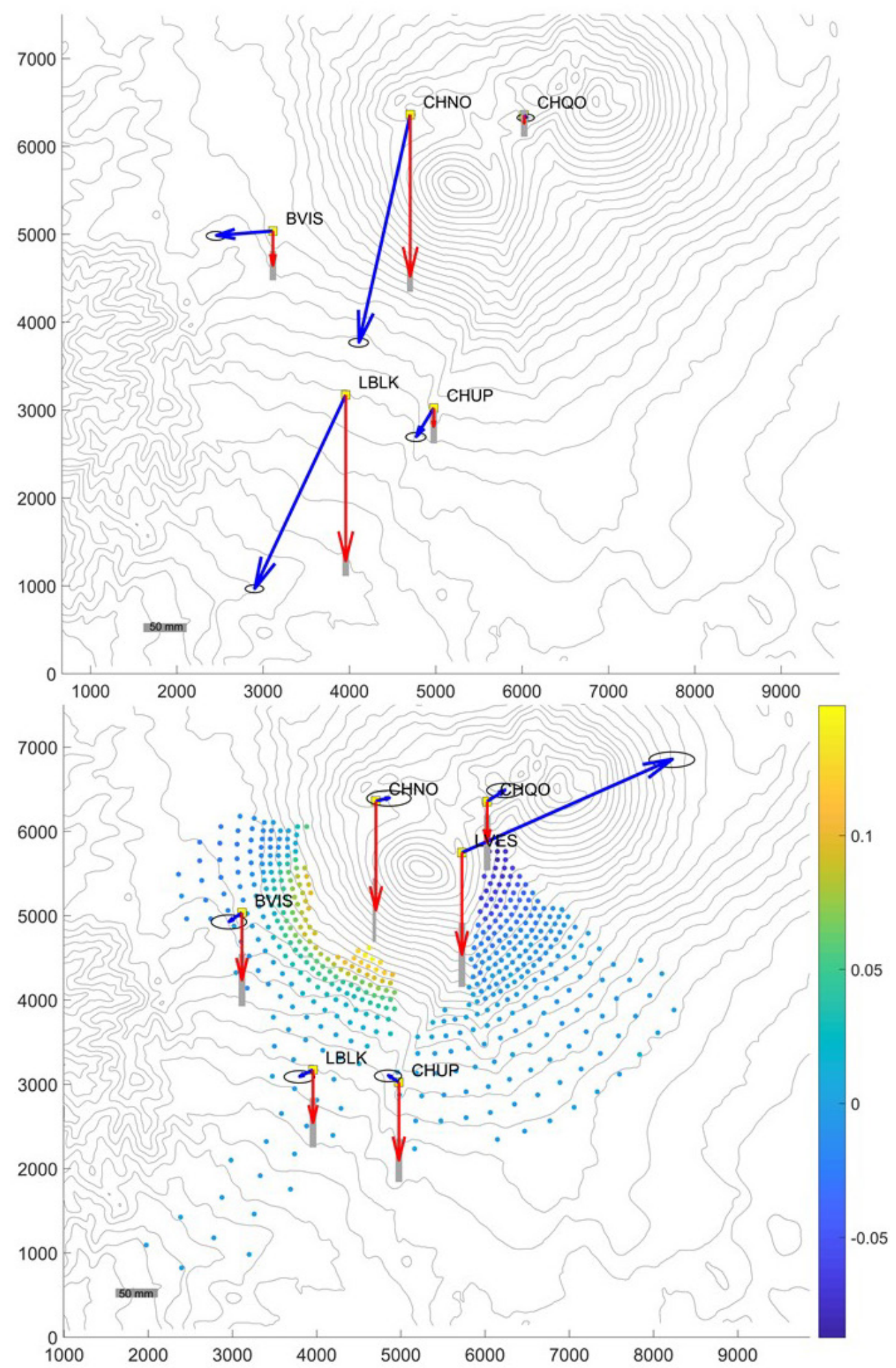

Figure 2.4 Observed deformation at Pacaya. Blue (horizontal) and red (vertical) arrows represent GPS observations. Two sigma error ellipses in black and vertical error bars shown in gray. A $50 \mathrm{~mm}$ scale bar is found in the lower left corner of maps. Subsampled points InSAR observations shown by colored dots. Color bar on right shows line-of-site displacement in meters. Top map represent TPA and bottom TPB. 


\subsection{Non-linear inversions}

To model the magmatic system and internal structure of Pacaya we constrained source locations by inverting deformations observed during TPA and TPB. Considering lack of previous GPS surveys and limited geodetic data at Pacaya, several assumptions were made during the modeling: sources are embedded in an isotropic, homogeneous, elastic half-space with a Poisson ratio of 0.25 and a shear modulus of $20 \mathrm{GPa}$. While these assumptions neglect realistic properties of the actual subsurface, applying these simple analytical models are appropriate to provide an accurate first-order approximation of the deformation sources (Dzurisin 2006). Additionally, radius for all spherical sources is fixed to 500 meters, given the known challenge of estimating separately radius and pressure/volume [Battaglia et al., 2013, Segall, 2010].

We relied on both observations of volcanic activity over the time periods and complementary data and models by Wnuk and Wauthier (2017) to guide our modeling efforts. The observed surface deformation trough and subsequent NNW-SSE vent locations implied that a dike had intruded into the Mackenney cone during the 2010 eruption and may still be an important magma pathway. Modeling of InSAR data over the period December 2012 to March 2014 pointed to upper crustal spherical sources and a shallow dike within the cone that had been active. Together, geology and prior geodetic models informed our modeling and helped to focus on the most likely sources of the observed deformation.

The GPS data from TPA and TPB both show downward vertical motion together with horizontal motion out away from the cone at several stations. This is difficult to explain with a single source. For example, a deflating, point pressure source would have downward displacement accompanied by inward horizontal motion. Nevertheless, we made attempts to invert for models that included a single source, in addition to models with two distinct sources. Three component locations as well as volume and geometry of sources were inverted for (Table 2-2). Our inversion uses a Monte Carlo neighbourhood algorithm designed to find a global minimum using a cost function (Sambridge 1999a) that minimizes the misfit (Eq. 1) during a "search" stage and further estimates $95 \%$ confidence intervals on inverted parameters during a second "appraisal" stage (Sambridge 1999b). During the appraisal stage, marginal posterior probability density functions are calculated from the distribution of misfit values previously found in the search stage and then produces $95 \%$ confidence intervals for individual model parameters and shows any trade-off that could exist between inverted model parameters.

$\chi^{2}=\left(u_{0}-u_{m}\right)^{T} C_{D}^{-1}\left(u_{0}-u_{m}\right)$

Where $u_{0}$ and $u_{m}$ are vectors of subsampled observed and modeled surface displacements. $C_{D}$ represents the covariance matrix related to data-noise correlation added to the synthetic data. 


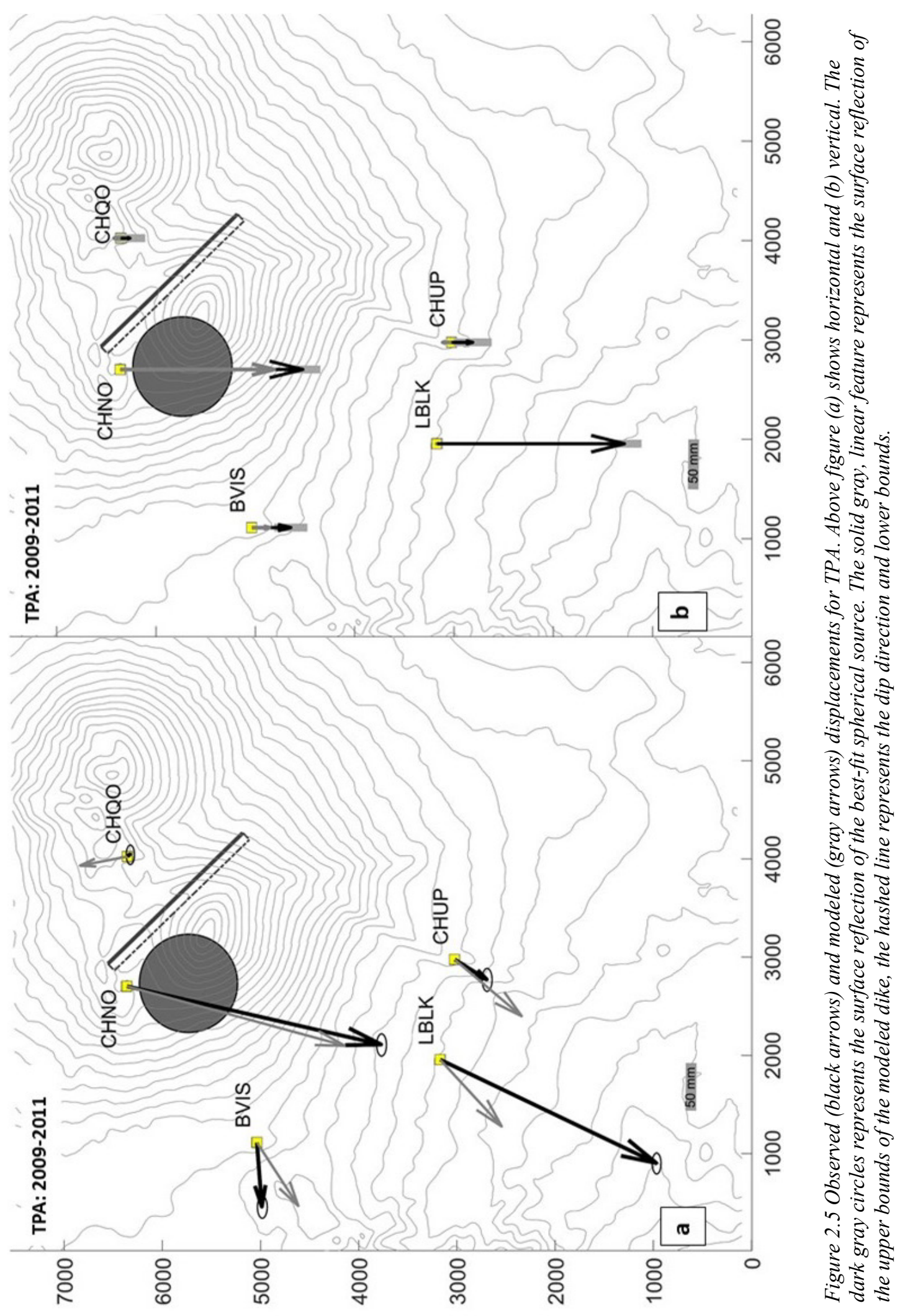




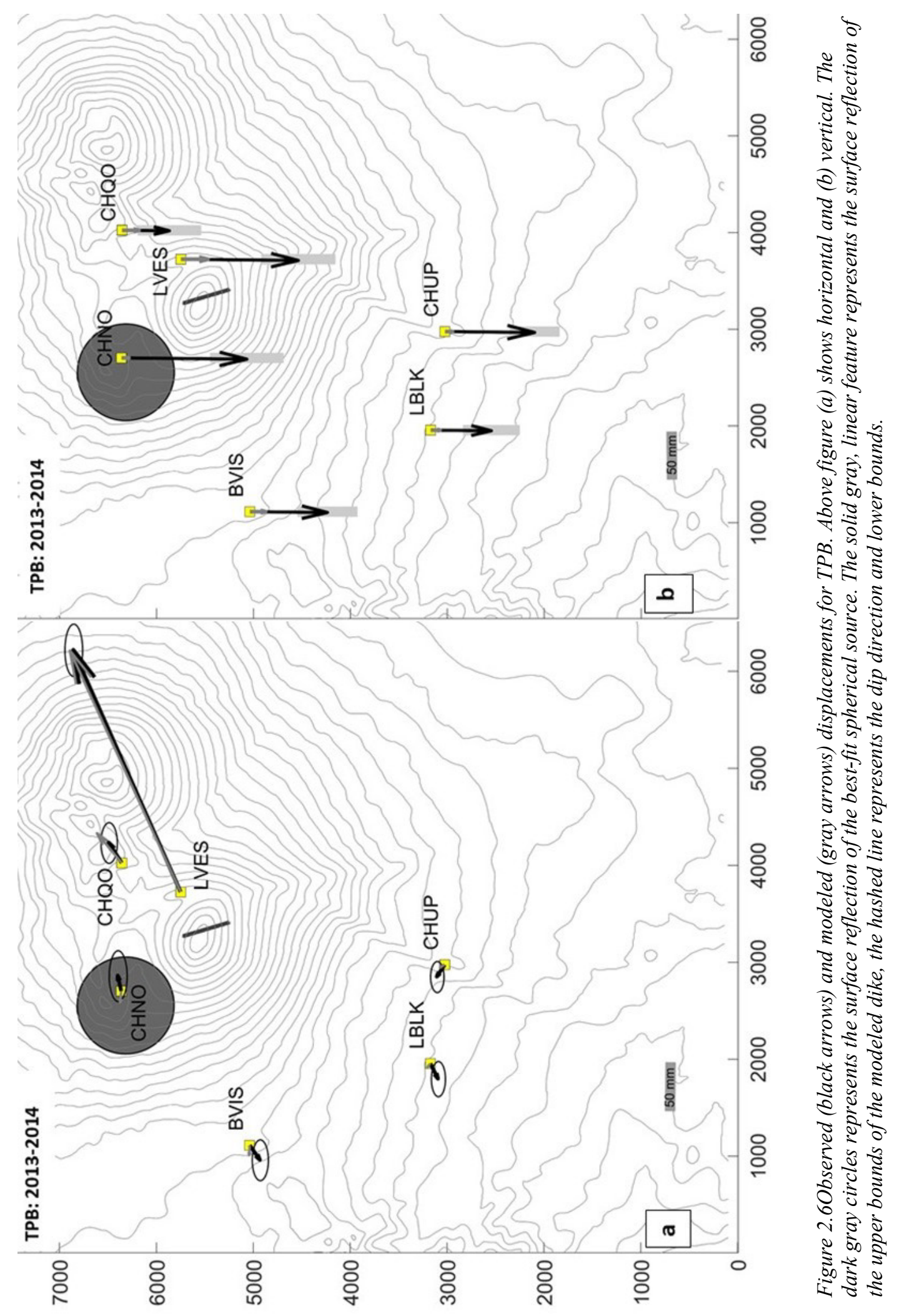







Table 2-2 Input parameters from non-linear inversions on the left and best fit outputs (bold text) for the preferred models in TPA and TPB are shown on the right with their 95\% confidence intervals following. $U C$ denotes model parameters that are unconstrained. Depth z0 represents the depth parameter for the lower left corner of the dike structure.

\begin{tabular}{|c|c|c|c|c|c|c|c|c|}
\hline \multicolumn{3}{|c|}{ Input Parameters } & \multicolumn{3}{|c|}{ 2009-2011 (TPA) GPS only } & \multicolumn{3}{|c|}{ 2013-2014 (TPB) GPS-InSAR } \\
\hline $\begin{array}{l}\text { Source } \\
\text { type }\end{array}$ & \multicolumn{2}{|c|}{$\begin{array}{l}\text { Spherical reservoir } \\
\text { (McTigue, 1987) }\end{array}$} & Best Fit & Min & Max & Best Fit & Min & Max \\
\hline $\begin{array}{l}\text { Depth } \\
\text { (m) }\end{array}$ & 1000 & 5000 & 1001 & UC & UC & 4586 & 4337 & 4600 \\
\hline East UTM & 756810 & 760660 & 758134 & 757692 & 759173 & 757955 & 757952 & 758248 \\
\hline North & 159282 & 1588755 & 1591534 & 1591256 & 159264 & 159211 & 159192 & 159237 \\
\hline UTM & 0 & & & & 3 & 6 & 4 & 0 \\
\hline $\begin{array}{l}\Delta \text { volume } \\
\left(10^{6} \mathrm{~m} 3\right)\end{array}$ & -1.0 & -21.0 & -2.1 & UC & UC & -1.6 & -1.7 & -1.6 \\
\hline $\begin{array}{l}\text { Source } \\
\text { Type }\end{array}$ & \multicolumn{2}{|c|}{ Dike (Okada, 1985) } & & & & & & \\
\hline $\begin{array}{l}\text { Opening } \\
\text { (m) }\end{array}$ & 0.1 & 5 & 4.8 & UC & UC & 4 & 4 & 4 \\
\hline $\begin{array}{l}\text { Width } \\
\text { (m) }\end{array}$ & 100 & 4000 & 430 & 176 & 766 & 101 & UC & UC \\
\hline $\begin{array}{l}\text { Length } \\
\text { (m) }\end{array}$ & 500 & 4000 & 1915 & 644 & 1629 & 500 & UC & UC \\
\hline Strike $\left({ }^{\circ}\right)$ & 110 & 170 & 136 & 124 & 137 & 163 & 162 & 166 \\
\hline $\operatorname{Dip}\left({ }^{\circ}\right)$ & 30 & 90 & 77 & UC & UC & 83 & 80 & 84 \\
\hline East UTM & 757678 & 760241 & 758264 & 757886 & 758461 & 758659 & 758589 & 758831 \\
\hline North & 158978 & 1592461 & 1592288 & UC & UC & 159152 & 159138 & 159163 \\
\hline UTM & 3 & & & & & 2 & 7 & 3 \\
\hline $\begin{array}{l}\text { Depth zO } \\
\text { (m) }\end{array}$ & 100 & 1000 & 992 & UC & UC & 100 & UC & UC \\
\hline \multicolumn{3}{|c|}{ RMS Error (mm) } & 41 & & & 32 & & \\
\hline
\end{tabular}

We investigated three types of simple analytical geodetic models to fit the data in both time periods separately: 1) a single spherical source after McTigue (1987) ; 2) a single tensile-opening dislocation after Okada (1985), which we use to model a dike source; and 3 ) a combined two-source model that consists of a McTigue spherical source together with an Okada dike source (Table 2-2). The depths of single source models varied from $100 \mathrm{~m}$ to $5 \mathrm{~km}$ over a $\sim 4 \mathrm{~km} \mathrm{x} 4 \mathrm{~km}$ area centered on Mackenney cone and both positive and negative volume changes were explored. For the combined two-source model we also explored a similar spherical source over the same area and depths between 1-5 km combined with a second tensile-opening dislocation source with a NW-SE orientation aligned with the 2010 SE flank eruption, the Mackenney crater, and the $2010 \mathrm{NW}$ collapse trough; which is roughly parallel to the upper section of the ancestral collapse scarp (Schaefer et al. 2016). We searched a range of dike parameters: strike, dip, length, width and opening (Table 2-2), and imposed a depth constraint on the upper bounds to discarded any negative depth solutions. 
While misfits were lower for the combined source models, and the data seem to suggest a combination of inflationary and deflationary sources, the increased number of model parameters does not always represent the most realistic solution (Wauthier et al. 2015). To determine the best model fit relative to model free parameters we felt it appropriate to apply the modified Akaike criterion (AICc) (Eq. 2) where the additional term tends toward zero as $N$ increases (O'Brien et al. 2010):

$$
A I C c=2 k+N \ln \left(\frac{x^{2}}{N}\right)+\left(\frac{2 k(k+1)}{N-k-1}\right)
$$

Where $k$ is the number of inverted parameters $+1 ; N$ is the number of subsampled data points; and $\chi^{2}$ is the misfit.

We compared sets of models inverted from the same data sets to find the model for each time-period with the lowest AICc value and found that our two-source model fit the criteria (Table 2-3).

Table 2-3 Results of the modified Akaike information Criterion (AICc) for single source and two source models.

\begin{tabular}{|c|c|c|c|}
\hline \multicolumn{4}{|c|}{ TPA (2009-2011) GPS only } \\
\hline Model type & AICc & Misfit & RMSE mm \\
\hline McTigue & 761.33 & $8.7 \times 10^{9}$ & $1.5 \times 10^{5}$ \\
\hline Okada & 150.51 & 994.40 & 50 \\
\hline McTigue/Okada & 145.28 & 571.76 & 38 \\
\hline \multicolumn{4}{|c|}{ TPB (2013-2014) GPS-InSAR } \\
\hline Model type & AlCc & Misfit & RMSE mm \\
\hline McTigue & 10443.25 & $6.5 \times 10^{11}$ & $1.5 \times 10^{5}$ \\
\hline Okada & 1780.95 & 17329.59 & 34 \\
\hline McTigue/Okada & 1771.67 & 16651.90 & 29 \\
\hline
\end{tabular}




\subsection{Discussion}

The observed GPS deformation for both time-periods shows outward horizontal and downward vertical motion. The vertical motion for both time-periods is dominated at station CHNO, while the horizontal deformation is most evident at stations CHNO for Time-Period-A and CHNO and LVES during Time-Period-B. Considering the proximity of these two stations to Mackenney cone, we assume that observed displacements are elastic and indicative of the magmatic system, therefore, models that fit displacements best at these locations were generally considered more favorable. Of course, the down and out surface displacement observed at most stations is difficult to resolve with a single source model. The AICc for both time-periods favors a two-source model consisting of an inflating Okada dike and deeper deflating sphere (Table 2-3). Results from the preferred two-source models are presented in Figure 2.5, Figure 2.6, Figure 2.7, and Table 2-2. The 95\% confidence intervals for all model parameters are listed in Table 2-2 and a-posteriori probability density functions for preferred models are included in the appendix in Figure 6.1, Figure 6.2, Figure 6.3, and Figure 6.4. Best source parameters from each inversion are referenced to local UTM coordinates with an arbitrary reference elevation of zero.

In TPA (Figure 2.5), a modeled spherical source is located $\sim 1000 \mathrm{~m}$ below the NW flank of the Mackenney cone with a dike dipping SW at $77^{\circ}$ to a depth of $992 \mathrm{~m}$ below the NW-SE vent alignment. The comparison between the observed displacements and those calculated from the forward model show good agreement in the azimuth and magnitude for TPA, however, modeled horizontal displacement vectors do not fit within the $2 \sigma$ error ellipses. When considering vertical displacements for TPA, the misfit between observed and modeled displacements are quite apparent at stations CHQO, CHUP, and LBLK. We attribute the small observed displacement at $\mathrm{CHQO}$ to its placement on an ancient and stable cone. Given that there was up to $4 \mathrm{~m}$ of co-eruptive slope movement to $\mathrm{SW}$ (Schaefer et al. 2016) during the 2010 eruption, it is plausible that the large magnitude deformation observed at LBLK, and subsequent misfit within the model reflect the toe of the rotational slope movement and therefore may not be entirely elastic. Likewise, while we have found no InSAR images during TPA that show good coherence near BVIS, we believe that site may have also experienced non-elastic deformation as a result of this rotational slope movement. Vertical displacement vectors for TPA do show good agreement in both direction and magnitude, and fit within the error at stations CHNO and BVIS, however, vertical fit at other stations especially LBLK is not in good agreement. The vertical deformation and large misfit with the model at station LVES will be discussed later.

In TPB (Figure 2.6 and Figure 2.7), a modeled spherical source is also located $\sim 4600 \mathrm{~m}$ below Cerro Chino with a dike dipping SW at $83^{\circ}$ to a depth of $\sim 100 \mathrm{~m}$. Similar to TPA, the dike is well aligned with the NW-SE linear orientation of vent features. The large vertical displacements observed at all stations in the GPS data are highly indicative of a deflating source; however, our modeled deflating source does a poor job of resolving the 
observed deformation (Figure 2.6 (b)). The comparison between modeled and observed GPS displacements from the depth-controlled inversion show a good fit to the horizontal motion (Figure 2.6 (a)), especially for sites on the eastern flanks of the volcano: CHQO, LVES and CHUP. The large magnitude displacement vector in the horizontal at LVES and the smaller vector at $\mathrm{CHQO}$ show excellent fit when compared to modeled displacement and are within the $2 \sigma$ error ellipses. Sites BVIS, CHNO and LBLK on the western flanks all show very small measured horizontal displacements $(4-16 \mathrm{~mm})$ and larger residuals, but modeled displacements at BVIS and LBLK show good agreement in both direction and magnitude with observed displacement.

The modeled InSAR data for TPB (Figure 2.7, middle) fits well with the observed data (Figure 2.7, left) with relatively small residuals (Figure 2.7, right), especially on the east flank of the edifice and directly west of the active crater. The subsidence on the western flanks of the volcano is consistent with the GPS observations; however, the "inflation" observed by InSAR on the eastern flank does not match the downward motion observed at GPS station LVES, which is the most proximal to the eastern flank. The residuals on the southwest flank, $\sim 5-10 \mathrm{~cm}$, are not effectively modeled with either a deflating sphere or inflating dike source. The larger residuals in the vertical GPS displacements (Figure 2.6 (b)) and InSAR on the SW flank near GPS station LBLK (Figure 2.7, right) perhaps do not account for the full extent of observed deformation. This disagreement may indicate the presence of other deformation sources not included in our model, more complex source geometries, topography, decorrelation due to atmospheric interference, oversimplification of our model, or compromises between inverted parameters.

The depth of the upper bounds of the modeled dike ranges between $570 \mathrm{~m}$ for TPA and slightly greater than $0 \mathrm{~m}$ for TPB. These shallow depths are consistent with the proposal for a magma reservoir situated high in the cone as suggested by (Eggers 1983) and Vallance et al. (1995). Vents on the south flank of Pacaya that opened after the main 2010 eruption are near the surface projection of the modeled dike. The fissure-like trough and observed fire fountaining associated with the 2010 event is suggestive of a fissure eruption and further evidence of a dike feature seated high within the edifice. Our models support the idea of a high-level magma-body that is fed by a deeper magma source. This in turn leads to the assumption that over-pressurization and evacuation of magmatic material from a shallow dike source during the 2010 eruption is responsible for the formation of the $\sim 600 \mathrm{~m} \mathrm{NW-SE}$ oriented collapse trough. This fissure-like trough extends from the summit towards Cerro Chino and likely played a significant role in $\sim 4 \mathrm{~m}$ flank motion of the SW flank (Escobar-Wolf 2010, 2013, Schaefer et al. 2015, 2016). While no comparable morphological changes occurred during the 2013-2014 events, the GPS data and InSAR show a deformation signal consistent with a deflating magma source at depth and the opening of a shallow dike that fits the orientation of recent eruptive vents. The two models based on our geodetic data are in general agreement with models produced by Wnuk and Wauthier (2017) in which their multi-source model, based on an in-depth analysis of InSAR data spanning December 2012 to April 2014, 
produced two spherical magma reservoirs, one shallow $<1 \mathrm{k}$ below the $\mathrm{SW}$ flank and a larger reservoir a $\sim 4 \mathrm{~km}$ depth $\mathrm{NW}$ of the edifice, in addition to a dike source with similar location, orientation and depth (see Appendix material Table 6-3 and Figure 6.5).

While there is no published research beyond this work and that of Wnuk and Wauthier (2017) that directly infers any specific depths of magma storage reservoirs, we will take the opportunity to discuss two previous studies (Bardintzeff and Deniel 1992, Lanza 2016). The petrologic analysis by Bardintzeff and Deniel identifies the lavas at Pacaya as basalts and basaltic-andesites and concludes that magmas from two separate chambers have mingled, likely through a shared conduit. Their interpretation presents two possible models of Pacaya's shallower interior: 1) a single magma chamber where re-melting of amphibole bearing cumulates occurs, differentiation of the magma by fractionation, followed by general mingling; 2) two magma chambers coexisting - filled by magmas from the same mantle source - where dacitic chamber eventually connects to a shallower basaltic-andesitic chamber through a shared conduit and mingling occurs. While Bardintzeff and Deniel (1992) do not hypothesize any specific depths for these chambers, their two-reservoir model is consistent with our results pointing to one shallow and one deeper magma chamber as well as the two-chamber model presented by (Wnuk and Wauthier 2017). We also highlight the dissertation research conducted by Lanza (2016) who attempted seismic tomography at Pacaya in 2014. While this research has not been published in any peer reviewed journal, the analysis shows many small-magnitude volcano-tectonic earthquakes located at depths between $500 \mathrm{~m}$ and $1 \mathrm{~km}$ below the Mackenney cone, suggestive of a brittle conduit above a relatively shallow magma chamber and fairly consistent with the shallow magma reservoir that we have presented in our model for the 2009-2011 time-period.

In the discussion regarding the dike features we present dike models showing an outward dip and orientation that we believe may coincide with the dip angle and orientation of the ancestral collapse scarp beneath the Mackenney cone (Figure 2.8). Previous studies have suggested that edifice load, cone morphology, and local stress fields can influence dike propagation (Pinel and Jaupart 2000, Tibaldi 2003, Acocella and Tibaldi 2005, Taisne and Tait 2009, Taisne et al. 2011). These factors are important to consider in the case of Pacaya as the Mackenney cone has grown rapidly over the last $\sim 50$ years by emplacement of intermittent lava flows and tephra deposits, and is buttressed by the far more consolidated Pacaya Viejo cone. Therefore, the unbalanced edifice load coupled with varying rheology at the interface of the Mackenney cone and Pacaya Viejo may provide a path of least resistance promoting favorable conditions for near vertical dike propagation along a pre-existing fracture, weak basal-layer or ancestral collapse scarp (Schaefer et al. 2013).

Furthermore, our dike models for both TPA and TBP show a dike orientation that aligns very well with the linear arrangement of the NNW-SSE vents that transect the Mackenney cone. Additionally, the outward dip angles of $77^{\circ}$ and $83^{\circ}$ to the SW from our dike models for each time period (Figure 2.8) could be interpreted as a representation 
of the ancestral collapse scarp functioning as a control on the dike propagation path and vent emplacement. The increasing dip and shallower depths of the dike from TPA to TPB could represent the reorientation of the dike as it approaches the upper slope of the volcano and parallels the ancestral collapse scrap (Tibaldi 2003). This of course could have significant hazard implications as over-pressurization and dike propagation could trigger another sector collapse and massive debris avalanche along this zone of weakness. 


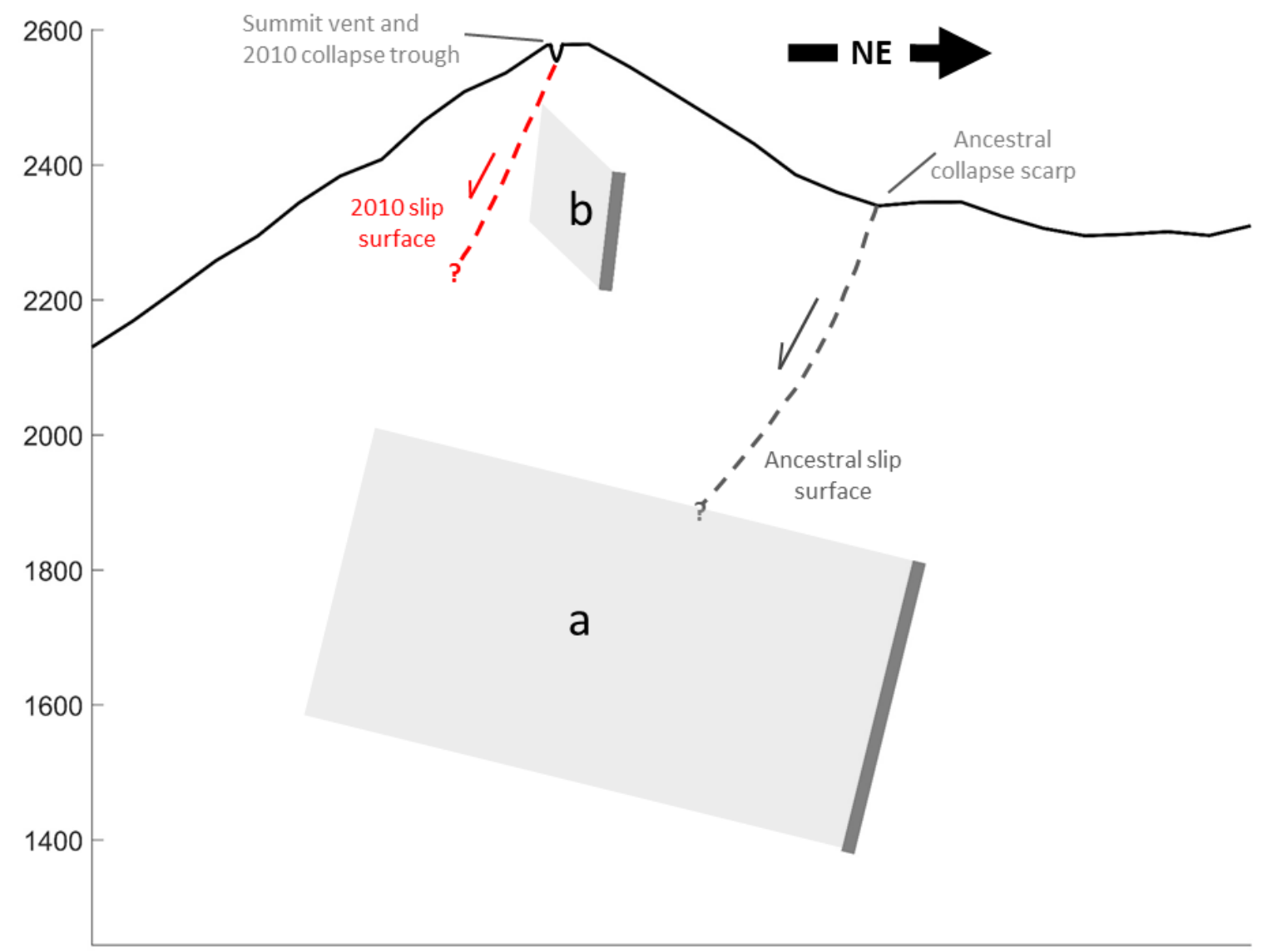

Figure 2.8 Cross section of Mackenney cone from the SW to the NE. Linear features represent approximated depths, strike and dip geometry of the dike features. Depths are relative to station LVES at $2385 \mathrm{~m}$. Dike feature (a) represents TPA and dike (b) represents TPB. Dashed lines represent conceptual models for the 2010 and ancestral slip surfaces, modified from Schaefer et al (2017). 


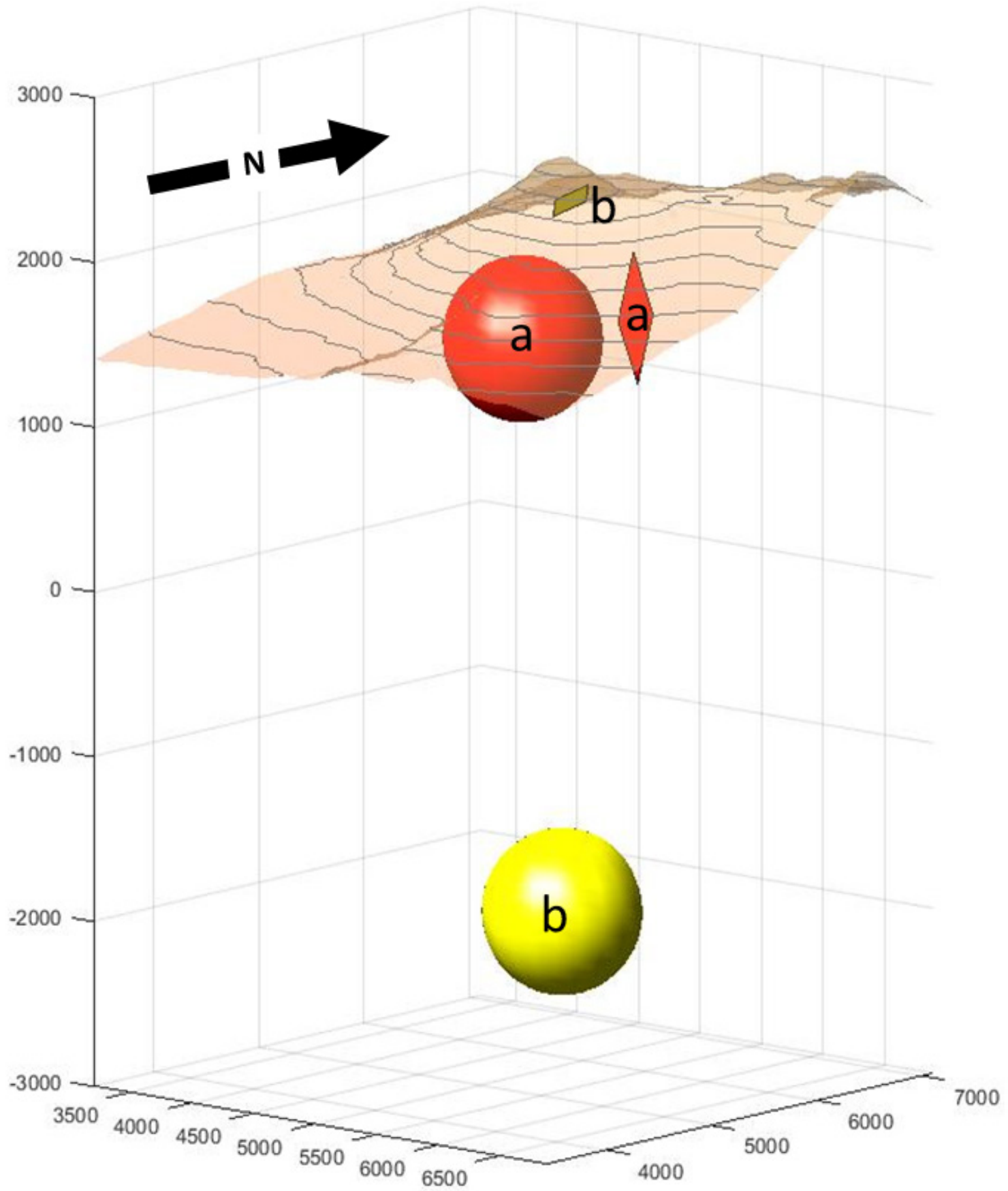

Figure 2.9 Three-dimensional view of Mackenney cone and modeled source features. Red features labeled " $a$ " correspond to time-period-a, while yellow features labeled " $b$ " represent the modeled sources for time-period-b. Source depths are relative to GPS station LVES at $2385 \mathrm{~m}$. 


\subsection{Conclusions}

Geodetic survey techniques have allowed us to present GPS campaign data dating back to 2009 combined with InSAR data from 2013-2014 and produce two analytical models of Pacaya's internal structure. Several components of our observations and subsequent models are consistent with volcanic and geologic trends observed at Pacaya volcano. First, the NW-SE, linear alignment of vent positions fits well with our modeled dike. Second, the agreement between existing vent features and our modeled dike are parallel or subparallel with the ancestral collapse scarp suggesting the scarp feature may act as a control on dike propagation, a phenomena that has previously been observed at Stromboli (Tibaldi 2003, Acocella and Tibaldi 2005). Third, a possible deflating magma reservoir at depth below the NW flank accommodates the observed vertical displacements coupled with the SW dip of the dike feature suggests that a spherical chamber supplies the shallow source within the cone, which is likely responsible for 2010 and 2013-2014 eruptive events. Fourth, the range in depths observed for the modeled spherical sources for TPA and TPB (Figure 2.9) may be indicative of two interconnected magma reservoirs at various depths deflating differentially following eruptive events, a hypothesis in good agreement with work published by Wnuk and Wauthier (2017). While these models are not ideally constrained by the relatively sparse GPS network, they provide some valuable insight into the plumbing system at Pacaya volcano and may be helpful in monitoring endeavors during future episodes of unrest, as well as to better constrain further and more rigorous modeling efforts. Lastly, considering the asymmetrical and unbalanced growth of the Mackenney cone within the ancestral Pacaya, the over-pressurization and propagation of a high elevation magma chamber or dike could result in serious hazard implications related to future edifice collapse and should be closely monitored. The deformation detected at Pacaya suggests GPS as a functional and accessible tool for monitoring efforts here and at other unstable volcanoes throughout Central America and the world. 


\subsection{References}

Acocella, V. \& M. Neri (2009) Dike propagation in volcanic edifices: overview and possible developments. Tectonophysics, 471, 67-77.

Acocella, V. \& A. Tibaldi (2005) Dike propagation driven by volcano collapse: a general model tested at Stromboli, Italy. Geophysical Research Letters, 32.

Bardintzeff, J.-M. \& C. Deniel (1992) Magmatic evolution of Pacaya and Cerro Chiquito volcanological complex, Guatemala. Bulletin of volcanology, 54, 267-283.

Bertiger, W., S. D. Desai, B. Haines, N. Harvey, A. W. Moore, S. Owen \& J. P. Weiss (2010) Single receiver phase ambiguity resolution with GPS data. Journal of Geodesy, 84, 327-337.

Biggs, J., Z. Lu, T. Fournier \& J. T. Freymueller (2010) Magma flux at Okmok Volcano, Alaska, from a joint inversion of continuous GPS, campaign GPS, and interferometric synthetic aperture radar. Journal of Geophysical Research: Solid Earth, 115.

Cabral-Cano, E., F. Correa-Mora \& C. Meertens (2008) Deformation of Popocatépetl volcano using GPS: Regional geodynamic context and constraints on its magma chamber. Journal of Volcanology and Geothermal Research, 170, 24-34.

Correa-Mora, F., C. DeMets, D. Alvarado, H. Turner, G. Mattioli, D. Hernandez, C. Pullinger, M. Rodriguez \& C. Tenorio (2009) GPS-derived coupling estimates for the Central America Subduction zone and volcanic arc faults: El Salvador, Honduras and Nicaragua. Geophysical Journal International, 179, 1279-1291.

Costantini, M. (1998) A novel phase unwrapping method based on network programming. IEEE Transactions on geoscience and remote sensing, 36, 813-821.

Dalton, M. P., G. P. Waite, I. M. Watson \& P. A. Nadeau (2010) Multiparameter quantification of gas release during weak Strombolian eruptions at Pacaya Volcano, Guatemala. Geophysical Research Letters, 37.

DeMets, C. (2001) A new estimate for present-day Cocos-Caribbean plate motion: Implications for slip along the Central American volcanic arc. Geophysical Research Letters, 28, 4043-4046.

Dixon, T. H., A. L. Mao, M. Bursik, M. Heflin, J. Langbein, R. Stein \& F. Webb (1997) Continuous monitoring of surface deformation at Long Valley Caldera, California, with GPS. Journal of Geophysical Research-Solid Earth, 102, 12017-12034.

Dzurisin, D. (2003) A comprehensive approach to monitoring volcano deformation as a window on the eruption cycle. Reviews of Geophysics, 41, 1001.

Dzurisin, D. 2006. Volcano deformation: new geodetic monitoring techniques. Berlin: Springer.

Dzurisin, D., M. Lisowski \& C. W. Wicks (2009) Continuing inflation at Three Sisters volcanic center, central Oregon Cascade Range, USA, from GPS, leveling, and InSAR observations. Bulletin of Volcanology, 71, 1091-1110.

Ebmeier, S., B. Andrews, M. Araya, D. Arnold, J. Biggs, C. Cooper, E. Cottrell, M. Furtney, J. Hickey \& J. J. J. o. A. V. Jay (2018) Synthesis of global satellite observations of magmatic and volcanic deformation: implications for volcano monitoring \& the lateral extent of magmatic domains. 7, 2.

Eggers, A. A. (1971) The geology and petrology of the Amatitlán quadrangle. Guatemala [Ph. D. thesis]: Hanover, New Hampshire, Dartmouth College. 
Eggers, A. A. (1983) Temporal gravity and elevation changes at Pacaya volcano, Guatemala. Journal of volcanology and geothermal research, 19, 223-237.

Escobar-Wolf, R. (2010) The eruption of Volcan de Pacaya on May - June, 2010. Report in progress. Michigan Technological University.

Fournier, T., M. Pritchard \& S. Riddick (2010) Duration, magnitude, and frequency of subaerial volcano deformation events: New results from Latin America using InSAR and a global synthesis. Geochemistry, Geophysics, Geosystems, 11.

Goldstein, R. M. \& C. L. Werner (1998) Radar interferogram filtering for geophysical applications. Geophysical research letters, 25, 4035-4038.

Grapenthin, R., J. T. Freymueller \& A. M. Kaufman (2013) Geodetic observations during the 2009 eruption of Redoubt Volcano, Alaska. Journal of Volcanology and Geothermal Research, 259, 115-132.

Kitamura, S. \& O. Matías (1995) Tephra stratigraphic approach to the eruptive history of Pacaya volcano, Guatemala. Science Reports-Tohoku University, Seventh Series: Geography, 45, 1-41.

Lanza, F. 2016. Nonlinear inversion strategies applied to source characterization and 3D earthquake tomography in volcanic environments: a case study at Pacaya volcano, Guatemala. In Geological and Minning Engineering and Sciences, 128. Houghton, MI: Michigan Technological University.

Lechner, H. N., C. DeMets, D. Hernandez \& W. Rose (2013) A pilot GPS study of Santa Ana Volcano (Ilamatepec) and Coatepeque caldera, El Salvador. Geological Society of America Special Papers, 498, 57-75.

Massonnet, D. \& K. L. Feigl (1998) Radar interferometry and its application to changes in the Earth's surface. Reviews of geophysics, 36, 441-500.

Matías, R. 2009. Volcanological Map of the 1961-2009 Eruption of Volcan de Pacaya, Guatemala. MS Thesis Michigan Technological University, Houghton MI.

McTigue, D. F. (1987) Elastic stress and deformation near a finite spherical magma body: Resolution of the point source paradox. Journal of Geophysical Research: Solid Earth, 92, 12931-12940.

O'Brien, G. S., I. Lokmer \& C. Bean (2010) Statistical selection of the "best" seismic source mechanisms from inversions of synthetic volcanic long-period events. Journal of Geophysical Research: Solid Earth, 115.

Okada, Y. (1985) Surface deformation due to shear and tensile faults in a half-space: Okada, Y Bull Seismol Soc AmV75, N4, Aug 1985, P1135-1154. International Journal of Rock Mechanics and Mining Sciences \& Geomechanics Abstracts, 23, 128.

Pinel, V. \& C. Jaupart (2000) The effect of edifice load on magma ascent beneath a volcano. Philosophical Transactions of the Royal Society of London A: Mathematical, Physical and Engineering Sciences, 358, 1515-1532.

Poland, M. P., M. Lisowski, D. Dzurisin, R. Kramer, M. McLay \& B. Pauk (2017) Volcano geodesy in the Cascade arc, USA. Bulletin of Volcanology, 79, 59.

Pritchard, M., J. Biggs, C. Wauthier, E. Sansosti, D. Arnold, F. Delgado, S. Ebmeier, S. Henderson, K. Stephens \& C. Cooper (2018) Towards coordinated regional multisatellite InSAR volcano observations: results from the Latin America pilot project. Journal of Applied Volcanology, 7, 5. 
Rose, W. I., J. L. Palma, R. E. Wolf \& R. O. M. Gomez (2013) A 50 yr eruption of a basaltic composite cone: Pacaya, Guatemala. Geological Society of America Special Papers, 498, 1-21.

Saballos, J. A., V. Conde, R. Malservisi, C. B. Connor, J. Alvarez \& A. Munoz (2014) Relatively short-term correlation among deformation, degassing, and seismicity: a case study from Concepción volcano, Nicaragua. Bulletin of Volcanology, 76, 843.

Sambridge, M. (1999a) Geophysical inversion with a neighbourhood algorithm - I. Searching a parametere space. Geophys. J. Int., 138, 479-494.

Sambridge, M. (1999b) Geophysical inversion with a neighbourhood algorithm-II. Appraising the ensemble. Geophysical Journal International, 138, 727-746.

Schaefer, L. N., Z. Lu \& T. Oommen (2015) Dramatic volcanic instability revealed by InSAR. Geology, 43, 743-746.

Schaefer, L. N., Z. Lu \& T. Oommen (2016) Post-Eruption Deformation Processes Measured Using ALOS-1 and UAVSAR InSAR at Pacaya Volcano, Guatemala. Remote Sensing, 8, 73.

Schaefer, L. N., T. Oommen, C. Corazzato, A. Tibaldi, R. Escobar-Wolf \& W. I. Rose (2013) An integrated field-numerical approach to assess slope stability hazards at volcanoes: the example of Pacaya, Guatemala. Bulletin of volcanology, 75, 1-18.

Schaefer, L. N., T. Wang, R. Escobar-Wolf, T. Oommen, Z. Lu, J. Kim, P. R. Lundgren \& G. P. Waite (2017) Three-dimensional displacements of a large volcano flank movement during the May 2010 eruptions at Pacaya Volcano, Guatemala. Geophysical Research Letters, 44, 135-142.

Sparks, R. S. J. (2003) Forecasting volcanic eruptions. Earth and Planetary Science Letters, 1-15.

Stephens, K. \& C. Wauthier (2018) Satellite geodesy captures offset magma supply associated with lava lake appearance at Masaya volcano, Nicaragua. Geophysical Research Letters, 45, 2669-2678.

Taisne, B. \& S. Tait (2009) Eruption versus intrusion? Arrest of propagation of constant volume, buoyant, liquid-filled cracks in an elastic, brittle host. Journal of Geophysical Research: Solid Earth, 114.

Taisne, B., S. Tait \& C. Jaupart (2011) Conditions for the arrest of a vertical propagating dyke. Bulletin of Volcanology, 73, 191-204.

Tibaldi, A. (2003) Influence of cone morphology on dykes, Stromboli, Italy. Journal of Volcanology and Geothermal Research, 126, 79-95.

Vallance, J. W., L. Siebert, W. I. Rose Jr, J. R. Girón \& N. G. Banks (1995) Edifice collapse and related hazards in Guatemala. Journal of Volcanology and Geothermal Research, 66, 337-355.

Wardman, J., V. Sword-Daniels, C. Stewart \& T. Wilson. 2012. Impact assessment of the May 2010 eruption of Pacaya volcano, Guatemala. GNS Science Report.

Wauthier, C., V. Cayol, B. Smets, N. d'Oreye \& F. Kervyn (2015) Magma pathways and their interactions inferred from InSAR and stress modeling at Nyamulagira Volcano, DR Congo. Remote Sensing, 7, 15179-15202.

Werner, C., U. Wegmüller, T. Strozzi \& A. Wiesmann. 2000. Gamma SAR and interferometric processing software. In Proceedings of the ers-envisat symposium, gothenburg, sweden, 1620. 
Wnuk, K. \& C. Wauthier (2017) Surface deformation induced by magmatic processes at Pacaya Volcano, Guatemala revealed by InSAR. Journal of Volcanology and Geothermal Research, 344, 197-211.

Zumberge, J., M. Heflin, D. Jefferson, M. Watkins \& F. Webb (1997) Precise point positioning for the efficient and robust analysis of GPS data from large networks. Journal of Geophysical Research: Solid Earth (1978-2012), 102, 5005-5017. 


\section{Chapter 3: Should we stay or should we go now? Factors affecting evacuation decisions at Pacaya volcano, Guatemala}

\subsection{Abstract}

The current paper reports the results of a survey on past and future evacuation decisionmaking in response to a volcanic eruption (or the threat thereof) at Pacaya volcano, Guatemala. In 2010, Pacaya experienced its largest eruption in over half a century, causing more than 2,500 evacuations and resulting in the damage or destruction of hundreds of homes, injuries to dozens of people, and the death of one journalist. Despite a pronounced increase in eruptive activity and the high threat of injury or death, many residents surrounding Pacaya volcano chose to stay in their homes throughout the eruption event. Our study seeks to understand why some individuals ignored social cues, physical hazards, and evacuation messages, and instead chose to stay in harm's way during a volcanic crisis. Using data obtained from a door-to-door survey conducted in the Pacaya region in October 2016, we found that evacuation behavior during the 2010 eruption was influenced most strongly by one's exposure to hazards, perception of hazards, and perception of readiness. We also found that prior evacuation experience from the 2010 eruption, perceptions of home vulnerability, and warning messages all have a strong influence on one's intention to evacuate in a future volcanic crisis. Finally, we found that perceived risk to one's home or property may have less of an impact on evacuation intention than emergency personnel tend to assume. Building on these findings, we discuss ways to improve evacuation communication in the face of a future eruption.

\subsection{Introduction}

Should we stay or should we go now? While this question is clearly a nod to the 80's punk band The Clash, it is also one of the most important questions to answer in the midst of a volcanic crisis. The current paper investigates how people living near Pacaya volcano, Guatemala answered this question during the massive eruption there in 2010 and the impact this decision has had on their future evacuation intentions. We specifically wanted to know why so many people chose to stay in their homes rather than evacuate in response to the 2010 eruption and whether this decision has had a positive or negative impact on intentions to evacuate in the event of a future eruption. Ultimately, our goal was to identify the factors most responsible for the decision to remain in harm's way so as to better tailor communication efforts and risk reduction strategies to minimize injury or death during future crises at Guatemalan or other similar volcanoes.

Evacuation decision-making in response to a volcanic eruption is a relatively underexplored subject in natural hazards research (Chester et al. 2002, Barclay et al. 2008). Much of what is known about evacuation behavior has been gleaned from research 
focused on hurricanes, flooding, and other meteorological hazards in the developing world (Baker 1979, Baker 1991, Lindell et al. 2005). It was not until just recently that the geographic scope of this work expanded to cover parts of the developing world, such as Indonesia (Lavigne et al. 2008), Papua New Guinea (To_Waninara 2000), the Philippines (Gaillard 2008, Usamah and Haynes 2011), and the West Indies (Haynes et al. 2008a). However, aside from a few recent studies in Mexico (Gavilanes-Ruiz et al. 2009, Tobin et al. 2011), El Salvador (Bowman and White 2012, Bowman and Henquinet 2015), and Ecuador (Tobin and Whiteford 2002a, Tobin and Whiteford 2002b) that focus mainly on risk perception and resettlement issues, no study has yet to systematically explore evacuation decision-making in response to an actual volcanic eruption in the context of Latin America. We believe this is an unfortunate gap in the literature that should be filled because Latin America presents an interesting opportunity to examine the interplay of protective action decision-making and social vulnerability (Macías and Aguirre 2006).

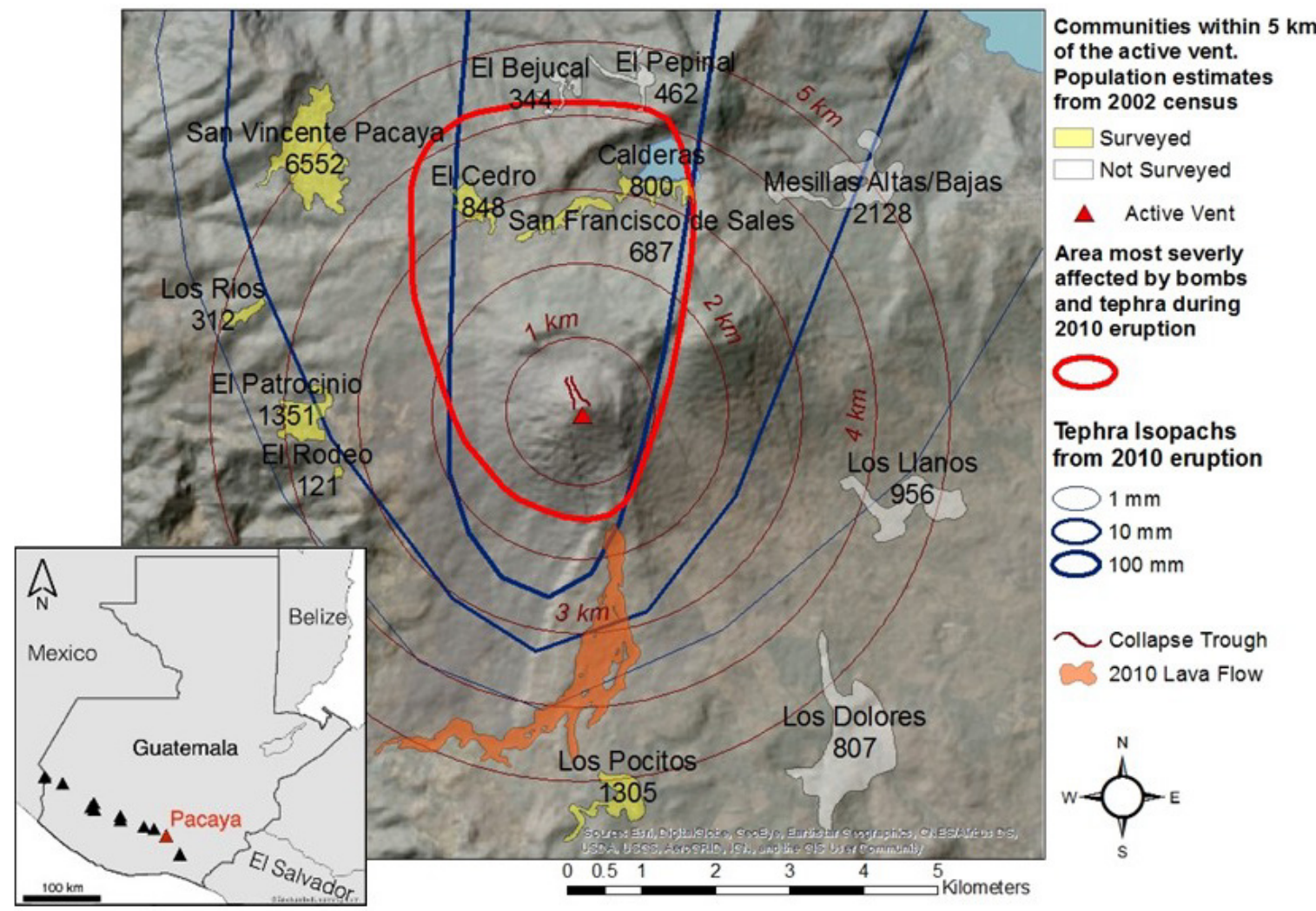

Figure 3.1 Map of Pacaya volcano, 2010 eruption products, and our target population within the surrounding communities. Communities colored in yellow were surveyed for this research. Concentric circles show $1 \mathrm{~km}$ distances from the active vent. Dark blue lines represent isopachs of reported tephra accumulations from the 2010 eruption and the red polygon represents the area most severely impacted by bombs and ballistics (Escobar-Wolf, 2010). The communities of El Cedro, San Francisco de Sales, and Calderas are inside the area most severely affected and experienced significant property damage and personal injury. Inset shows Pacaya's location relative to Guatemala and the Central American Volcanic Arc 
This paper reports the results of a household survey on evacuation decision-making conducted at communities in the Pacaya region of Guatemala (Figure 3.1). Our survey asked respondents about their 2010 evacuation experience, their evacuation decisionmaking process, perception of hazard risk, trust in authorities, preparedness for a future eruption, and other relevant demographic information. We found that $41 \%$ of the households in our survey failed to evacuate during the 2010 eruption while only $54 \%$ claimed that they would evacuate in the future in the event of another major eruption. We then used a series of statistical analysis techniques to determine what set evacuees and those who intend to evacuate apart from non-evacuees and those who do not intend to evacuate. We found that age, community of residence, damage experience, and the importance placed on protecting one's home were all significant predictors of evacuation behavior during the 2010 eruption. We also found that past evacuation behavior during the 2010 eruption, education, community of residence, sense of readiness to protect others during an eruption, and the importance placed on warning messages from friends/family and the news, as well as the importance placed on seeing others evacuate were all significant predictors of one's intention to evacuate from another major eruption in the future. The remainder of this paper details how we came to these conclusions and what implications these findings might have for existing natural hazards literature and the emergency management strategies used to minimize harm during a volcanic eruption.

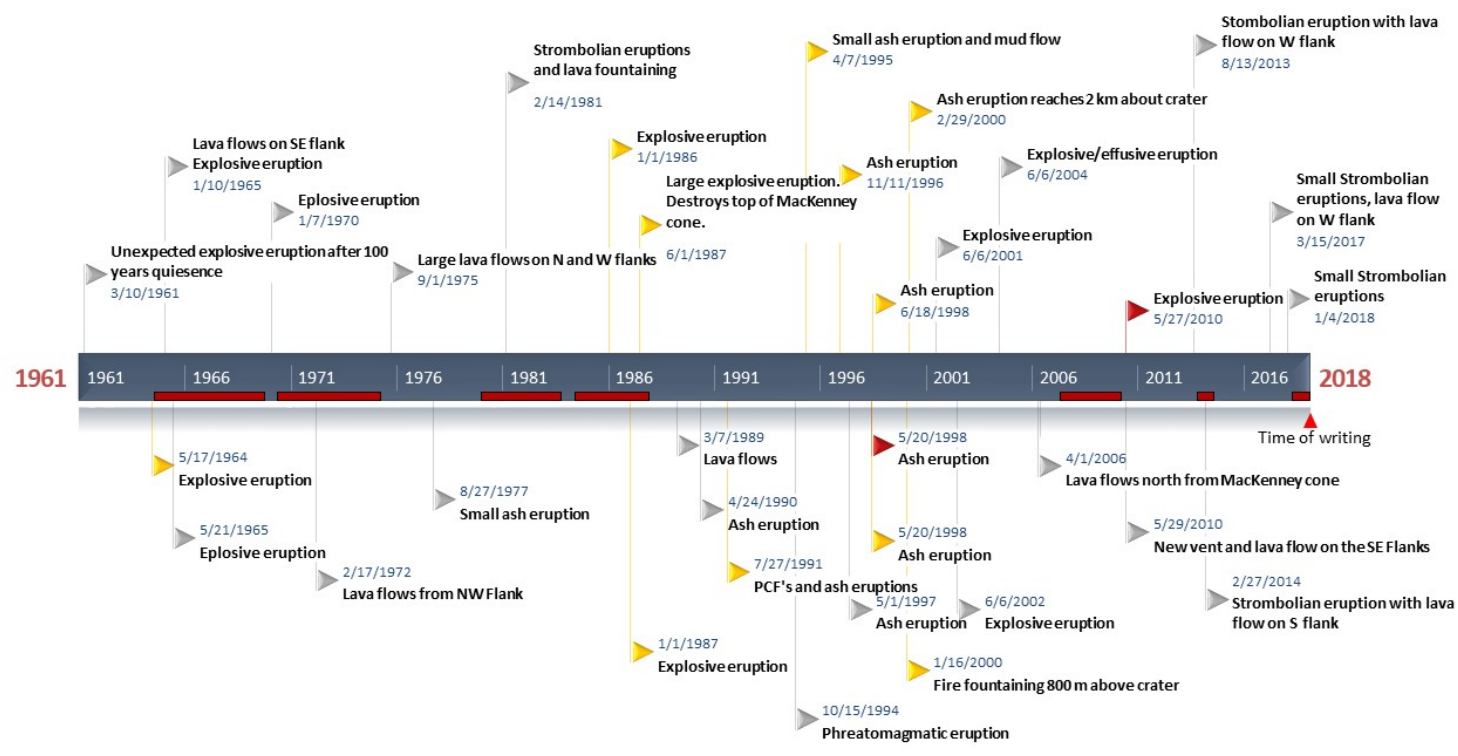

Figure 3.2 Timeline of Pacaya's recent history. Flags represent a sample of eruptive events. Yellow flags indicate eruptions that prompted an evacuation of communities to the south and southwest. Red flags indicate evacuation from communities in the north. Horizontal red bars indicate periods of effusive, lava producing eruptions. 


\subsection{Background}

\subsubsection{Pacaya volcano}

Pacaya is a 2,550-m subduction zone, basaltic stratovolcano which is fairly representative of the roughly 200 Holocene volcanoes found throughout the world and one that is quite common to Central America. Pacaya, like many volcanoes in the developing world, is home to a growing agrarian population living on its flanks who must live with the constant threat of eruption because it is often the only way for the poorest members of the region to maintain a livelihood heavily dependent on subsistence agriculture, livestock, coffee production, or the tourism industry whose visitors are attracted to the national park established as a consequence of Pacaya's prolific volcanic activity. Roughly 20,000 people live within $5 \mathrm{~km}$ of Pacaya's active vent and close to 3 million people, including the residents of the capital Guatemala City, live within $40 \mathrm{~km}$.

As is common in most of the developing world and Latin American in particular, national authorities have made few direct efforts to raise the resident's awareness of the risks of an eruptive event nor has a national evacuation plan been implemented to guide residents during such a crisis. Despite this lack of coordinated national action, residents near Pacaya are still quite familiar with the hazard itself because it is one of Central America's most active volcanoes. Since its reawakening in 1961, Pacaya has experienced persistent volcanic activity with at least 10 eruptions that have prompted evacuations (Figure 3.2). Finally, like many subtropical volcanic regions, the area surrounding Pacaya is also prone to a variety of other natural hazards, including hurricanes and earthquakes. So most residents of the communities surrounding Pacaya are both socially vulnerable and more than familiar with natural hazard crises and evacuation scenarios.

\subsubsection{The 2010 eruption}

On the evening of May 27, 2010, Pacaya experienced its largest eruption in over 20 years, causing the rapid evacuation of over 2,500 people. The event sent ash, tephra, and ballistics uncharacteristically to the north rather than the south as in most prior eruptions (Figure 3.1). This unexpected outcome caught residents in those northern communities completely by surprise despite all that was known about the possibility of an eruption prior to this event. For instance, the National Institute of Seismology, Volcanology, Meteorology, and Hydrology (INSIVUMEH), which was responsible for monitoring the volcano, had already notified the Guatemalan Government Coordination Agency for Disaster Reduction (CONRED) almost three months prior to this eruption that seismicity and effusivity, were increasing. Further warnings were given to CONRED when seismicity and effusivity increased dramatically around May 15 . This prompted the national park to restrict visitor access but little to no information was forwarded by CONRED to the communities surrounding the volcano. Then, on May 26, a small eruption deposited ash on nearby communities to the south prompting the complete closure of the national park, but still no evacuation orders were issued. 
Finally, on the morning of May 27, explosive activity increased significantly and, by early afternoon, strombolian eruptions began sending ash plumes to the southwest in a manner that is typical for Pacaya. At this point, CONRED issued a belated evacuation notice but only to the communities in the southwest who began to mobilize to emergency shelters established in San Vicente. Then, sometime between 17:00 and 18:30 on the evening of May 27, a paroxysmal eruption with directed blasts to the north began unlike anything Pacaya had experienced in the past 50 years. This 45 -minute eruption rained ash, tephra and volcanic bombs of up to $50 \mathrm{~cm}$ in diameter down on the northern communities located within $5 \mathrm{~km}$ of the vent. Hot ballistics pierced through sheet-metal roofs, igniting fires, while tephra accumulations collapsed roofs, damaged water supplies and withered crops. Approximately 400 homes were ultimately destroyed, hundreds more damaged, countless livestock were killed, and crops were completely devastated. Once this eruptive activity subsided, roughly $80 \%$ of the residents in the northern communities of San Francisco, El Cedro, and Las Calderas began to self-mobilize in the absence of an official evacuation notice and fled to San Vicente to avoid any possible aftereffects.

When considering the degree of damage and destruction the 2010 eruption caused, it is quite miraculous that so few people were injured and only a single journalist was killed. What is more difficult to comprehend is why so many residents chose to stay in harm's way immediately following the initial eruption despite the possibility of further eruptive activity repeating the disaster they had just survived. Although fate was kind enough to spare them tragedy, there was no guarantee that these individuals would be so lucky the next time. Understanding why these individuals chose to stay in harm's way in the face of such a harrowing experience while others fled is critical to developing better evacuation strategies that can possibly minimize such unnecessary risk-taking in the future. The recent tragedy at Fuego volcano, which is just $25 \mathrm{~km}$ west of Pacaya and shared many of the same evacuation problems, only increases the urgency of developing a better approach to evacuation decision-making in Guatemala.

\subsubsection{Evacuation decision-making and risk perception}

The study of how people respond to natural hazards is rooted in the earliest work on risk analysis - for a review, see Montz et al. (2017). The basic premise of this work is that people respond to risk differently simply because they have different perceptions of the same risk (Slovic 1987, Pidgeon et al. 1992, Slovic 2000, Slovic 2006). Those who studied natural hazards realized it was possible to combine this general understanding of risk with a rational-choice understanding of behavioral decision-making to explain why individuals chose certain risk adjustment behaviors over others (Gaillard and Dibben 2008). These researchers assumed that individuals made hazard adjustments by first rationally calculating the consequences of all available behavioral alternatives and then choosing the alternative thought to be in their best interest, which occasionally resulted in behaviors that appeared irrational on the surface due to the limitations of bounded rationality or misunderstandings of objective risk (Burton 1993). Additionally, it was assumed that individuals would only consider adjustment behaviors like evacuation when 
they believed a hazard threat was real so a failure to evacuate was often associated with low risk perception (Perry 1979). These ideas eventually formed the core of what came to be known as the "dominant approach" to natural hazards risk studies, which is still quite prominent today. They also led to the seemingly obvious conclusion that better adjustment behavior simply required better risk perception and, therefore, efforts to minimize risk to the general public should lean heavily toward hazard awareness campaigns as well as providing the technology necessary to better predict hazard events (Wisner et al. 2004).

Recently, two alternatives to the dominant paradigm have emerged in the natural hazards literature known as the cultural approach and the radical paradigm (Gaillard and Dibben 2008). The cultural approach takes issue with the dominant paradigm's atomistic understanding of risk perception and believes it to be both unreasonable and unrealistic (Wisner et al. 2004). It argues that perceptions of natural hazard risks are heavily dependent upon the culture, values, and norms one is enmeshed within and that certain social structures or organizations will promote different perceptions of risk in order to defend existing patterns of social relations and belief systems (Wildavsky and Dake 1990, Dake and Wildavsky 1991). This idea helps to explain how individuals come to develop different understandings of risk rather than just positing what happens to adjustment behavior as a consequence of unproblematized perceptional differences (Kasperson et al. 2003).

The radical paradigm also introduced the concept of social vulnerability to explain why certain social structures or socio-economic circumstances force the less powerful members of society to be more prone to natural hazard risk than others, which can reinforce perceptions of risk that condone adjustment behaviors that actually raise, rather than minimize, one's risk to a hazard threat (O'Keefe et al. 1976). Ultimately, both approaches remain highly skeptical of the simple solutions offered by the dominant approach and argue that much more must be done to understand how societal differences cause differences in both risk perception and adjustment behavior in order to develop more nuanced strategies that are better at minimizing hazard risk in different social circumstances.

The above ideas about the effects of risk perception on evacuation decision-making have been applied to explain a wide variety of evacuation scenarios (Baker 1991, Fischer et al. 1995, Dow and Cutter 1998, Riad et al. 1999, Dash and Gladwin 2007, Stephens et al. 2009, Lazo et al. 2015, Huang et al. 2016, Morss et al. 2016). In addition to risk perception (Pidgeon et al. 1992, Lindell and Hwang 2008), studies have found the following factors to also play an important role in evacuation decision-making: trust in authorities (Paton 2008); personal hazard experience (Tobin et al. 2011, Becker et al. 2017); prior evacuation behavior (Dow and Cutter 1998, Tobin and Whiteford 2002b); the chronic or acute nature of a hazard (Tobin et al. 2011); and demographic issues related to risk and vulnerability, such as age, race, gender, and spatial proximity to the hazard (Riad et al. 1999, Chakraborty et al. 2005, Lindell and Hwang 2008). However, 
nearly all of these factors stem from studies of more common hazards, such as hurricanes or wildfires, so their applicability to volcanic hazards is debatable given the relatively high uncertainty regarding the onset, magnitude, and duration of most volcanic eruptions (Eiser et al. 2012). It is difficult to directly transfer knowledge from studies of other hazards to volcanic hazards because greater uncertainty increases the opportunities for social structures to influence risk perception and adjustment behavior in ways that may be highly disconnected from "objective" risk (Dake and Wildavsky 1991, Haynes et al. 2008b). This is why scholars who study volcanic hazards are now beginning to push for more research that investigates the human dimension underlying eruption risk (Chester 1993).

Studies of volcanic risk do exist but most tend to adopt the dominant paradigm (Gaillard and Dibben 2008). This means that they assume risk perception is the main driver of behavior in the face of an eruption threat. In addition to explaining evacuation behavior (Burton 1993), these studies claim that hazard knowledge and prior hazard experience are the two most important drivers of risk perception and can therefore explain a wide range of volcanic risk adjustments, including: the decision to live in a hazard zone (Lindell and Perry 1993), preparedness actions taken (or not) in response to the threat of a future eruption (Barberi et al. 2008, Perry and Lindell 2008), the impact of educational campaigns on hazard awareness (Dominey-Howes and Minos-Minopoulos 2004), and the effectiveness of evacuation messages (Bird et al. 2009). However, these factors are mostly derived from studies conducted in the developed world where risk perception, adjustment behavior, and threat vulnerability can be dramatically different than in the developing world due to dissimilar socio-economic circumstances (Dibben and Chester 1999). Of the few published works that have studied volcanic risk in the developing world, most have found that culture and social vulnerability play a critical role in shaping risk perception and adjustment behavior in ways that often deviate from what is found in the developed world (Gaillard and Dibben 2008).

Studies conducted in the developing world are now beginning to appear more frequently in the volcanic hazards literature and all tend to emphasize the important role social factors play in shaping risk perceptions and hazard adjustments. For example, Laksono (1988) found that people who evacuated from the flanks of the Merapi volcano in Java, Indonesia soon returned to their communities upon resettlement because the threat of living in an unfamiliar environment was perceived to be greater than the threat of the volcano itself. Wisner et al. (2004) found that political institutions, dependent economies, access to livelihoods, and armed conflict all played a critical role in shaping social vulnerability and volcanic hazard perceptions in Colombia, Monserrat, and the Democratic Republic of Congo. Further studies have confirmed the importance of livelihood in shaping risk perception and adjustment behavior in Ecuador arguing that those whose livelihoods were strongly tied to the volcanic hazard were also likely to have lower risk perception that justified their decision to take riskier adjustment actions, such as relocating back to a hazard zone prematurely (Tobin and Whiteford 2002b, Lane et al. 
2003). Others have also confirmed the critical importance of political and socio-economic structures in shaping risk perception and adjustment behavior in Mexico (Macías 2005). Finally, a number of studies have found religion and the degree to which culture is intertwined with nature to be important risk perception factors (Lavigne et al. 2008). However, no study has yet examined evacuation decision-making in the developing world in the face of an actual eruption. Studies that come the closest to doing so have either focused more on responsiveness to evacuation orders (De la Cruz-Reyna and Tilling 2008), the effectiveness of hazard communication efforts (Barclay et al. 2008), the perceived hardships of evacuation (Lane et al. 2003), or the impacts of past exposure on future preparedness (Tobin et al. 2011) rather than investigating behavioral decisionmaking in direct response to eruptive activity. As far as we are aware, the present study is the first to systematically investigate evacuation decision-making in a socially vulnerable community in response to an actual eruption.

\subsection{Data and methods}

To obtain data for our analysis, we administered a survey in October 2016 to 172 randomly selected households from eight of the fifteen communities located within a five-km radius of Pacaya volcano (see appendix section 6.2 for the survey). The intended target population for our survey was households that experienced the 2010 eruption of Pacaya volcano and remained living within the hazard zone. Due to personal safety concerns, it was necessary to exclude some high crime and inaccessible communities from our survey, which limited our target population to households located within the following communities: Las Calderas, San Francisco de Sales, El Cedro, Los Rios, El Patrocinio, El Rodeo, Los Pocitos, San Vicente (Figure 3.1). We were able to reasonably represent households from both southern communities who have a historically higher rate of evacuation and eruption experience as well as northern communities who were unexpectedly hit the hardest during the 2010 eruption.

To administer our survey, we used systematic random sampling to identify eligible survey participants. We began the survey with the first house nearest the point of entry into our targeted community, which was either the first house visible from the bus stop or the outer periphery of the community if entered on foot. We then proceeded to administer the survey to every third household beyond this initial selection until all households were exhausted within the community. Occasionally, the survey was administered to individuals randomly encountered in the process of conducting their daily activities but not presently in their homes, such as going to and from a store or place of work. This was done because our presence in the community often and quickly drew attention, curiosity and suspicion, so by engaging community members openly in public we were able to reduce the perceived threat and explain our motives, which seemed to allow other community members to relax and engage with us. Regardless of the selection process, all survey participants agreed to complete our survey from the perspective of their role as head of household. This strategy made it possible to preserve critical elements of the 
random selection process despite lacking the means (e.g., a complete list of households within our communities) to conduct a truly random sample of our study region.

Once an eligible head of household was identified and agreed to participate in the survey, we then conducted an in-person face-to-face interview in which one member of our research team would read the questions and answer options to the selected respondent while recording respondent answers on paper. We chose the interview mode because literacy rates in our study region are quite low, which can be overcome when interviewers are able to read questions to respondents and clarify difficult to interpret answer options (Groves et al. 2009). It is also important to note that all interviewers were given advanced training on how to conduct the survey and field respondent inquiries in a way that would preserve consistency across all other interviewers, as per Fowler (2011). The questionnaire itself was also extensively pilot-tested, as per Groves et al. (2009), to ensure questions were posed adequately (expert review), question wording was translated from English to Spanish properly (language review), and questions were comprehensible from the perspective of members of our target population (content review). The average completion time for the typical interview was approximately 30 minutes per respondent.

Our survey questionnaire contained 29 total questions (see Appendix 6.2 for the complete survey questionnaire) and was designed following the Total Survey Design principles of Dillman (2011). The questionnaire was broken into six broad conceptual themes: 1) evacuation perception, 2) risk perception, 3) preparedness, 4) past evacuation experience, 5) future evacuation intentions, and 6) household characteristics. A 5-point Likert scale response format was used to guide respondent answers to individual questions whenever possible with the exception of household characteristics that required a listing of possible traits. The two key dependent variables of interest were past evacuation behavior and future intention, which were measured dichotomously using a yes/no question format that asked respondents if they or anyone in their household evacuated from the 2010 Pacaya eruption, as well as if they intended to evacuate in the future in the event of a similar eruption. The remaining survey questions were used as grouping, explanatory, or control variables in our statistical analysis.

Respondent answers were recorded on paper in the field and then digitized in the lab by a single member of our research team using a pre-specified coding scheme. IBM SPSS statistical software was used to analyze this data. Frequency reports provided a sense of the representativeness of our sample with respect to our target population, and described the general characteristics of our sample as a whole. Chi-square and t-Tests were used to compare key subgroups within our sample based on community of residence (to gauge impact severity), 2010 evacuation status, and future intention status. Finally, a series of nested binary logistic regressions were used to determine which factors had the strongest impact on past evacuation behaviors and future intentions while controlling for alternative explanations of these phenomena. 


\subsection{Results}

\subsubsection{Sample representativeness}

We first compared our sample demographics to the most recent national census figures for our region obtained from the Instituto Nacional de Estadística, Guatemala (INE 2003) to determine how well our sample represented our target population (Table 3-1 and Table $3-2)$. In terms of community representativeness, we found that our sample underrepresented the residents of San Vicente (only 11\% of our respondents were from San Vincente whereas the residents of San Vicente make up 55\% of the total population in our region) and slightly overrepresented the remaining communities. Since San Vicente is the largest urban community in our study region, this then resulted in an urban/rural sample distribution that was more skewed toward rural residents than would be expected (89\% rural to $11 \%$ urban in our sample compared to $59 \%$ rural and $41 \%$ urban in our target population). However, the proportional difference of respondents from the remaining communities in our sample was consistent with the actual distribution of population across those communities (with the slight exception of Rodeo and Rios). Therefore, we believe our sample is a reasonable cross-section of our target population with respect to community of residence with the obvious exception of San Vicente whose significantly larger population size made it difficult to proportionally represent given our limited survey resources. We also see no reason why the underrepresentation of San Vicente would critically impact our statistical results since it was not our intention to compare respondents across individual communities but rather to compare respondents based upon community impact (e.g., North vs South or severely impacted vs moderately impacted).

Gender and occupation were two household characteristics that also stood out as slightly less well represented in our sample. For example, although women and men make up roughly equal proportions of our target population, $67 \%$ of our respondents were female and only $33 \%$ were male. This was likely due to the fact that our interviews took place during the day when it was safest and more appropriate to approach potential interviewees, resulting in a greater likelihood of interviewing a female head of household given local gender expectations about workforce participation. There was also a slight underrepresentation of skilled labor in our sample due to the underrepresentation of urban residents, particularly those from San Vicente, as discussed above. This overrepresentation of women and underrepresentation of skilled labor in our sample is worth noting but, again, we see no reason why this would greatly impact our statistical results since we never intended to compare evacuation rates or intentions across genders or occupation. Rather, our analysis goal was to simply determine if one gender or occupation was more likely to evacuate (or intend to evacuate) than another, which simply required capturing sufficient information from each of these groups as we did in our sample. 
Finally, we found that our sample reasonably represented our target population with respect to a number of important household characteristics known to impact evacuation decision-making. For example, the distribution of housing and construction materials used in the homes of our respondents mapped well to this same distribution in the target population, indicating that our sample accurately represented the views of those living within the existing housing stock of the communities surrounding Pacaya. Our sample also shows a skewness with a slight overrepresentation of older and more educated respondents when compared to the general population. This is a justifiable result considering our specific targeting of heads-of-households who are typically older and more educated than the general population. Therefore, we find this distribution in line with our target population statistics considering an expected underrepresentation of the youngest age category (18-29 year olds) and the lowest education levels ("None" and "Some Primary") who typically are not heads-of-households. In addition, the overrepresentation of married couples with respect to single individuals in our sample was also expected given our focus on heads of household who are more likely to be married than their counterparts in the general population. Thus, we can say that our sample well represented our target population with respect to housing stock, age, education, and marital status. 
Table 3-1 Demographic data. Information from the 2002 national census compared to the target population and the sample data collected in 2016. Percentages in "target population" are relative to the national data, while the percentages for our sample data are relative to the "target population."

\begin{tabular}{|c|c|c|c|c|c|c|c|}
\hline \multicolumn{8}{|c|}{ Gender } \\
\hline & & & \multicolumn{2}{|c|}{ Men } & \multicolumn{2}{|r|}{ Women } \\
\hline \multirow[t]{2}{*}{ National } & Freq. & \multicolumn{2}{|c|}{$11,237,196$} & \multicolumn{2}{|c|}{$5,496,839$} & \multicolumn{2}{|r|}{$5,740,357$} \\
\hline & Percent & & & \multicolumn{2}{|c|}{48.92} & \multicolumn{2}{|r|}{51.08} \\
\hline \multirow[t]{2}{*}{ Target } & Freq. & \multicolumn{2}{|c|}{16435} & \multicolumn{2}{|c|}{8630} & \multicolumn{2}{|r|}{8251} \\
\hline & Percent & & & \multicolumn{2}{|c|}{53} & \multicolumn{2}{|r|}{50} \\
\hline \multirow[t]{2}{*}{ Sample } & Freq. & \multicolumn{2}{|c|}{172} & \multicolumn{2}{|c|}{57} & \multicolumn{2}{|r|}{115} \\
\hline & Percent & & & \multicolumn{2}{|c|}{33} & \multicolumn{2}{|r|}{67} \\
\hline \multicolumn{8}{|c|}{ Marital Status } \\
\hline & & \multicolumn{2}{|c|}{ Married/partnered } & Divorced & Widowed & \multicolumn{2}{|r|}{ Single } \\
\hline \multicolumn{2}{|l|}{ National } & \multicolumn{2}{|c|}{$54 \%$} & $2 \%$ & $4 \%$ & \multicolumn{2}{|r|}{$40 \%$} \\
\hline \multicolumn{2}{|l|}{ Target } & \multicolumn{2}{|c|}{$56 \%$} & \multirow{2}{*}{$\begin{array}{c}2 \% \\
*\end{array}$} & $3 \%$ & & $39 \%$ \\
\hline Sample & & $79 \%$ & & & $4 \%$ & & $18 \%$ \\
\hline & & & & Age & & & \\
\hline & & $18-29$ & $30-39$ & $40-49$ & $50-59$ & $60+$ & Total \\
\hline National & Freq. & 1793371 & 1225657 & 922383 & 616259 & 712726 & 5270396 \\
\hline & Percent & 34 & 23 & 18 & 12 & 14 & 100 \\
\hline Target & Freq. & 2836 & 1847 & 1441 & 934 & 1144 & 8202 \\
\hline & Percent & 35 & 23 & 18 & 11 & 14 & 100 \\
\hline Sample & Freq. & 26 & 49 & 43 & 26 & 28 & 172 \\
\hline & Percent & 15 & 28 & 25 & 15 & 16 & 100 \\
\hline
\end{tabular}


Table 3-2 Demographic data continued. Information from the 2002 national census compared to the target population and the sample data collected in 2016. Percentages in "target population" are relative to the national data, while the percentages for our sample data are relative to "target population."

\begin{tabular}{|c|c|c|c|c|c|c|c|c|c|c|c|c|}
\hline \multicolumn{13}{|c|}{ Level of Education } \\
\hline & & & None & $\begin{array}{l}\text { Some } \\
\text { Primary }\end{array}$ & \multicolumn{2}{|c|}{ Primary } & \multicolumn{2}{|c|}{ Secondary } & \multicolumn{2}{|c|}{ High School } & \multicolumn{2}{|c|}{ University } \\
\hline \multicolumn{2}{|l|}{ National } & & $28 \%$ & $28 \%$ & \multicolumn{2}{|c|}{$24 \%$} & \multicolumn{2}{|l|}{$8 \%$} & \multicolumn{2}{|c|}{$8 \%$} & & $4 \%$ \\
\hline \multicolumn{2}{|l|}{ Target } & & $26 \%$ & $31 \%$ & \multicolumn{2}{|c|}{$31 \%$} & \multicolumn{2}{|l|}{$7 \%$} & \multicolumn{2}{|c|}{$4 \%$} & & $1 \%$ \\
\hline \multicolumn{2}{|l|}{ Sample } & & $16 \%$ & $8 \%$ & & $6 \%$ & $8 \%$ & & 10 & & & $2 \%$ \\
\hline \multicolumn{13}{|c|}{ Occupation } \\
\hline & Govt & \multicolumn{2}{|c|}{$\begin{array}{c}\text { Professional } \\
\text { / Technical }\end{array}$} & \multicolumn{2}{|c|}{$\begin{array}{l}\text { Goods \& } \\
\text { Services }\end{array}$} & $\mathrm{Agr}$ & $\begin{array}{l}\text { Skilled } \\
\text { Trade }\end{array}$ & MFG & \multicolumn{3}{|c|}{$\begin{array}{l}\text { Unskilled / } \\
\text { Homemaker }\end{array}$} & MLTRY \\
\hline National & $2 \%$ & \multicolumn{2}{|r|}{$11 \%$} & \multicolumn{2}{|c|}{$10 \%$} & $10 \%$ & $18 \%$ & \multicolumn{2}{|c|}{$5 \%$} & \multicolumn{2}{|l|}{$44 \%$} & $0.3 \%$ \\
\hline Target & $0.4 \%$ & \multicolumn{2}{|r|}{$4 \%$} & \multicolumn{2}{|c|}{$6 \%$} & $14 \%$ & $16 \%$ & \multicolumn{2}{|c|}{$9 \%$} & \multicolumn{2}{|c|}{$50 \%$} & $0.05 \%$ \\
\hline Sample & $2 \%$ & \multicolumn{2}{|r|}{$11 \%$} & \multicolumn{2}{|c|}{$14 \%$} & $19 \%$ & $5 \%$ & \multicolumn{2}{|c|}{$3 \%$} & $56 \%$ & & $3 \%$ \\
\hline & & & & Housin & and & Roof I & laterial & & & & & \\
\hline & Urban & & Rur & & eet $r$ & netal & $\begin{array}{c}\text { Concret } \\
\mathrm{e}\end{array}$ & & Tile & $\begin{array}{l}\text { Fibr } \\
\text { Cem }\end{array}$ & & Other \\
\hline National & $46 \%$ & & $54 \%$ & & 67 & & $15 \%$ & & $12 \%$ & 29 & & $4 \%$ \\
\hline Target & $41 \%$ & & $59 \%$ & & 95 & & $4 \%$ & & $0.3 \%$ & 0.4 & & $0.6 \%$ \\
\hline Sample & $11 \%$ & & $89 \%$ & & 90 & & $5 \%$ & & $*$ & * & & $2 \%$ \\
\hline & & & & House $C$ & onstr & uction & Material & & & & & \\
\hline & Wc & od & & Block/ & Conc & rete & Adobe & & She & t Met & & Other \\
\hline National & 16 & $\%$ & & & $7 \%$ & & $24 \%$ & & & $2 \%$ & & $10 \%$ \\
\hline Target & 5 & $\%$ & & & $9 \%$ & & $4 \%$ & & & $6 \%$ & & $5 \%$ \\
\hline Sample & 2 & $\%$ & & & $3 \%$ & & $1 \%$ & & & $6 \%$ & & $5 \%$ \\
\hline
\end{tabular}




\subsubsection{Characteristics of our respondents as a whole}

We start with some descriptive statistics on our key survey variables. As already mentioned, we found that $41 \%$ of our respondents claimed that no member of their household evacuated during the 2010 eruption and that only $54 \%$ claimed that they would be willing to evacuate in the future in the event of a similar eruption. Of the respondents who did evacuate in $2010,60 \%$ claimed that they evacuated during the eruption, $33 \%$ waited until after the eruption to evacuate, while only $6 \%$ evacuated pre-emptively in response to a warning message. Eighty percent of those who evacuated also claimed to have spent at least one night in an emergency shelter and only $56 \%$ percent of our respondents as a whole reported hearing or seeing an official warning message. Respondents as a whole were also quite divided over whether or not they experienced an interruption to their work ( $28 \%$ did while $32 \%$ did not), home or property damage (36\% did while $28 \%$ did not), or damage to their animals or plants ( $48 \%$ did while $24 \%$ did not) during the 2010 eruption. Finally, we found that most respondents did not experience theft from robbers $(89 \%$ did not) or injury to a member of the household ( $85 \%$ did not) during the 2010 eruption.

Risk perception among our respondents was moderately high in that $66 \%$ of our respondents either strongly agreed (51\%) or agreed (15\%) that Pacaya was likely to have another eruption similar to or larger than the one in 2010 again in their lifetime (only $10 \%$ disagreed or strongly disagreed while $24 \%$ were neutral). Yet, respondents also reported relatively low levels of trust in authority figures with only $55 \%$ either strongly agreeing (26\%) or agreeing (29\%) that they trusted information from CONRED and only $50 \%$ saying the same about INSIVUMEH (23\% strongly agreeing and $27 \%$ agreeing). These national authorities received roughly the same levels of trust than church leaders (28\% strongly agreeing and 18\% agreeing), community leaders (26\% strongly agreeing and $20 \%$ agreeing), and one's family, friends, or neighbors (24\% strongly agreeing and $19 \%$ agreeing). Furthermore, while $61 \%$ either strongly agreed (27\%) or agreed (33\%) that INSIVUMEH had the necessary skills, training, and equipment to monitor the volcano, only $47 \%$ either strongly agreed $(23 \%)$ or agreed $(24 \%)$ that INSIVUMEH could predict an eruption whereas $68 \%$ either strongly agreed $(51 \%)$ or agreed $(17 \%)$ that the volcano itself will provide clear signs of an impending eruption. Finally, only $19 \%$ either strongly agreed $(8 \%)$ or agreed $(11 \%)$ that their community was prepared for a future eruption while $69 \%$ claimed to be prepared to keep their own family safe, which dropped to $62 \%$ when asked about keeping themselves safe, and dropped even further to $43 \%$ when asked about keeping their home safe.

Finally, respondents as a whole ranked health or physical ability the most important factor to their evacuation decision, with $87 \%$ claiming that this was either "Very Important" or at least "Important," resulting in a sample mean of 3.35 out of 4 (items were scored from 0 to 4 with 0 being "Not at all Important" and 4 being "Very Important"). The next highest ranked factors in order of importance were "seeing volcanic ash, bombs, or tephra falling from the sky" (mean of 3.25), "having a safe place 
to go" (mean of 2.94), "receiving an official evacuation message" (mean of 2.91), and "seeing friends, family, or neighbors evacuate (mean of 2.88)." The lowest ranked factors in order of least importance were "the need to protect plants or animals from fallout" (mean of 1.86), "the need to protect your home from fallout" (mean of 1.96), "feeling safe in your home" (mean of 2.00), and "hearing a warning message from friends or family" (mean of 2.24). Respondents also appeared quite divided over the following factors (in other words, they were highly clustered near both extremes of "Very Important" or "Not at All Important"): "fear of looters while evacuated," "the need to protect plants or animals from fallout," and "the need to protect home from fallout." Respondents also appeared quite uncertain about the importance of receiving a warning message from the following sources (in other words, they were relatively evenly distributed across all answer options): "friends or family," "church leaders," "community leaders," "elected officials," and "news sources, such as TV or radio

\subsubsection{Observed differences in evacuation experience, behavior, and intentions}

After describing our respondents as a whole with respect to key variables of interest, we then used chi-square and difference of means t-Tests to explore how respondents differed with respect to their evacuation experience, behavior, and future intentions. We first compared respondents from the North who experienced the worst of the 2010 eruption impacts to those from the South who were historically more experienced with eruption fallout. Using a chi-square test on our categorical variables, we found statistically significant relationships between community of residence and having received an official evacuation notice during the 2010 eruption $(p=0.013)$, knowledge of emergency shelters $(\mathrm{p}=0.001), 2010$ evacuation status $(\mathrm{p}=0.000)$, and future evacuation intentions $(\mathrm{p}=$ 0.007). Rates of receiving an evacuation message and knowledge of emergency shelters were significantly higher for those in the South while those in the North reported higher evacuation rates and future intentions to evacuate. Using a t-Test on our Likert-scale questions, we also found that those in the North reported significantly higher home or property damage $(p=0.000)$, animal or plant damage $(p=0.000)$, injury to a household member $(p=0.005)$, interruption of work $(p=0.000)$, importance placed on official warning messages $(p=0.025)$, need to protect one's home from fallout $(p=0.021)$, belief that the 2010 eruption was the largest ever at Pacaya $(p=0.000)$, intention to evacuate in the future in response to a warning message alone despite no visible signs of an eruption $(p=0.000)$, as well as trust in church leaders $(p=0.018)$, government $(p=0.000)$, and the PNC $(p=0.002)$.

Next, we compared respondents from households with at least one evacuee to those with no evacuees. Our chi-square tests found only one statistically significant relationship between evacuation status and intention to evacuation in the future with evacuees reporting significantly higher intentions to evacuate than non-evacuees $(p=0.001)$. Our $t-$ Tests found that evacuees also reported significantly higher home or property damage $(\mathrm{p}$ $=0.000)$, damage to animals or plants $(0.005)$, theft from robbers $(\mathrm{p}=0.001)$, interruption of work $(\mathrm{p}=0.000)$, belief that the 2010 eruption was the largest ever at 
Pacaya $(\mathrm{p}=0.001)$, and trust in government $(\mathrm{p}=0.006)$, the PNC $(\mathrm{p}=0.015)$, and the decisions of official emergency management authorities during an eruption $(p=0.043)$. Evacuees also reported significantly higher preparedness to do the following during a future eruption: evacuate $(p=0.000)$, keep oneself safe $(p=0.002)$, and know where to go $(p=0.003)$. Finally, evacuees reported significantly higher intentions to evacuate in response to an official warning message even without visible signs of an eruption ( $\mathrm{p}=$ $0.006)$ and to evacuate even without receiving an official warning message $(p=0.028)$.

Our final comparison was between those who intended to evacuate in the future in the event of an eruption similar to 2010 and those who did not. Our chi-square tests found statistically significant relationships between future intention and knowledge of emergency shelters $(p=0.034)$ as well as 2010 evacuation status $(p=0.000)$. Those who intended to evacuate reported both higher emergency shelter knowledge and higher rates of having evacuated in 2010. Our t-Tests found that those who intended to evacuate also reported statistically higher damage to home or property $(p=0.006)$, injury to a member of the household $(\mathrm{p}=0.038)$, and importance placed on warning message from friends or family $(p=0.000)$, church leaders $(p=0.050)$, community leaders $(p=0.011)$, and the news media $(\mathrm{p}=0.007)$. Those who intended to evacuate also reported significantly higher importance placed on fear of looters $(p=0.005)$ as well as trust in information from friends or family $(p=0.011)$, information from community leaders $(p=0.004)$, and the PNC $(\mathrm{p}=0.006)$.

\subsubsection{Controlling for alternative explanations}

The chi-square and t-test results reported above helped us to see how those in the North experienced the 2010 eruption differently than those in the South, how those who evacuated in 2010 differed from those who did not, and how those who intended to evacuate in the future differed from those who did not. However, we also wanted to know which of these differences mattered most to one's 2010 evacuation behavior and willingness to evacuate in the future. To explore these issues, we used binary logistic regression to isolate the effects of a single explanatory variable while controlling for the effects of all other possible alternative explanations. Below, we present the results of two separate nested regressions with our respondents' 2010 evacuation status as the dependent variable in the first regression (see Table 3-3) and our respondents' intention to evacuate as the dependent variable in the second (Table 3-4). Both regressions used the nested approach in which blocks of explanatory variables were added to the model incrementally.

We began both regressions with a basic model that included household demographics as the only explanatory variables because we wanted to control for these differences throughout the entire analysis. We then added the respondent's 2010 evacuation experience to this model to see how events that transpired during the 2010 eruption directly impacted past behavior and, as a consequence, may have influenced future evacuation intentions. Next, we added the respondent's self-ranked evacuation decision- 
making criteria to see how the importance placed on a certain criterion made it more or less likely for one to have evacuated in 2010 or for one to be willing to evacuate in the future while controlling for one's actual 2010 evacuation experience. Finally, we added measures of risk perception, evacuation perception, preparedness, and trust to our future intentions model but chose not to do so for our past behavior model because it was impossible to know what these values were prior to the 2010 eruption when they would have had a chance to impact past behavior.

\subsubsection{Regression 1: past evacuation behavior}

The basic model (Model 1) for our past evacuation behavior regression used the following household demographics as explanatory variables: gender, age, marital status (married or not), education (low or high), occupation (farmer or not), number of children, and community of residence (North or South). The r-squared of this model was 0.205 and community of residence was the only statistically significant predictor with those in the North being 5.193 times more likely to have evacuated than those in the South. Model 2 added in the following 2010 eruption experiences while continuing to control for household demographics: having received an official warning message, emergency shelter knowledge, access to transportation, and level of damage experienced. The rsquared of this model improved to 0.301 and community of residence remained statistically significant but slightly weakened (2.503). Damage experience was also found to be statistically significant with an increase in damage experienced making respondents 1.203 times more likely to have evacuated. Finally, Model 3 added in the respondent's self-ranked evacuation decision-making criteria while continuing to control for household demographics and 2010 eruption experience. The r-squared of this model improved slightly to 0.373 and age became statistically significant at the $90 \%$ confidence level with younger residents being 1.091 times more likely to have evacuated. Community of residence and damage experience remained statistically significant and strengthened slightly to 3.291 and 1.217 respectively. Finally, the importance one placed on protecting one's home when making evacuation decisions was also found to be statistically significant with decreasing importance on this criterion making respondents 1.406 times more likely to have evacuated. 
Table 3-3 Nested regression results using evacuation behavior in 2010 as the dependent variable. . Model 1 begins with a block of selected variables and then each progressive model adds another block of variables. Each model shows $r 2$ values in first cell of top row. Values in columns represent expected betas for each variable, those in bold type are statistically significant percent levels: 90*, 95**, and 99***






\subsubsection{Regression 2: future evacuation intentions}

The basic model (Model 1) for our future intentions regression used the same household demographics from our past behavior regression as its only explanatory variables. The rsquared of this model was 0.265 and community of residence was once again the only statistically significant variable with those in the North being 4.649 times more likely to intend to evacuate. Model 2 added in the respondent's 2010 evacuation experience and this improved r-squared to 0.433 while community of residence remained statistically significant and strengthened to 7.296. One's 2010 evacuation status, transportation availability, and emergency shelter knowledge were also found to be statistically significant with 2010 evacuees, those who had access to transportation, and those with knowledge of emergency shelters being 3.890, 3.445, and 3.865 times more likely to intend to evacuate. Model 3 added in risk and evacuation perceptions which improved rsquared to 0.512 . Community of residence as well as one's 2010 evacuation status, transportation availability, and emergency shelter knowledge all remained statistically significant and strengthened slightly. Having received an official warning message in 2010 , sense of community-preparedness, and sense of self-preparedness for a future eruption all became statistically significant with reception of an official warning message and increases in community and self-preparedness making one 3.131, 1.872, and 1.778 times more likely to intend to evacuate respectively. Finally, Model 4 added in trust and one's evacuation decision-making criteria which improved r-squared to 0.734 . Community of residence and past evacuation behavior remained statistically significant and strengthened dramatically to 60.345 and 30.499 respectively. Sense of preparedness to protect others and the importance placed on receiving warning messages from friends or family, receiving warning messages from the news, seeing others evacuate, and health or physical abilities were all found to be statistically significant. An increase in the importance placed on receiving warning messages from friends or family as well as receiving warning messages from the news made one 3.036 and 3.362 times more likely to intend to evacuate respectively while a decrease in preparedness to protect others, the importance of seeing others evacuate, and the importance of one's health or physical abilities made one 5.917, 2.058, and 6.993 times more likely to intend to evacuate respectively. Finally, having received an official warning message, transportation availability, and emergency shelter knowledge in 2010 all lost their statistical significance along with sense of community-preparedness and self-preparedness when controlling for one's trust and evacuation decision-making criteria. 
Table 3-4 Nested regression using future intention as the dependent variable. Values represent expected betas for each variable, those in bold type are statistically significant percent levels: $90^{*}, 95 * *$, and $99 * * *$.

\begin{tabular}{|c|c|c|c|c|c|}
\hline \multicolumn{2}{|c|}{$* p \leq 0.1, * * p \leq 0.05, * * * p \leq 0.01$} & $\begin{array}{l}\text { Model } 1 \\
\left(r^{2}=0.265\right)\end{array}$ & $\begin{array}{l}\text { Model } 2 \\
\left(r^{2}=0.433\right)\end{array}$ & $\begin{array}{l}\text { Model } 3 \\
\left(r^{2}=0.512\right)\end{array}$ & $\begin{array}{l}\text { Model } 4 \\
\left(r^{2}=0.734\right)\end{array}$ \\
\hline \multirow{9}{*}{  } & & Odds Ratio & Odds Ratio & Odds Ratio & Odds Ratio \\
\hline & Constant & 0.225 & $0.010 * * *$ & $0.003 * *$ & 20.647 \\
\hline & Gender & 0.412 & 0.432 & 0.507 & 0.078 \\
\hline & Age & 1.029 & 1.034 & 1.039 & 0.984 \\
\hline & Education & 0.522 & 0.655 & 0.801 & $0.031 * *$ \\
\hline & Marital Status & 0.719 & 0.997 & 0.759 & 0.014 \\
\hline & Occupation & 1.826 & 1.160 & 1.098 & 5.346 \\
\hline & Number of Children & 1.201 & 1.183 & 1.172 & 1.048 \\
\hline & Community of Residence & $4.649 * * *$ & $7.296 * * *$ & $10.905^{* *}$ & $60.345^{* *}$ \\
\hline \multirow{5}{*}{ 完 } & Warning Message Received & $\overline{---}$ & 1.685 & $3.131^{*}$ & 2.358 \\
\hline & Transportation Availability & --- & $3.445^{* *}$ & $4.498 * *$ & 5.053 \\
\hline & Evacuation Status & --- & $3.890 * *$ & $5.870 * * *$ & $30.499 * * *$ \\
\hline & Emergency Shelter Knowledge & --- & $3.865^{* *}$ & $4.406 * *$ & 1.186 \\
\hline & Damage Experience & --- & 0.996 & 0.966 & 0.904 \\
\hline \multirow{8}{*}{ 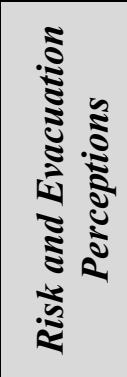 } & Risk Perception & --- & --- & 0.873 & 0.815 \\
\hline & Ability to Evacuate & --- & --- & 1.034 & 1.220 \\
\hline & Perception of Evacuation & --- & --- & 1.268 & 0.810 \\
\hline & Friends/Neighbors Help & --- & --- & 0.964 & 1.246 \\
\hline & Community Prepared & --- & --- & $1.872 * *$ & 0.948 \\
\hline & Officials Help & --- & --- & 0.669 & 0.501 \\
\hline & Ready to Protect Others & --- & --- & 0.831 & $0.169 * *$ \\
\hline & Ready to Protect Self & --- & --- & $0.563 *$ & 0.663 \\
\hline \multirow{19}{*}{ 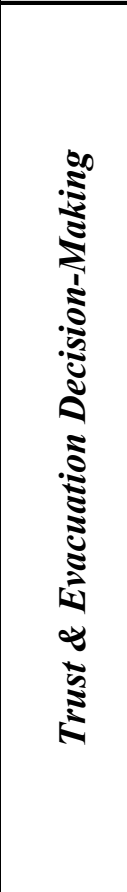 } & Trust in CONRED/INSIVUMEH & --- & --- & --- & 0.950 \\
\hline & TRUST in Friends/Family/Church & --- & --- & --- & 1.974 \\
\hline & Trust in National Agencies & --- & --- & --- & 0.489 \\
\hline & National Warning Importance & --- & --- & --- & 0.958 \\
\hline & Friends/Family Warning & --- & --- & --- & $3.036 * *$ \\
\hline & Church Leader Warning & --- & --- & --- & 0.768 \\
\hline & Community Leader Warning & --- & --- & --- & 2.594 \\
\hline & News Warning & --- & --- & --- & $3.362 * *$ \\
\hline & Elected Official Warning & --- & --- & --- & 0.524 \\
\hline & Seeing Fallout & --- & --- & --- & 1.139 \\
\hline & Seeing Others Evacuate & --- & --- & --- & $0.486 * *$ \\
\hline & Fear of Looters Importance & --- & --- & --- & 1.547 \\
\hline & Protect Home Importance & --- & --- & --- & 2.346 \\
\hline & Protect Plants/Animals Importance & --- & --- & --- & 0.879 \\
\hline & Feeling of Safety Importance & --- & --- & --- & 0.665 \\
\hline & Means to Evacuate Importance & --- & --- & --- & 1.121 \\
\hline & Access to Transport Importance & --- & --- & --- & 0.785 \\
\hline & Safe Place to Go Importance & --- & --- & --- & 1.131 \\
\hline & Health/Ability Importance & --- & --- & --- & $0.143^{* *}$ \\
\hline
\end{tabular}




\subsection{Discussion and summary}

The goal of this study is to determine why individuals choose to stay in harm's way in response to a volcanic eruption when evacuation is the only guaranteed strategy to ensure their safety. We have shown above that the dominant paradigm in natural hazards research assumes that risk perception is the primary driver of this protective action but we have also shown that the cultural and radical paradigm give us a reason to assume social vulnerability may play an important role as well. We have argued that most volcanic hazard evacuation studies have been conducted in the developed world where social vulnerability is less of a factor and that few studies exist in the developing world that have explored evacuation decision-making in response to an actual eruption. Our study is one of the first to do so in the context of Latin America and we believe our findings are useful for those who want to better understand evacuation decision-making in the context of socially vulnerable populations.

Above, we presented the findings of a household survey on evacuation behavior and future intentions conducted in the Pacaya region of Guatemala. Our survey respondents were asked about their evacuation behaviors during the 2010 eruption, their future evacuation intentions, their 2010 eruption experiences, their perceptions of hazard risk and evacuation, their evacuation decision-making criteria, their trust in others, and their sense of preparedness for a future eruption. We found that $41 \%$ of the households in our survey failed to evacuate during the 2010 eruption and only $54 \%$ claimed to be willing to evacuate in the future in the event of a similar eruption. Damage experience during the 2010 eruption varied widely for our respondents as a whole, while risk perception was relatively high but trust in others and preparedness were relatively low. On the surface, these results suggest two things. First, heightened risk perception in response to the 2010 eruption does not appear to have translated directly into higher intentions to evacuate in the future nor has it necessarily led to other protective actions that would make respondents feel more prepared for a future eruption. Second, it is not clear who respondents were likely to turn to in the event of a future eruption given the relatively low levels of reported trust among our respondents as a whole. However, this picture became a bit clearer when we examined our findings in greater detail.

The dominant paradigm assumes that risk perception and protective action decisionmaking go hand-in-hand and this certainly seems like a plausible explanation for why evacuation rates in 2010 were so low. However, it is not entirely clear why intentions to evacuate in the future were lower than expected given the relatively high risk perceptions of our respondents that seemed to stem from this past eruption experience. To shed more light on this issue, we first took a closer look at the importance respondents placed on various evacuation decision-making criteria that could potentially influence their understanding of risk as they determined whether or not to evacuate. We found that respondents as a whole ranked their own capabilities (health/physical safety and having a safe place to go), official warning messages, and direct cues of an impending disaster (seeing fallout or others evacuate) the most important decision-making factors, while the 
need to protect one's home/property and animals/plants from fallout, as well as the feeling of safety in one's home and the importance placed on warning messages from friends or family were the lowest ranked factors. We also found that respondents as a whole were quite divided over the importance of protecting one's home/property and animals/plants from both fallout and looters while being quite uncertain about the importance of receiving a warning message from friends/family, church leaders, community leaders, elected officials, and news sources. These findings provide a number of important insights into the evacuation decision-making of our respondents that can help us to see how they may be interpreting risk both with respect to the hazard itself and the actual act of evacuating.

It is interesting to note how the decision-making factors ranked most important to our respondents align with the Protective Action Decision Model (PADM), which is one of the most prominent and well respected theories of evacuation decision-making in natural hazards research and one that is largely grounded in the dominant paradigm (Lindell and Perry 2012). The PADM claims that it is possible to predict evacuation behavior if one knows something about a person's exposure to evacuation messages, environmental cues, and social cues that are typically the most important drivers of protective action decisionmaking as well as existing situational impediments or facilitators that determine what is or is not a possible protective action. All of these factors appear to have a prominent place in the evacuation decision-making of our respondents, with situational impediments/facilitators (health/physical ability and having a safe place to go) being most important, followed by warning messages, environmental cues (seeing fallout), and social cues (seeing others evacuate). Yet, PADM is simply a general framework for evacuation decision-making so it cannot necessarily explain why these factors were ranked more important than others nor why our respondents placed relatively low importance on protecting one's property (home, animals, plants, etc.) from fallout or looters, the feeling of safety in one's home, or receiving warning messages from friends or family. Although these findings are somewhat specific to our respondents, we believe they can tells us something about the role social vulnerability plays in their evacuation decisions.

The fact that our respondents ranked situational impediments (health/physical abilities) and facilitators (having a safe place to go) more important to their evacuation decisionmaking than nearly anything else is not surprising since resource constraints are often endemic to rural Latin America and it is partly this lack of resources in the communities surrounding Pacaya that makes this population socially vulnerable. Nevertheless, it is worth noting that our respondents not only appeared to be aware of these issues but also claimed that these were the most important factors driving their evacuation decisions. What is somewhat more surprising is the level of importance respondents placed on receiving an official warning message when only $52 \%$ actually received such a message during the 2010 eruption. This seems to suggest that respondents as a whole valued timely warning messages, which were severely lacking in 2010 but, as with situational 
impediments or facilitators, are within the control of emergency management officials. It is also helpful to know that respondents placed more importance on these factors than environmental and social cues while placing little importance on feelings of safety in one's home or receiving warning messages from friends or family, which emergency management officials would have much less control over during a future eruption. Finally, the low importance placed on protecting one's property from fallout or looters was interesting because these factors were cited most frequently in the retrospective accounts of emergency management officials when they were asked to speculate why the residents of Pacaya failed to evacuate in 2010. These are also factors the radical paradigm would expect socially vulnerable populations to care more about.

To this point, we have focused solely on findings that applied to our respondents as a whole. However, we also found that our respondents were relatively divided in terms of their 2010 evacuation status, future intentions, 2010 eruption experience, trust in authorities, and the importance they placed on protecting one's property from fallout or looters. The latter division was particularly interesting given that these factors were ranked lowest in terms of their self-reported importance to our respondents' evacuation decisions. Upon closer inspection, it became clear that this result was largely a consequence of respondents clustering toward the extremes with relatively equal numbers both caring a great deal or not at all about these factors. Results like this made it clear that critical differences among our respondent population were worth exploring and, since the purpose of our study was to determine what set evacuees apart from nonevacuees and those who intended to evacuate from those who did not, we chose to conduct a series of chi-square and t-Test analyses using these characteristics as grouping variables. We also ran an additional set of tests with community of residence as the grouping variable to show how much one's experience with eruption severity in 2010 could account for any observed differences. Ultimately, we found that respondents from the North who experienced the greatest eruption impacts in 2010 shared many things in common with respondents who evacuated in 2010 and those who intended to evacuate in the future but there were also a number of important differences between these groups that are worth noting.

Our chi-square and t-Test analyses showed us that respondents from the North were significantly more likely to have evacuated in 2010 and to intend to evacuate in the future than those in the South, which indicates that eruption severity played an important role in determining past evacuation behavior and is likely a strong influence over future intentions. This is certainly in line with existing natural hazards literature which claims that past hazard experience is often the most important reason why individuals evacuate (Burton 1993). We also saw that those in the North reported significantly lower rates of receiving an official warning message and knowledge of emergency shelters as well as significantly higher damage experience and severity perception as was expected. Yet, those in the North also placed more importance on official warning messages despite their lower rates of having received one and fear of looters despite their higher evacuation 
rates and the fact that very few of our respondents actually experienced this problem. Finally, those in the North also reported significantly higher trust in church leaders, the government, and the National Police (PNC). Although these findings alone do not indicate anything about past behavior or future intentions per se, they do tell us that negative environmental cues were much more severe in the North while situational facilitators were much better in the South. These findings also seem to suggest that those hit the hardest had a relatively positive evacuation experience with emergency authorities and that prompt evacuation messages from these officials could have made a difference.

We also found that many of the factors that set respondents from the North apart from those in the South were the same factors that set respondents who evacuated in 2010 apart from those who did not. Evacuees and those from the North both had significantly higher damage experience, severity perception, and levels of trust in government and the PNC than their counterparts. The fact that evacuees reported higher damage experience and severity perception than non-evacuees was not surprising since we had already established that evacuees were more likely to have been from the North where both of these factors were higher in 2010 . These results are also consistent with existing hazards literature that assumes direct hazard experience leads to heightened risk perception and, therefore, increased evacuation rates (Burton 1993). Higher trust in the government and PNC among evacuees also makes sense given the prominent role these authorities play during an evacuation (Kasperson 1992, Wynne 1992) but it is not entirely clear why these trust levels would also be higher in the North. Furthermore, evacuees reported significantly higher levels of trust in emergency management decisions during an eruption, preparedness for a future eruption, and willingness to evacuate with or without a warning message even though none of these items were statistically significant for community of residence. This seems to suggest that trust, preparedness, and willingness were all important factors that led one to evacuate in 2010 separate from living in a severely impacted community.

Comparisons between community of residence and one's 2010 evacuation status make it possible to see the degree to which severity of impact may have influenced one's past evacuation behavior but we were also interested in the degree to which past evacuation behavior may have influenced one's future intentions as existing natural hazards literature would expect (Burton 1993). Although those who evacuated in 2010 were also more likely to intend to evacuate in the future, we found that these groups shared only two statistically significant differences in common: damage experience and trust in the PNC, both of which were significantly higher for evacuees and those who intended to evacuate as well as those in the North. This seems to suggest that damage experience and trust in the PNC played a mutually supportive role in shaping past behavior and future intentions. On the other hand, we also found that knowledge of emergency shelters, the importance placed on warning messages from non-official sources, and fear of looters were also significantly higher for those who intended to evacuate, despite not being significant for community of residence or past behavior. Here we can only speculate that 
those with higher knowledge of emergency shelters and those who were more open to information in general were also more likely to see evacuation as a realistic option in a hypothetical situation as opposed to during an actual evacuation where unexpected situational issues or unforeseen environmental and social cues alter one's evacuation decision. It is also interesting that greater trust in the PNC seems to have cancelled out greater fear of looters among those who intended to evacuate in the future. Finally, we note that the significantly higher levels of preparedness reported among those who actually evacuated in 2010 did not carry over to those who intended to evacuate in the future, which seems to suggest that past behavior had a greater influence on preparedness than preparedness had on future intentions.

Our chi-square and t-Test analyses helped us see the commonalities and differences between one's community of residence, past evacuation behavior, and future intentions but they could not isolate the effects of a single explanatory variable to determine its relative impact on past behavior or future intentions. To determine this, we used two binary logistic nested regressions with past behavior as the dependent variable in the first and future intentions as the dependent variable in the second. Our first regression found that community of residence, the importance placed on protecting one's home, damage experience, and age (listed in order of most to least impactful) were all statistically significant predictors of past evacuation behavior. Our second regression found that community of residence, education, past evacuation behavior, importance placed on health/physical abilities, sense of readiness to protect others, importance placed on warning messages from the news, from friends/family, and seeing others evacuate (listed in order of most to least impactful) were all statistically significant predictors of future evacuation intentions.

It makes sense that respondents from the North, those who placed less emphasis on protecting one's home, those who experienced more damage, and younger respondents were all more likely to have evacuated in 2010 . We already saw from above that those who evacuated were also more likely to be from the North and to have experienced more eruption damage but it is interesting to see that these factors remained significant even when controlling for alternative explanations. The fact that older respondents were less likely to have evacuated than younger respondents was a new finding but also made sense given that age is more likely to become a situational inhibitor. The lower likelihood of having evacuated for those who placed more emphasis on protecting their home was also a new finding and made sense given that it is necessary to be physically present to protect one's home, which is not possible when one evacuates. We can also say that, since risk perception was not a statistically significant predictor of past behavior, these final two results seem to support the radical paradigm understanding of evacuation behavior better than the dominant paradigm. In other words, it appears that the social vulnerability of older respondents and those who felt it was necessary to risk their lives to protect their home was a stronger predictor of whether or not one evacuated in 2010 than risk perception alone. 
As for future intentions, it makes sense that those from the North, those who evacuated in 2010 , those who claimed to be less ready to protect others, those who placed more emphasis on warning messages from friends/family and the news media, and those who placed less emphasis on seeing others evacuate or on their health/physical abilities would be more likely to intend to evacuate in the future. Once again, community of residence was the most important predictor here, even though damage experience failed to achieve statistical significance. This seems to suggest that exposure to eruption severity alone was enough to influence one's future intentions without the need for experiencing actual eruption damage. We also found that age was a significant predictor of past behavior but not for future intentions whereas importance placed on health/physical abilities was a significant predictor of future intentions but not for past behavior. Additionally, we found that the importance placed on protecting one's home mattered more to past behavior whereas readiness to protect others and the importance placed on warning messages from friends/family and the news as well as the importance placed on seeing others evacuate mattered more to future intentions. These results suggest that environmental cues and concrete situational barriers like age matter more when one is taking a protective action whereas the perceived need for social cues and perceptions of situational barriers like health/physical abilities matter more to the hypothetical possibility of taking such an action.

Finally, we should note that the effect of education on future intentions was opposite of what the literature (Dominey-Howes and Minos-Minopoulos 2004) and our intuition would expect. We found that those with less education were more likely to intend to evacuate. We believe this may simply be due to the artificial way in which we divided respondents into high and low education categories, which required us to place the great majority of respondents with a primary education in the low category to maintain a reasonable balance across categories for analytical purposes. Therefore, this result is really saying that those with a primary education were more likely to intend to evacuate than those with a higher education but it is entirely possible that we simply lacked a sufficient number of respondents with a higher education to make a valid inference regarding the relationship between education and future intentions.

In conclusion we showed that risk perception and protective action decision-making do not necessarily go hand-in-hand for the residents of Pacaya. In other words, heightened risk perception in response to the 2010 eruption has not directly translated into increased preparedness or willingness to evacuate in the future, as the dominant paradigm would assume. Second, we showed that the residents of Pacaya placed more emphasis on situational issues and official warning messages in their evacuation decisions than on environment or social cues. We argued that this was an understandable outcome for a socially vulnerable population lacking in critical resources but also one that emergency management authorities could potentially control. Third, we found that eruption severity and damage experience played a key role in determining who evacuated in 2010 and who did not. But severity alone was enough to raise one's willingness to evacuate in the 
future. We also found that past behavior appeared to have a greater impact on preparedness than preparedness had on future intentions. Finally, we found that community of residence based on severity of impact was the strongest predictor of both past behavior and future intentions and that issues of social vulnerability, such as age or health and physical abilities as well as the need to protect one's home or protect others, were much stronger predictors of past behavior and future intentions than was risk perception alone. These findings suggest that, although emergency management authorities have no control over eruption impacts, it is entirely within their control to better inform residents of an impending eruption and that such information would have a positive impact on evacuation. It is also clear that efforts to address the situational impediments of older or less capable residents as well as the perception that one must stay in harm's way to protect one's home or others should help to encourage greater evacuation rates while minimizing harm in a future eruption at Pacaya. Thus, there is much more to the evacuation story at Pacaya than an improper perception of risk alone can explain. 


\subsection{References}

Baker, E. J. (1979) Predicting response to hurricane warnings: A reanalysis of data from four studies. Mass emergencies, 4, 9-24.

Baker, E. J. (1991) Hurricane evacuation behavior. International Journal of Mass Emergencies and Disasters, 9, 287-310.

Barberi, F., M. Davis, R. Isaia, R. Nave \& T. Ricci (2008) Volcanic risk perception in the Vesuvius population. Journal of Volcanology and Geothermal Research, 172, 244258.

Barclay, J., K. Haynes, T. Mitchell, C. Solana, R. Teeuw, A. Darnell, H. S. Crosweller, P. Cole, D. Pyle \& C. Lowe (2008) Framing volcanic risk communication within disaster risk reduction: finding ways for the social and physical sciences to work together. Geological Society, London, Special Publications, 305, 163-177.

Becker, J. S., D. Paton, D. M. Johnston, K. R. Ronan \& J. McClure (2017) The role of prior experience in informing and motivating earthquake preparedness. International journal of disaster risk reduction, 22, 179-193.

Bird, D. K., G. Gísladóttir \& D. Dominey-Howes (2009) Resident perception of volcanic hazards and evacuation procedures. Natural Hazards and Earth System Sciences, 9, 251-266.

Bowman, L. \& P. White (2012) 'Community' perceptions of a disaster risk reduction intervention at Santa Ana (Ilamatepec) Volcano, El Salvador. Environmental HazardsHuman and Policy Dimensions, 11, 138-154.

Bowman, L. J. \& K. B. Henquinet (2015) Disaster risk reduction and resettlement efforts at San Vicente (Chichontepec) Volcano, El Salvador: toward understanding social and geophysical vulnerability. Journal of Applied Volcanology, 4, 1-18.

Burton, I. 1993. The environment as hazard. The Guilford Press.

Chakraborty, J., G. A. Tobin \& B. E. Montz (2005) Population evacuation: assessing spatial variability in geophysical risk and social vulnerability to natural hazards. Natural Hazards Review, 6, 23.

Chester, D. K. 1993. Volcanoes and society. E. Arnold.

Chester, D. K., C. J. Dibben \& A. M. Duncan (2002) Volcanic hazard assessment in western Europe. Journal of Volcanology and Geothermal Research, 115, 411-435.

Dake, K. \& A. Wildavsky. 1991. Individual differences in risk perception and risk-taking preferences. In The analysis, communication, and perception of risk, 15-24. Springer.

Dash, N. \& H. Gladwin (2007) Evacuation decision making and behavioral responses: Individual and household. Natural Hazards Review, 8, 69-77.

De la Cruz-Reyna, S. \& R. I. Tilling (2008) Scientific and public responses to the ongoing volcanic crisis at Popocatépetl Volcano, Mexico: Importance of an effective hazards-warning system. Journal of Volcanology and Geothermal Research, 170, 121134.

Dibben, C. \& D. K. Chester (1999) Human vulnerability in volcanic environments: the case of Furnas, São Miguel, Azores. Journal of Volcanology and Geothermal Research, 92, 133-150.

Dillman, D. A. 2011. Mail and Internet surveys: The tailored design method--2007 Update with new Internet, visual, and mixed-mode guide. John Wiley \& Sons. 
Dominey-Howes, D. \& D. Minos-Minopoulos (2004) Perceptions of hazard and risk on Santorini. Journal of Volcanology and Geothermal Research, 137, 285-310.

Dow, K. \& S. L. Cutter (1998) Crying wolf: Repeat responses to hurricane evacuation orders.

Eiser, J. R., A. Bostrom, I. Burton, D. M. Johnston, J. McClure, D. Paton, J. Van Der Pligt \& M. P. White (2012) Risk interpretation and action: A conceptual framework for responses to natural hazards. International Journal of Disaster Risk Reduction, 1, 5-16.

Fischer, H. W., G. F. Stine, B. L. Stoker, M. L. Trowbridge \& E. M. Drain (1995) Evacuation behaviour: why do some evacuate, while others do not? A case study of the Ephrata, Pennsylvania (USA) evacuation. Disaster prevention and management: an international journal, 4, 30-36.

Fowler, F. J. 2011. Reducing Interviewer-Related Error Through Interviewer Training, Supervision, and Other Means. In Measurement Errors in Surveys, eds. P. P. Biemer, R. M. Groves, L. E. Lyberg, N. A. Mathiowetz \& S. Sudman. Hoboken, NJ: John Wiley \& Sons.

Gaillard, J.-C. (2008) Alternative paradigms of volcanic risk perception: The case of Mt. Pinatubo in the Philippines. Journal of Volcanology and Geothermal Research, 172, 315-328.

Gaillard, J.-C. \& C. J. Dibben (2008) Volcanic risk perception and beyond. Journal of Volcanology and Geothermal Research, 172, 163-169.

Gavilanes-Ruiz, J. C., A. Cuevas-Muñiz, N. Varley, G. Gwynne, J. Stevenson, R. Saucedo-Girón, A. Pérez-Pérez, M. Aboukhalil \& A. Cortés-Cortés (2009) Exploring the factors that influence the perception of risk: The case of Volcan de Colima, Mexico. Journal of Volcanology and Geothermal Research, 186, 238-252.

Groves, R. M., F. Fowler Jr, M. Couper, J. Lepkowski, E. Singer \& R. Tourangeau (2009) Survey methodology (2nd). Hoboken: John Wiley and Sons, 97-98.

Haynes, K., J. Barclay \& N. Pidgeon (2008a) The issue of trust and its influence on risk communication during a volcanic crisis. Bulletin of Volcanology, 70, 605-621.

Haynes, K., J. Barclay \& N. Pidgeon (2008b) Whose reality counts? Factors affecting the perception of volcanic risk. Journal of Volcanology and Geothermal Research, 172, 259-272.

Huang, S.-K., M. K. Lindell \& C. S. Prater (2016) Who leaves and who stays? A review and statistical meta-analysis of hurricane evacuation studies. Environment and Behavior, 48, 991-1029.

INE, I. N. d. E. G. 2003. Censo nacionales XI de población y VI de habitación 2002. In Instituto Nacional de Estadística.

Kasperson, J. X., R. E. Kasperson, N. Pidgeon \& P. Slovic (2003) The social amplification of risk: Assessing fifteen years of research and theory. The social amplification of risk, 1.

Kasperson, R. (1992) The Social Amplification of Risk: Progress in Developing an Integrative Framework, Krimsky, S. and Golding.

Laksono, P. M. (1988) Perception of volcanic hazards: villagers versus government officials in Central Java. The real and imagined role of culture in development: case studies from Indonesia. University of Hawaii Press, Honolulu, 183-200. 
Lane, L. R., G. A. Tobin \& L. M. Whiteford (2003) Volcanic hazard or economic destitution: hard choices in Baños, Ecuador. Global Environmental Change Part B: Environmental Hazards, 5, 23-34.

Lavigne, F., B. De Coster, N. Juvin, F. Flohic, J.-C. Gaillard, P. Texier, J. Morin \& J. Sartohadi (2008) People's behaviour in the face of volcanic hazards: Perspectives from Javanese communities, Indonesia. Journal of Volcanology and Geothermal Research, $172,273-287$.

Lazo, J. K., A. Bostrom, R. E. Morss, J. L. Demuth \& H. Lazrus (2015) Factors affecting hurricane evacuation intentions. Risk analysis, 35, 1837-1857.

Lindell, M. K. \& S. N. Hwang (2008) Households' perceived personal risk and responses in a multihazard environment. Risk Analysis, 28, 539-556.

Lindell, M. K., J.-C. Lu \& C. S. Prater (2005) Household decision making and evacuation in response to Hurricane Lili. Natural Hazards Review, 6, 171-179.

Lindell, M. K. \& R. W. Perry. 1993. Risk area residents' changing perceptions of volcano hazard at Mt. St. Helens. In Prediction and perception of natural hazards, 159-166. Springer.

Lindell, M. K. \& R. W. Perry (2012) The protective action decision model: theoretical modifications and additional evidence. Risk Analysis, 32, 616-632.

Macías, J. M. 2005. La disputa por el riesgo en el volcán Popocatépetl. CIESAS.

Macías, J. M. \& B. E. Aguirre (2006) A critical evaluation of the united nations volcanic emergency management system: Evidence from Latin America. Journal of International Affairs, 43-61.

Montz, B. E., G. A. Tobin \& R. R. Hagelman. 2017. Natural hazards: Explanation and integration. Guilford Publications.

Morss, R. E., J. L. Demuth, J. K. Lazo, K. Dickinson, H. Lazrus \& B. H. Morrow (2016) Understanding public hurricane evacuation decisions and responses to forecast and warning messages. Weather and Forecasting, 31, 395-417.

O'Keefe, P., K. Westgate \& B. Wisner. 1976. Taking the Naturalness Out of Natural Disaster. In Enviromental Risks and Hazards, ed. S. Cutter, 94-96. New Jersey: Prentice Hall.

Paton, D. (2008) Risk communication and natural hazard mitigation: how trust influences its effectiveness. International Journal of Global Environmental Issues, 8, 2-16.

Perry, R. W. (1979) Evacuation decision-making in natural disasters. Mass Emergencies, 4, 25-38.

Perry, R. W. \& M. K. Lindell (2008) Volcanic risk perception and adjustment in a multihazard environment. Journal of Volcanology and Geothermal Research, 172, 170-178.

Pidgeon, N., C. Hood, D. Jones, B. Turner \& R. Gibson (1992) Risk perception. Risk: analysis, perception and management, 89-134.

Riad, J. K., F. H. Norris \& R. B. Ruback (1999) Predicting evacuation in two major disasters: Risk perception, social influence, and access to resources. Journal of Applied Social Psychology, 29, 918-934.

Slovic, P. (1987) Perception of risk. Science, 236, 280-285.

Slovic, P. (2006) Informing and educating the public about risk. Risk analysis, 6, 403415.

Slovic, P. E. 2000. The perception of risk. Earthscan Publications. 
Stephens, N. M., M. G. Hamedani, H. R. Markus, H. B. Bergsieker \& L. Eloul (2009) Why did they "choose" to stay? Perspectives of Hurricane Katrina observers and survivors. Psychological Science, 20, 878-886.

To_Waninara, C. (2000) The 1994 Rabual volcanic eruption: human sector impacts on the Tolai displaced communities. Melanesian Research Institute, Goroka.

Tobin, G. A. \& L. M. Whiteford (2002a) Community resilience and volcano hazard: the eruption of Tungurahua and evacuation of the faldas in Ecuador. Disasters, 26, 28-48.

Tobin, G. A. \& L. M. Whiteford. 2002b. Economic ramifications of disaster: experiences of displaced persons on the slopes of Mount Tungurahua, Ecuador. 316-324. [np]; 1998.

Tobin, G. A., L. M. Whiteford, E. C. Jones, A. D. Murphy, S. J. Garren \& C. V. Padros (2011) The role of individual well-being in risk perception and evacuation for chronic vs. acute natural hazards in Mexico. Applied Geography, 31, 700-711.

Usamah, M. \& K. Haynes (2011) An examination of the resettlement program at Mayon Volcano: what can we learn for sustainable volcanic risk reduction? Bulletin of Volcanology, 74, 839-859.

Wildavsky, A. \& K. Dake (1990) Theories of risk perception: Who fears what and why? Daedalus, 41-60.

Wisner, B., P. Blaikie, T. Cannon \& I. Davis. 2004. At risk: natural hazards, people's vulnerability and disasters. Psychology Press.

Wynne, B. (1992) Risk and social learning: reification to engagement. 


\section{Chapter 4: An experiment using high-rate GPS (HRGPS) to monitor inflation and deflation at Santiaguito volcano, Guatemala}

\subsection{Introduction}

Monitoring natural deformation and surface displacement is an important process in forecasting the onset of explosive eruptions, which is one of the primary goals in the field of volcanology. As volcanic unrest is often preceded by increased seismicity and ground deformation these processes present the opportunity to identify patterns of activity that can aid in the interpretation, understanding and prediction of volcanic eruptions. Episodes of surface displacement in volcanic settings are often related to magmatic fluid displacements and indicate possible precursors of eruptive activity (Mattia et al. 2008). The surface deformation from this activity can be continuous and quite rapid before, during, and after eruptive events. Serious volcano monitoring requires adequate instrumentation and geodetic observations to monitor short-term or rapid changes in the signal to provide timely insight into magma movement and eruptions. GPS as a monitoring tool can precisely constrain timing of deformation and eruptive events that is not always possible with other geodetic data.

The experiment discussed in this chapter was conceived in an effort to investigate the feasibility and efficacy of using high-rate GPS to monitor inflation and deflation associated with explosive eruptions at Santiaguito volcano in Guatemala Therefore, during my attendance at the "Workshop on Volcanoes 2016" that took place in January, 2016 in Quetzaltenango, Guatemala we decided to deploy our two available geodetic instruments on to the volcano. We installed two GPS receivers within $\sim 600 \mathrm{~m}$ and 2000 $\mathrm{m}$ from the active Caliente vent and started monitoring at approximately 02:30 UTM. Data was recorded continuously using a $1 \mathrm{~Hz}$ sample rate for roughly 34 hours. The goal was to analyze data and assess if any visible deformation above the range of GPS noise levels and allow us to track and better understand rapid volcano dynamics, and transient changes in morphology prior to an eruption at Santiaguito. If this method proves suitable it could be used to enhance the monitoring capabilities at volcanoes and volcano observatories in Guatemala as it would provide a first order observation of magma migration and eruption potential.

Until recently, GPS in geophysical applications was often done through the comparison of static position estimates taken before and after a geophysical event, usually on the order of days, weeks months and sometimes years. Through the years continuous, static GPS observations have been one of the most common and precise data logging strategies. These static positions are estimated by averaging the observations usually sampled at every 30 -second epoch. In this way, the use of GPS in the field of volcanology has proven to be a robust monitoring tool (Dzurisin 2006). GPS, often coupled with other 
monitoring instrumentation, can help constrain the timing of eruptions, provide threedimensional positions estimates related to surface deformation, and can complement other geodetic data sets (Larson et al. 2010a). Many GPS geodetic studies at volcanoes have employed a 24-hour daily position average (Cervelli et al. 2006, Dzurisin et al. 2017, Lagios et al. 2018), which is an adequate technique when the deformation rates are fairly slow (e.g. several mm/day). Daily position estimates notwithstanding, sub-daily and hourly solutions have also been used to examine large deformation signals associated with magma and dike intrusion (Owen et al. 2000, Segall et al. 2001, Grapenthin et al. 2013, Lechner et al. 2018) and inter-eruptive behavior at volcanoes. These studies have typically utilized Precise Point Positioning (PPP) strategies when post processing the GPS data. Kinematic GPS on the other hand, can provide instantaneous GPS positioning, and can be used to monitor rapid deformations occurring on the order of seconds to hours at a receiver, however, often with worse precision than static positions estimates.

There have been a number of investigations (Bock et al. 2000, Choi et al. 2004b, Bilich 2006) that demonstrate epoch-by-epoch positioning as a valuable alternative to the traditional GPS batch processing (commonly used in static, or campaign GPS) that allows for examination and manipulation of the error sources. Such techniques that monitor deformation at a high-rate must consider two important factors to determine a reliable position. The first being single epoch ambiguity resolution, and second multipath error. Multipath error is a consequence of the reflection of the GPS signal from nearby surfaces and is commonly one of the most limiting factors in precise GPS positioning (Ragheb et al. 2009).

There are two basic approaches to estimate precise positions from GPS data: 1) Precise Point Positioning (PPP) and 2) network (or relative) positioning. Both methods estimate positions with respect to an Earth Centered Earth Fixed terrestrial reference frame. Relative positioning (also referred to as differential GPS or just dGPS) uses data from a network of stations which are analyzed simultaneously to estimate positions and integer ambiguities (Bock et al. 2011). The underlying premise of dGPS requires that one GPS receiver function as a base station that is deployed at a precisely known position while the position of the other receiver (rover) is determine relative to the base station (Hofmann-Wellenhof et al. 2012). The principle of dGPS allows for the elimination and reduction of multiple sources of error over short baselines and yields a more precise relative position estimate. This methodology takes advantage of the fact that many similar atmospheric error sources which may bias receiver-satellite range measurements are spatially correlated and can be easily cancelled out (Bock et al. 2011, Martin 2013). Precise Point Positioning, on the other hand, is an optimal approach for post processing and estimating terrestrial positions for a single receiver as it relies on error correction and modelling instead of error cancellation. PPP incorporates single-receiver, phase ambiguity resolution (Bertiger et al. 2010) and precise clock and orbit determinations (Zumberge et al. 1997), which can achieve centimeter level, or better, position accuracy when the full precision of the carrier-phase observations are achieved. 
Ground deformation studies using HRGPS have been developed and improved over the last decade and various applications have been successful in detecting time-dependent surface displacements with periods longer than $1 \mathrm{~s}$ and amplitudes greater than $\sim 2-3 \mathrm{~mm}$ and $\sim 40 \mathrm{~mm}$ (horizontal and vertical respectively) caused by remote $(\leq 3900 \mathrm{~km})$ earthquakes (Bock et al. 2000, Larson et al. 2003, Bock et al. 2004). When considering the advancements in accuracy, precision and ease of processing, the application of HRGPS to volcano geodesy offers unique opportunity to track and monitor volcano deformation and enhance eruption forecasting (Dzurisin 2000).

Some research using HRGPS has already been done at volcanoes. At Stromboli, Mattia et al. (2004) sampled data using a $1 \mathrm{~Hz}$ rate but averaged down to 10 minute position estimates, likely to reduce noise and achieved $5 \mathrm{~mm}$ horizontal to $25 \mathrm{~mm}$ vertical precision over $25 \mathrm{~km}$ baselines. Patane et al. (2007) also estimated positions at Stromboli from $1 \mathrm{~Hz}$ data but used a passband filter at 2-5 minutes to investigate the plumbing system. Cannavò et al. (2015) examined near real time deformation from $1 \mathrm{~Hz}$ GPS data at Etna and used an Interquartile Range filter to remove large outliers followed by a multipath filter to reduce noise. While HRGPS is well suited to volcano geodesy applications and its use is gaining momentum, few if any research has been conducted that uses a campaign style data acquisition strategy with a high sampling rate in close proximity to an actively erupting volcanic dome.

\subsection{Geologic setting}

The Santiaguito dacitic dome complex (Figure 4.1) in Guatemala, provides unparalleled opportunities for observations and monitoring short-term eruption dynamics (Bluth and Rose 2004, Johnson et al. 2008). Santiaguito is part of the Central American volcanic arc in southwestern Guatemala (Figure 4.2). The volcanic arc runs roughly parallel to the convergent boundary where the Cocos Plate subducts under the Caribbean plate. The volcano is part of a complex that trends roughly east to west and is located in the 1902 eruption crater of its parent volcano, Santa Maria and has been continuously active for ca. 90 years. The currently active "partially open-vent," Caliente dome has been producing episodic, low-intensity, ash-rich explosions with low altitude columns reaching $\sim 0.5-2$ $\mathrm{km}$; extrusive lava flows; persistent degassing, small pyroclastic flows; rock falls and lahars since the 1970's. While activity has varied over the last several decades, its present activity is characterized by blocky lava extrusions and explosive eruptions of pyroclastic material. Occasionally, the collapse of lava flow-fronts or vertical ash eruptions generate small pyroclastic flows down the SW flank. The explosive eruptions typically occur at intervals of 5 minutes to 3.5 hours and are a common feature and have been observed regularly for over 40 years (Rose 1987). The eruptive bursts usually last for 1-5 minutes and produce ultra-long period seismic signals for up to 15 minutes, which seems to suggest incremental plug flow within the conduit (Bluth and Rose 2004, Sanderson et al. 2010). 
Volcanoes of intermediate composition such as Santiaguito are responsible for some of the most explosive and hazardous eruptions: Soufriere Hills, Mount Saint Helens, and Pinatubo (Holland et al. 2011). These volcanoes can extrude lava for long periods of time, while simultaneously exhibiting short-term variations - days or hours - in flux, stagnancy, and explosivity (Johnson et al. 2008), thus complicating monitoring and forecasting. Understanding the short-term variations at these volcanoes is typically accomplished through theoretical modeling to account for the shallow magma storage and ascent dynamics, however, field corroboration is often needed but lacking (Johnson et al. 2008). Furthermore, understanding the long-term behavior and associated hazards at dome systems of intermediate volcanoes requires an understanding of the deeper magma storage and ascent paths, however, considering Santiaguito's $\sim 90$ year of activity, little is known about the internal structure at depth (Scott et al. 2012).

Current understanding about the deep magmatic structure and pathways at Santiaguito are based on petrologic analysis of amphilole and plagioclase phenocrysts by Scott et al. (2012). This study suggests a deep storage zone between $24-12 \mathrm{~km}$ beneath the surface and infers that the final phases of magma ascent from depth occur relatively rapidly ( $\sim 27-$ $84 \mathrm{~m} / \mathrm{h}$ ), and while there is some understanding about the deep, internal dynamics more research is needed. However, there are two competing models related to the very shallow process and eruption dynamics at Santiaguito. The first is based primarily on seismic, geodetic and visual observations (Johnson et al. 2008, Sanderson et al. 2010, Johnson et al. 2014), while the second was developed from SO2 emissions data (Holland et al. 2011). Overall, both models suggest a trend of pre-eruptive, eruptive, and inter-eruptive cycles accompanied by periods of inflation and deflation. 


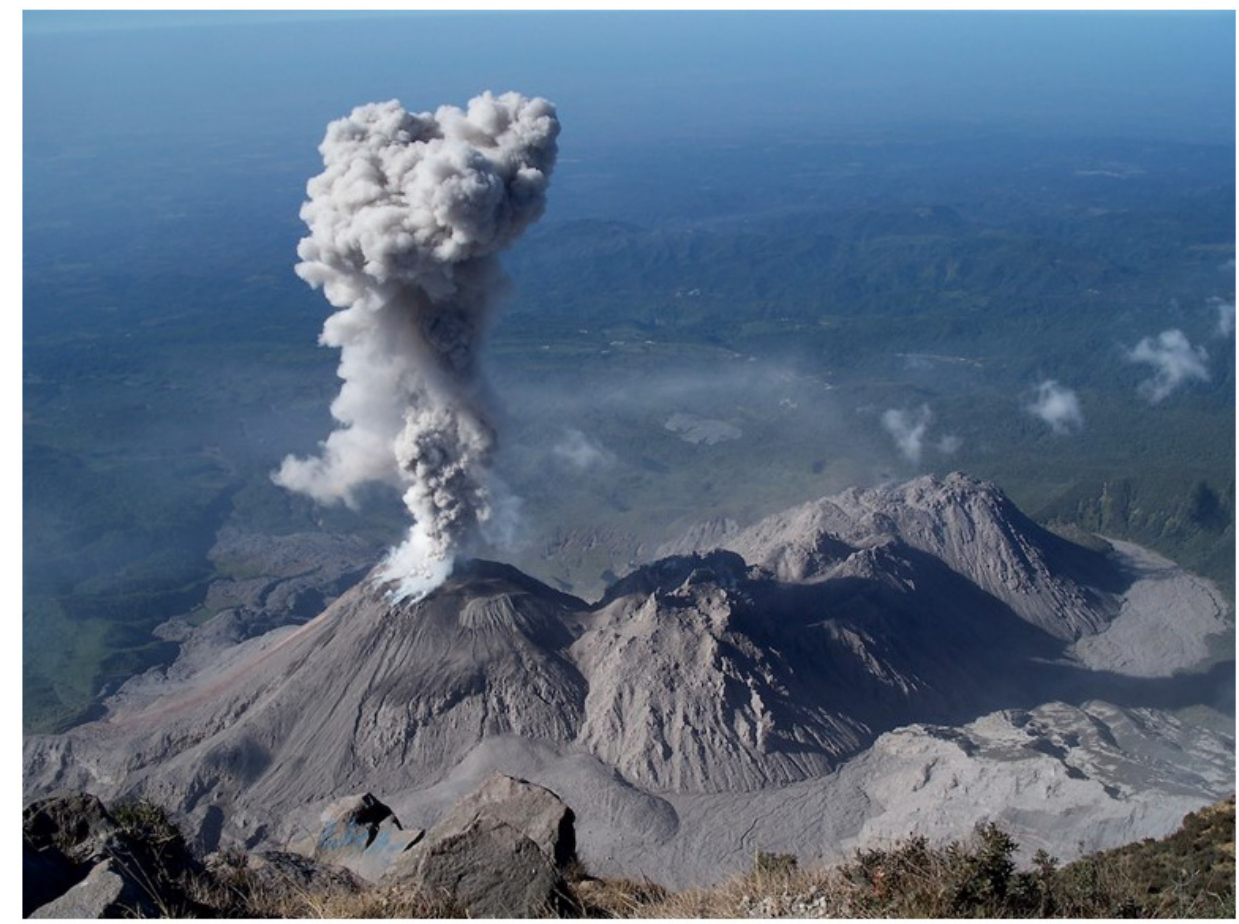

Figure 4.1 Santiaguito with eruption column from the Caliente dome as seen from the summit of Santa Maria. Photo by Jeff Johnson.

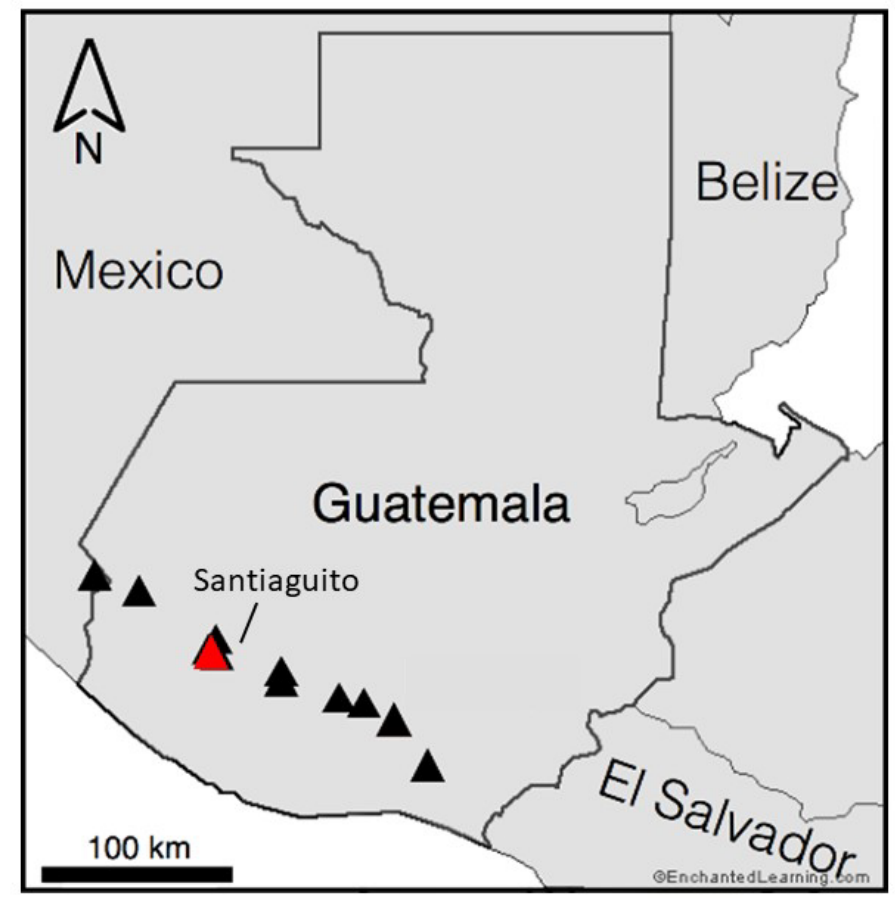

Figure 4.2 Map of Guatemala and location of Santiaguito (red) relative to the portion of the Central American Volcanic Arc. 
Using a combination of optical geodetic and seismic observations, Johnson et al. (2008) reports $20-50 \mathrm{~cm}$ of subvertical displacement at the top of the Caliente dome corresponding with the explosive eruptions. This study also observed long-period earthquakes that produced 7.5-23.5 $\mu \mathrm{m}$ of displacement at a station $1 \mathrm{~km}$ from the vent. The model introduced by Johnson et al. (2008), and augmented by Sanderson et al. (2010), and Johnson et al. (2014) interprets data collected by seismic, tilt and visual observations to explain the frequent explosions as a steady accumulation of gas beneath a viscoelastic dome. As the pressure builds in the subsurface it eventually exceeds the shear strength of the boundary between the plug and the wall rock, thus inducing motion of the plug and allowing for rapid depressurization and explosive degassing. Using 3 broadband seismometers, Sanderson et al. (2010) observed ultra-long-period events (2-5 minutes) and recorded $0.3 \mu \mathrm{r}$ to $4.3 \mu \mathrm{r}$ of deformation at a station $1.1 \mathrm{~km}$ from the vent. The deflation occurs during the co-eruptive period, lasting several minutes and is coincident with the onset of the eruption. The model postulates that during the explosions pressure is released allowing the surface of the dome to collapse, closing the gas pathways and resetting the cycle for the next eruption. Re-inflation occurs much slower during the inter-eruptive period over the next tens of minutes to several hours and is below the detection threshold of the broadband instruments. A Mogi model (Mogi 1958) based on these data (Sanderson et al. 2010) places a small, 75-100 m wide x $50 \mathrm{~m}$ thick, source at roughly $200 \mathrm{~m} \mathrm{WNW}$ of the Caliente vent at depth of 250-300 m below the surface. This source location is coincident with the 1929 crater position.

The model presented by Holland et al. (2011) also interprets the deformation and explosions as a function of pressurization of a shallow, $\sim 250 \mathrm{~m}$ deep, source, however their model diverges from the previous plug-flow model by suggesting a model that is a by-product of a predominately extrusive eruption. In their model, stress builds up in the conduit marginal region during flow of a viscous, crystal rich magma. This in turn leads to shear fracturing generating small cracks. As pressure builds, gas and ash fill the cracks preventing them from closing. This process repeats until the fractures reach the surface thus causing rapid pressure changes and explosive expansion. After the evacuation of the gas and ash, new magma rises to fill the void and the process repeats.

Whether the explosions are the result of the plug-flow model or the shear-fracturing model, the observations of deformation are fairly consistent with a rising melt that feeds and pressurizes a gas reservoir and facilitates inflation/deflation cycles associated with eruptions. If the occurrence of explosive eruptions is strongly influenced by inflation at Santiaguito it is likely that this would be the case at other volcanoes as well. This then introduces the prospect for using near-field, long-period transient deformation as an indicator of impending explosive eruptions. Given the frequency and regularity of explosive eruptions, Santiaguito is considered one of the most reliable, active dacitic domes for volcanological research. 


\subsection{Methodology}

On January 7, 2016, we installed GPS antenna and receivers at two locations near the active Caliente dome of Santiaguito volcano. One station designated SMRA was deployed near the summit of the old Santa Maria volcano roughly $2 \mathrm{~km}$ from the dome, while the second station designated CLNT was installed roughly $500 \mathrm{~m}$ from the active dome (Figure 4.3). At both stations we used a 24-channel, dual frequency Trimble 5700 receivers and Trimble Zephyr Geodetic choke ring antennas. The base station antenna, SMRA, on the summit of Santa Maria was leveled on three-point, fixed-height, spikemount tripod, while the rover antenna, CLNT, was installed on a four-point, fixed height, spike-mount tripod. Receivers were set with a $10^{\circ}$ Elevation Mask and a PDOP mask of 15. Data were collected using a $1 \mathrm{~Hz}$ sample rate starting from January $7^{\text {th }}$ at $8: 38 \mathrm{PM}$ local time and continued until 8:33 AM, local time, January $9^{\text {th }} 2016$.



Figure 4.3 The two GPS locations used in this study. Station CLNT is in the 1902 crater and surrounded on all sides by steep topography. 
Considering the previously observed maximum deformation of 20-50 $\mathrm{cm}$ of displacement at the dome and $4.3 \mu \mathrm{r}$ in the far-field $\sim 1 \mathrm{~km}$ (Sanderson et al. 2010), and according to Dzurisin (2000) $1 \mu \mathrm{r}$ displacement at $1 \mathrm{~km}$ is roughly equivalent to $1 \mathrm{~mm}$ vertical displacement it seems reasonable to assume that ultra-long period deformation closer to the source, at the GPS station should be observable as well. To further test this assumption we developed a Mogi model using the depth, volume and radial distance parameters discussed in Sanderson et al. (2010) for a point roughly 300 meters from the hypothesized source (Figure 4.4). Based on this model we should be able to observe up to $\sim 1.6 \mathrm{~mm}$ and $1.9 \mathrm{~mm}$ displacement radial and vertical (respectively).


Figure 4.4 Mogi model of displacement at 300 meters from the hypothesized source. Top figure (a) shows radial displacement and bottom figure (b) shows vertical displacement. 


\subsubsection{Data processing}

The experiment was designed for post-processing relative positions using commercially available software following the principal of differential GPS (dGPS) after Lechner et al. (2013). However, we discovered that processing software was far too expensive for the scope of this experiment; we therefore, utilized two different processing strategies Precise Point Positioning and relative positioning. We used three different processing programs in an effort to compare and assess the most precise and repeatable position estimates. To obtain the PPP solutions we used GIPSY-OASIS software provided by the Jet Propulsion Laboratory's (JPL) web-based Automatic Precise Positioning Service (APPS) and the online software package GPSPACE provided by the Geodetic Survey of Natural Resources Canada as part of the Canadian Spatial Reference System (CSRS-PPP). To evaluate the relative positions using differential GPS we used GAMIT/GLOBK/TRACK the software package developed at the Massachusetts Institute of Technology. The GPS data was provided in RINEX format for the two online processing services and also for the TRACK software for the dGPS solution. The two processing methodologies are based on two different approaches in reducing the raw phase data: in the PPP approach, the kinematic station only needs fiducial, high-rate satellite orbits and clock information while the differential approach used by TRACK performs relative kinematic positioning requiring a reference station assumed to be fixed in the time interval affected by the dynamic displacements (Avallone et al. 2012, Avallone et al. 2016).

We began our initial data processing using APPS. This service is a GIPSY, version 5, based processing software requiring GPS RINEX files and provides a rapid turnaround at no cost to the user. Furthermore, the APPS software is optimized for kinematic processing and provides a time series of coordinate position estimates at a rate equal to or slower than the measurement rate. While APPS is easy to use it only reports the position estimate to the nearest decimeter in geographic coordinates, while ECEF coordinates are reported at a fraction of a millimeter. Therefore using APPS for our purposes required manual conversion of ECEF XYZ coordinates to geographic coordinates after data processing. We processed the data from both station SMRA and CLNT using the APPS online service. We then converted the XYZ position and standard deviation estimates from ECEF to geographic and produced a time series for each directional component at both stations.

Our second effort at PPP positioning was done using CSRS-PPP. With this service, initial position coordinates are extracted from the RINEX file header during processing and are used to compute all output position differences. Similar to the JPL APPS service, the CSRS-PPP is designed as a simple user interface requiring minimal input and rapid turnaround at no cost to the user and is optimized for kinematic processing. CSRS-PPP will provide a kinematic solution for each epoch for the submitted RINEX file. CSRS produces a three-dimensional, geographic coordinate estimates using the IGS absolute receiver and satellite antenna phase variations and tropospheric delay mapping and also includes cycle-slip filtering. Position estimates are based on the best orbit and clock 
products and GPS observations available at the time of submission. Results are computed for the exact epoch of observation for kinematic processing and highly dependent on the quality and content of the submitted observation files. We produced a time series for each station containing each directional component.

For kinematic mode the goal of online processing is to estimate positions using data from a single receiver, thus negating the need for an established reference stations. PPP positions from online sources are computed using combined data from analysis centers and the IGS global tracking network of roughly 300 continuously operating GNSS stations, sub-centimeter precision may difficult to achieve if the IGS stations are not within range of a few hundred kilometers (El-Mowafy 2011). The IGS CORS station nearest to Santiaguito is located at La Aurora International Airport in Guatemala City, more than $110 \mathrm{~km}$ away. Considering this fairly long baseline and the occasional poor behavior of station GUAT we also tried dGPS processing.

These data were ultimately processed using TRACK, which is developed as the kinematic module of the GAMIT-GLOBK software package to perform epoch-by-epoch position estimates and produce a $3 \mathrm{D}$ time series. TRACK uses floating point $\mathrm{L} 3$ observations between our two receiver stations, with ionoshperic constraints to determine integer ambiguities at each epoch. With our dGPS data we applied a sidereal filtering technique known as Instantaneous Position develop by Bock et al. (2000) and produced a time series for each directional component.

\subsection{Results and discussion}

We first processed data with JPL's Automatic Precise Positioning Service APPS. The data from station SMRA shows peak-to-peak variance between 16.65 to $63.19 \mathrm{~m}$ and $97.525 \mathrm{~m}$ in the horizontal and vertical components respectively with mean standard deviations between 1.351 to $2.739 \mathrm{~m}$ and $4.385 \mathrm{~m}$ horizontal and vertical respectively, and an RMS of 0.72 .6 to 1.3447 horizontal and $2.226 \mathrm{~m}$. vertical The $1 \mathrm{~Hz}$ data collected at CLNT show a peak-to-peak noise level between 39.954 to 45.757 horizontal and $69.028 \mathrm{~m}$ vertical with mean standard deviations of 3.928 to $5.005 \mathrm{~m}$ horizontal and 390 $\mathrm{mm}$ horizontal and vertical (Figure 4.5).

We then processed the data using the Canada's Natural Resources geodetic processing service CSRS-PPP (Figure 4.6). For the $1 \mathrm{~Hz}$ data collected at SMRA we see noise varies peak-to-peak between $0.266 \mathrm{~m}$ to $0.141 \mathrm{~m}$ in the horizontal and $0.573 \mathrm{~m}$ in the vertical. Mean standard deviations range between $0.0276 \mathrm{~m}$ to $0.0215 \mathrm{~m}$ in the horizontal and $0.0638 \mathrm{~m}$ vertical and an RMS of $0.011 \mathrm{~m}$ to $0.0482 \mathrm{~m}$ and $0.0467 \mathrm{~m}$ horizontal and vertical respectively. The $1 \mathrm{~Hz}$ data from CLNT and processed with CSRS-PPP shows peak-to-peak that varies between $0.41 \mathrm{~m}$ to $0.142 \mathrm{~m}$ horizontal and $0.618 \mathrm{~m}$ vertical with mean standard deviations between $0.016 \mathrm{~m}$ to $0.055 \mathrm{~m}$ horizontal and $0.07 \mathrm{~m}$ vertical and an RMS of $0.055 \mathrm{~m}$ to $0.016 \mathrm{~m}$ and $0.061 \mathrm{~m}$ horizontal and vertical respectively 
The data were then processed using TRACK the kinematic module of MIT's differential processing software GAMIT/GLOBk (Figure 4.7). We found that the peak-to-peak data variance ranges between $0.5 \mathrm{~m}$ to $1.7 \mathrm{~m}$ horizontal and $1.3 \mathrm{~m}$ vertical with mean standard deviations between $0.023 \mathrm{~m}$ to $0.042 \mathrm{~m}$ horizontal and $0.054 \mathrm{~m}$ vertical. The RMS values range between $0.08 \mathrm{~m}$ to $0.45 \mathrm{~m}$ and $0.185 \mathrm{~m}$ horizontal and vertical respectively. After initial processing with TRACK we then applied a modified version of instantaneous positioning (Bock et al. 2000) known as modified sidereal filtering (Choi et al. 2004a, Bilich 2006, Larson et al. 2007). This filtering method reduced the noise variance down to a peak-to-peak range between $0.171 \mathrm{~m}$ to $0.095 \mathrm{~m}$ in the horizontal components and $1.12 \mathrm{~m}$ in the vertical with an RMS between $0.0115 \mathrm{~m}$ to $0.019 \mathrm{~m}$ and $0.1898 \mathrm{~m}$ in the horizontal and vertical components (Figure 4.8).

After processing the data we focused much of our attention on the CSRS-PPP time series for station CLNT as this seemed to provide the best output with the least noise. We compared each directional component to very long period data from seismic stations SAB1 and SAB2 in an effort to identify any correlation between very long period (VLP) or ultra-long period (ULP) events that might correspond to any GPS signal (Figure 4.9). Ultimately, we wanted to investigate deformation associated with explosive eruptions, so we plotted eruptions that had been recorded as broadband explosions (many of which were also visually verified) over the GPS time series. The eruption catalogue that was recorded only overlaps our GPS time series for the $8^{\text {th }}$ of January. In both sets of figures that look at the GPS time series and the seismic data and eruption events we can see that the level of noise and/or error within the GPS signal obfuscates any possible deformation signal that might have occurred. We believe that the deformation signal was too small to be seen beyond the signal-to-noise ration with the GPS data. We therefore made an effort to understand the error sources and possible improvements for future endeavors in this field of research. 

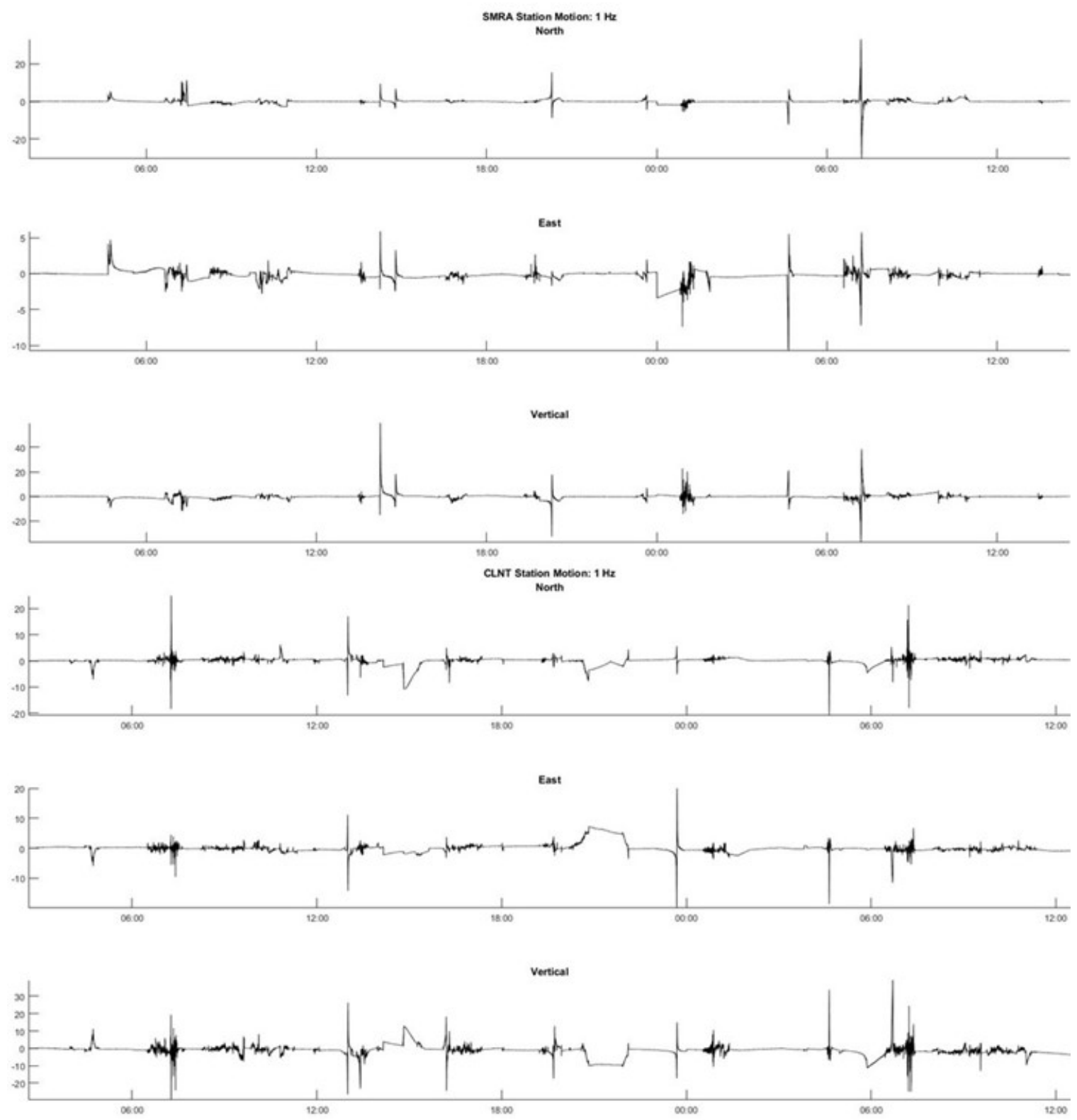

Figure 4.5 Time series from APPS processing results. Top figure (a) North, east and height components from site SMRA. Bottom figure (b) north, east and height components from site CLNT. 

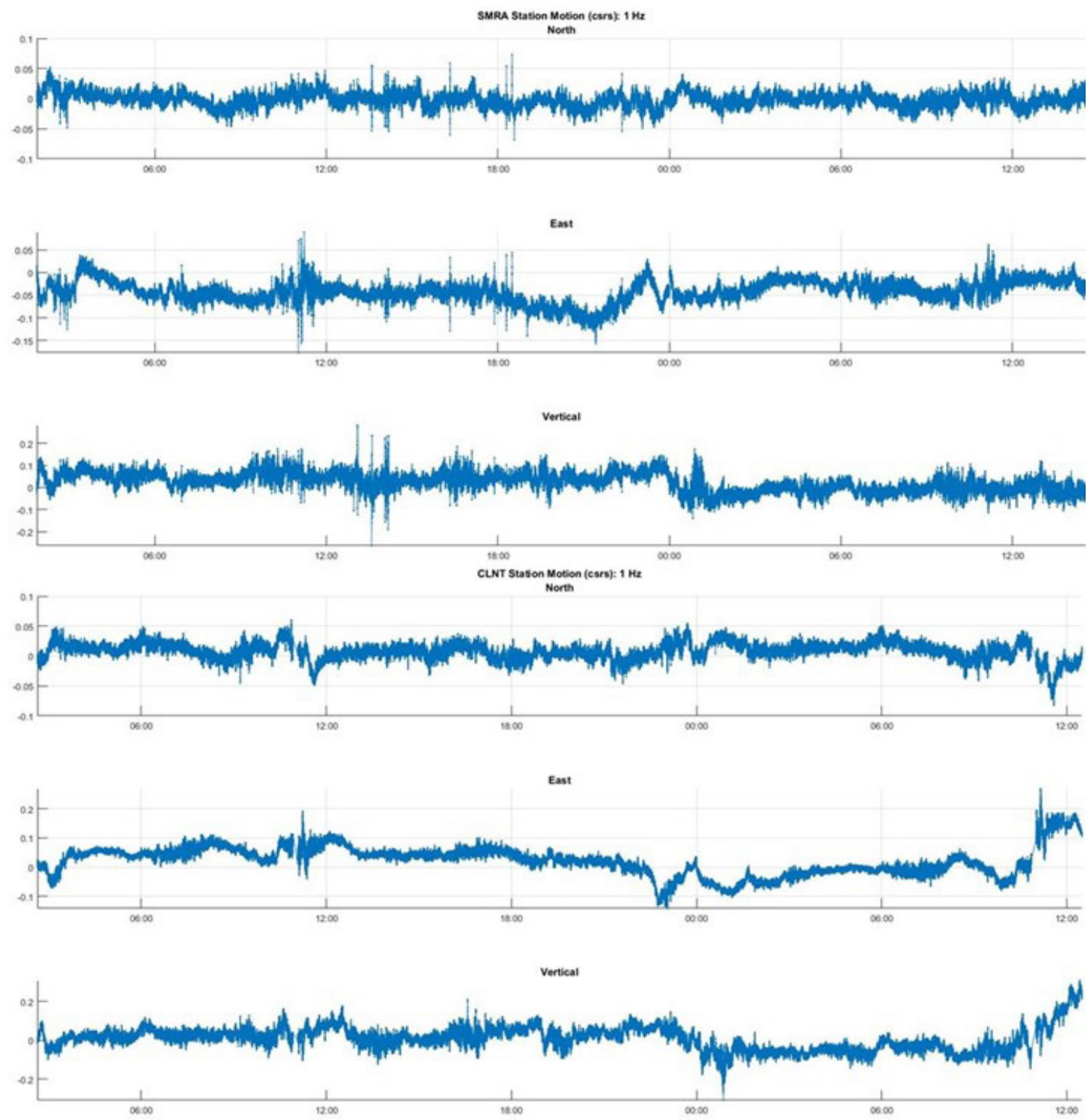

Figure 4.6 Time series from CSRS-PPP processing results. Top figure a) North, east and height components from site SMRA. Bottom figure b) north, east and height components from site CLNT. 

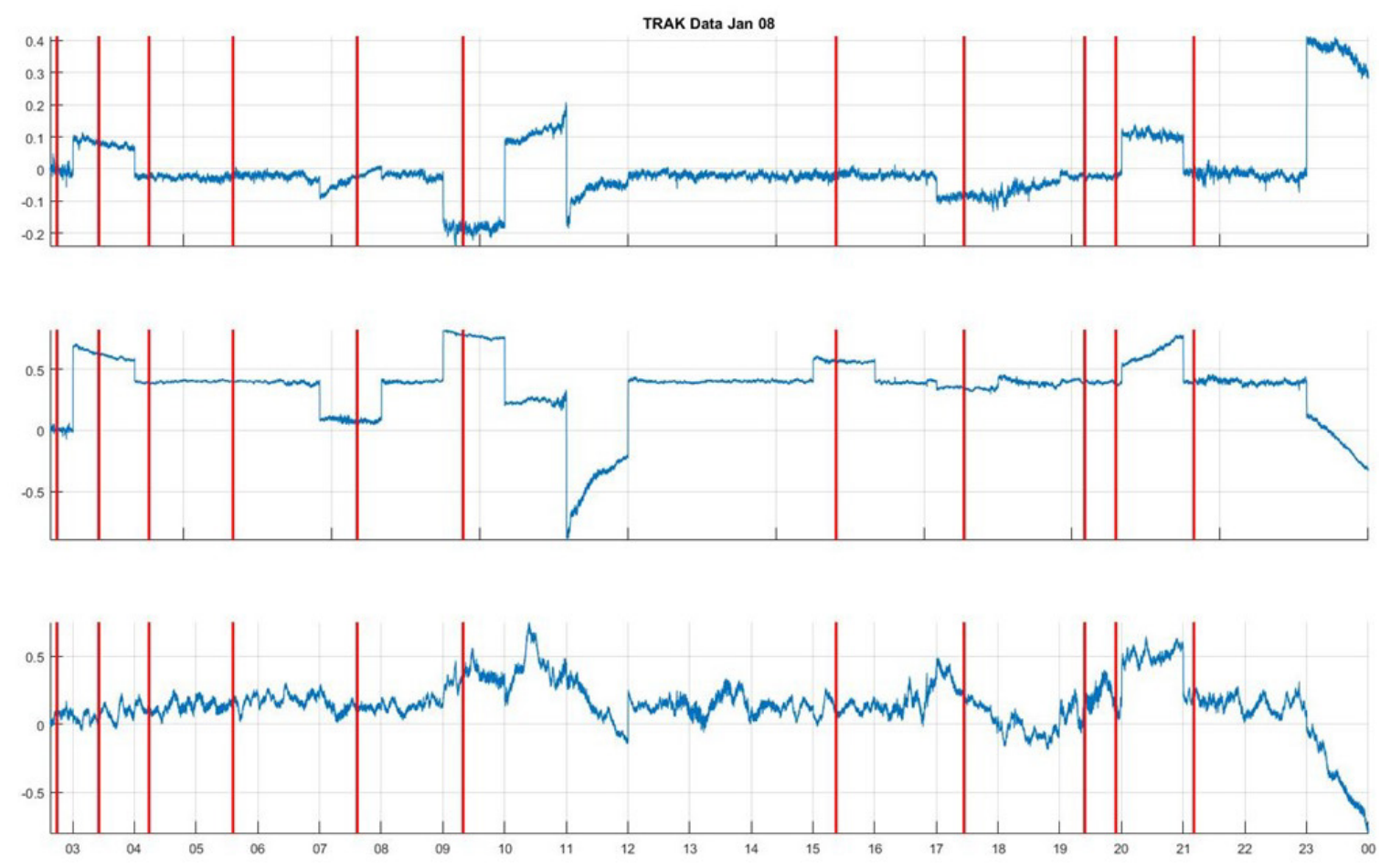

Figure 4.7 Time series from TRACK processing results. Top of figure shows north, middle shows east and bottom shows height components. 



Figure 4.8 Time series from modified sidereal filtering results. Top of figure shows north, middle shows east and bottom shows height components. 

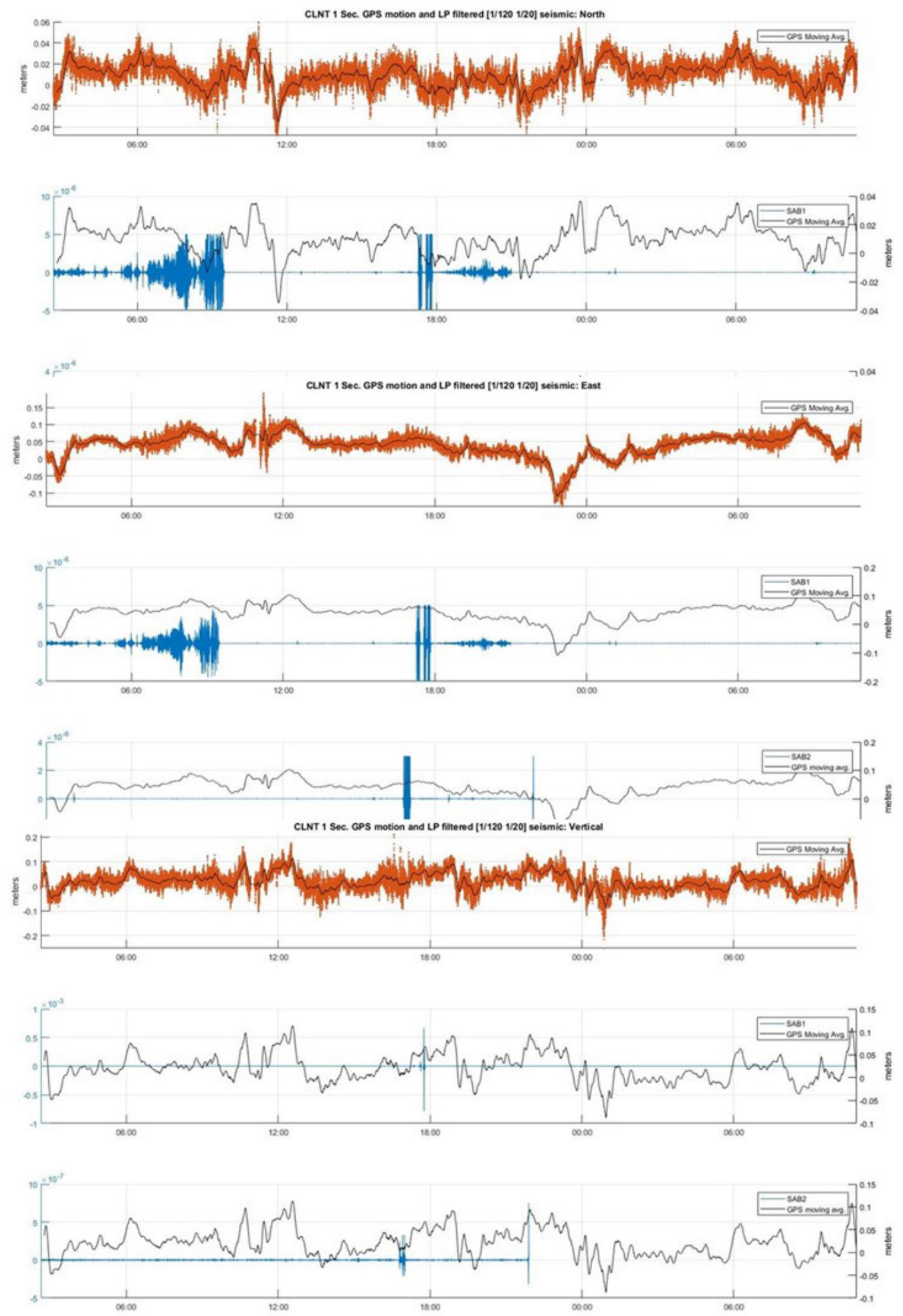

Figure 4.9 Time series from CSRS-PPP processing results with filtered seismic data. Top of figure shows north, middle shows east and bottom shows height components. 


\subsection{Probable sources of error}

Processed GPS positions contain systematic errors including multipath, unmodeled antenna phase center variations, errors in satellite orbit solutions, and random noise (Bilich 2006). When a single daily or sub-daily position is calculated stochastically using many position estimates from each data epoch many of these errors will average out. However, when calculating positions at a high rate for each data epoch the estimates are significantly influenced by these errors. Therefore, the key to improving the precision of HRGPS depends on removing or minimizing these errors.

While PPP can provide centimeter-level position accuracies with only a few epochs of 1 $\mathrm{Hz}$ data, it may require up to 20-90 minutes for initial convergence - the time period necessary for an estimated position to reach a given accuracy (Bock et al. 2011, Martin 2013). Achieving initial convergence is critical to achieving the most accurate position; however, it is also important that carrier-phase ambiguities remain fairly stable during the arc of each satellite. Each new satellite arc requires the estimation of a new carrier phase ambiguity. However, since all other parameters, including other satellite ambiguities are known, new ambiguities can rapidly be determine with only a few epochs of data. Frequent ambiguity resets (such as loosing lock on the L2 carrier-phase signal and eliminating the L1 and L2 iono-free combination) will greatly reduce the accuracy of PPP estimates.

During a GPS campaign if the signal is tracked and without the occurrence of a loss-oflock, than the integer ambiguities that are resolved at the start of the observation would be maintained for the duration of the entire kinematic campaign. However, the GPS satellite signals are occasionally blocked due to topography and satellite geometry, which will cause the loss of the integer ambiguity value and require a redetermination. This reinitialization process after these cycle-slips can take up to 20-90 minutes during which time the carrier-range data cannot be obtained and is therefore lost. These cycle slips are a discontinuity in a receivers continuous phase lock. They occur when the receiver phase tracking loop experiences a temporary loss of lock due to some signal interference or disruption. The most common cause is obstructions between the satellite and receiver. When this happens the cycle counter in the receiver resets causing a jump in the instantaneous accumulated phase by an integer number of cycles. Therefore, the ambiguities is once again unknown and the integer counter must re-initialize thus producing a change in the carrier phase observation. In a position estimate time series cycle slips may present themselves as spike or a jump. If these interruptions occur repeatedly, ambiguity re-initialization will create a substantial weakness to the data and position estimates (Rizos and Han 1998). While cycle slips can cause detrimental errors in position estimates over time, it has been demonstrated that ambiguity resolution (bias fixing) is relatively unimportant relative to systematic noise and can be reduced using a sidereal filter methodology (Bilich 2006). 
Many of the non-random noise sources are directly related to satellite-receiver geometry and will therefore repeat each day given identical relative positions of the satellitereceiver pair (Bilich 2006). Previous work by Bock et al. (2000) and Genrich and Bock (1992) have successfully reduced noise in 30 second position estimates after identifying the repetitive systematic position errors. As HRGPS data are severely affected by multipath noise, which can reach the same magnitude of co-seismic displacement it needs to be removed consistently. For this reason we attempted to apply a sidereal filter to perform a time and spatial filtering on our time series to improve the signal to noise ratio of the position estimates. The filter after Bock et al. (2000) and modified by Choi et al. (2004a) is designed to remove the effects of multipath and other noise by creating a three-day, sidereal time-varying average of positions and subtracting them from the position estimates from the fourth day.

To develop a sidereal filter, positions from two or more different days must be aligned relative to the GPS satellite-receiver geometry in an Earth-centered Earth-fixed reference frame. Satellite-receiver geometry is a function of the satellite orbital repeat periods. The GPS satellite periods were designed to repeat exactly half a sidereal day. Therefore, a GPS receiver will observe the same satellites in the exact same locations one sidereal day later (23 hours, 56 minutes and 4 seconds). However, other research has shown that satellite repeat periods are not entirely sidereal and slightly vary about 8 seconds shorter depending on the satellite (Choi et al. 2004a). Research done by Agnew and Larson (2007) show a mean period of GPS satellites at 246 seconds earlier each day. Therefore, in our modified sidereal filter we will use mean satellite repeat time of 23 hours 55 minutes and 56 seconds.

The process of the modified sidereal filter used in this study is as follows:

1. Analyze our two days of data (Jan. 8-9, 2016) and establish 3D station coordinates

2. Apply a low pass filter, 3 times the interquartile range (IQR) to remove large outliers

3. Establish the roughly 9 hours 56 minutes and 31 seconds of overlapping data

4. Apply the mean orbital repeat period as discussed above (02:38:02-12:33:31 UTC, Jan. 8 and 02:33:58-12:29:27 UTC, Jan. 9) resulting in a shift of 23 hours 55 minutes and 56 seconds.

5. Use the position estimates from the two days of data to generate the error profile. This is the modified sidereal filter.

6. Subtract the two-day modified sidereal filter from the January 8 position estimates.

We estimated the sidereal periodic noise in each coordinate direction as the weighted average of the daily time series for the two days of data after Bock et al. (2000) and Choi et al. (2004a). 


$$
\left(m p_{i}\right)=\sum_{k=d-1}^{k=d+1}\left[\frac{\left(x_{i}\right)_{k}}{\left(\sigma_{i}^{2}\right)_{k}}\right] / \sum_{k=d-1}^{k=d+1}\left[\frac{1}{\left(\sigma_{i}^{2}\right)_{k}}\right]
$$

Where $d$ denotes the sequential day number, $i$ denotes the epoch number within each day (e.g. $\mathrm{i}=1 \ldots, 76851$ ), and $x_{i}$ and $\sigma_{i}$ denote the coordinate estimates and their standard deviations, respectively. We than compute the filtered series by subtracting the sidereal periodic noise from the unfiltered position estimate time series:

$$
\left(x_{i}\right)_{d}^{f l t}=\left(x_{i}\right)_{d}-\left(m p_{i}\right)_{d}
$$

In longer data collection campaigns the number of days contributing to the modified sidereal filter can be varied, as can the orbital repeat period, and the degree of the low pass filter (i.e. the IQR filter). Unfortunately, considering our data set was less than two full days we were significantly limited in the parameters we were able to evaluate. Bilich (2006) has shown that multiday filtering can lead to a $10 \%-25 \%$ reduction of RMS scatter of position with the inclusion of additional days in sidereal filter. The purpose of applying the sidereal filter was to minimize noise in the GPS time series with the intention of visualizing and resolving short-period and low magnitude deformation. Unfortunately, our modified sidereal filter suggests several periods where large displacements are introduced to the data rather than removed. It is likely that these sources of error are not systematic and do not repeat between days thus violating the underlying principle of sidereal filtering. For this technique to be effective, error sources must be consistent between all days used in the data analysis (Bilich 2006).

The results from the modified sidereal filter show peak-to-peak noise between $0.095 \mathrm{~m}$ to $0.172 \mathrm{~m}$ and $1.12 \mathrm{~m}$ and RMS 0.0112 to 0.0189 and 0.2 in the horizontal and vertical components respectively. These results are a slight improvement when compared to the results output from TRACK alone and are comparable or slightly worse than the results from CSRS-PPP. Based on these poor results we do not use the time series produced from the multipath filter.

The main sources of error in GPS positioning are related to orbital position determination, satellite clock, ionosphere, troposphere, receiver clock, multipath and receiver noise, and human error. In GPS terminology Dilution of Precision (DOP) relates to the configuration of satellite geometry and is a function of the number of visible satellites in a direct line-of-site to the receiver (Langley 1999). Position Dilution of Precision (PDOP respectively) is refers to the accuracy of a GPS position determination. A PDOP value can be interpreted as the reciprocal to the volume $V$ of a body created by the intersection points of the site-satellite vectors with the unit sphere centered at the observing receiver (Hofmann-Wellenhof et al. 2012). At a minimum this body is a tetrahedron that is formed from the intersection points of four satellites and user positions $(\mathrm{PDOP}=1 / V)$. A high PDOP indicates a poor observation, and conversely a low PDOP is more favorable. Geometrical Dilution of Precision (GDOP) is often used interchangeably 
for PDOP as it represents a measure of accuracy in 3D position and time. For this experiment, I believe our main sources of error to be satellite position determination, multipath and human error.

In a highly topographic area, the blocking of the satellite signal can vary dramatically and impact the determination of satellite constellation geometry for fixing the position of the receiver. The GPS station at CLNT was deployed within the old 1902 eruption crater (Figure 4.3). In all four directions the crater walls rise vertically between $140 \mathrm{~m}$ to greater than $350 \mathrm{~m}$ in $500 \mathrm{~m}$ to $800 \mathrm{~m}$ horizontal distance with the most dramatic elevation difference being to the NW where the Santa Maria edifice rises roughly $1400 \mathrm{~m}$ in under $2 \mathrm{~km}$ horizontal distance. At best, to the south there is a visible elevation angle cutoff at $12^{\circ}$ while to the east and west it is $16^{\circ}$, and the worst being to the north and northwest at $25^{\circ}$ and $35^{\circ}$. This dramatic topography in the crater significantly reduces the sky view and diminishes the receiver's ability to track the satellites through their entire arc and results in blocked signal. Our receiver at CLNT had elevation cut off at $10^{\circ}$ which, is moot considering our best sky view was at $12^{\circ}$, however, our PDOP Mask was set at 15, which is generally considered quite high and likely to produce questionable or very rough position measurements (Langley 1999). Looking at a plot of GDOP values from our data (Figure 4.10) shows there is a clear correlation between GDOP value and visible satellites. Ultimately, these topographic obstructions affect satellite geometry and visibility, occluding the GPS signal and significantly diminishing accuracy and likely responsible for multiple cycle-slips and the ambiguity resets (Figure 4.11 and Figure 4.12). In times when GIPSY produces huge, nonsense values it is likely that the processor thinks there is a cycle slip and then re-estimates a new bias. If these biases are too frequent, they will grossly underestimate the position. This could be the result of poor satellite geometry or signal. If there are only four satellites visible there will be a much worse position estimate than when you have six. When there are only three visible satellites it will produce a nonsense solution. This can be assessed by examining the standard deviations (Figure 4.13). When they are large it usually means poorly determine phase ambiguity.

Multipathing is also another likely source of position error in this experiment. Multipathing is the phenomenon that occurs when GPS signals arrive at an antenna having traversed more than one path (Hofmann-Wellenhof et al. 2012). The primary cause of multipath is reflective surfaces near the receiver. As a consequence, the received signal has a relative phase offset that can lead to a phase difference proportional to the differences of the path lengths (Hofmann-Wellenhof et al. 2012). From a geometrical standpoint, signals that are received from low elevation satellites $\left(<25^{\circ}\right)$ are more susceptible to multipath than signals from high elevations (Bilich 2006, Larson et al. 2010a, Hofmann-Wellenhof et al. 2012). Considering the high elevation angles present in our study site it seems possible that multipath caused by poor satellite geometry would be a factor. However, volcanic ash on and around the antenna may have induced greater degree of multipath than normal conditions. The reflectivity of the ash may have produce 
a greater degree of signal reflectance and scatter causing more than normal multipath (Larson et al. 2017). Furthermore, the accumulation of ash on the antennae over the 34hour period may have also contributed to poor signal reception and varying levels of multipath during the same sidereal day period. While multipath modeling and noise filtering has been shown to work at some places, it does not mean that it will be successful at other sites. This failure at our site may be the result of the low antenna elevation relative to the ground ( $\sim 1$ meter), the nonconformity and changing reflective ground surface where rocks and ridges may be tilted in dimensions that are close to the GPS wavelengths (19 and $24.4 \mathrm{~cm}$ ), or the higher reflectivity of the smoother, ashcovered ground (Larson et al. 2010b, Larson 2013). Considering the frequent eruptions were continuously depositing ash on and around our antenna could be cause for unfixable errors.

Lastly, human induced error is considered another possible cause of poor position determination. At SMRA, the quality of tripod deployment and sky view is extremely dubious. Considering the high degree of noise in the data collected from that site, we have difficulty relying on these data from that site in differential positioning. For station SMRA we relied on a three-point spike mount tri-pod borrowed from UNAVCO. The antenna rests on a central mast and has two adjustable legs extending radially. During field preparation, equipment testing showed this tri-pod to be difficult to setup and challenging to remain stable. Therefore, if the tripod was not setup properly, or was disturbed during acquisition using SMRA as a fixed reference station would introduce a level of noise that would make relative positioning decidedly ineffective.

Regardless of which processing technique or error reduction method provided the best results in this experiment, based on the past analysis of displacement associated with cyclical, explosive eruptions at Santiaguito it is unlikely that decimeter or even centimeter level precision in a GPS survey would capture any small, short-term transient deformation signal. In fact, it seems necessary to achieve millimeter to submillimeter precision for that goal. It seems clear that large degree of noise makes it impossible to see the small signals that would be expected with these events.

Our Mogi model (Figure 4.4) suggests the range of deformation that we could expect to capture at our CLNT station $300 \mathrm{~m}$ from the source is between $0.2 \mathrm{~mm}$ to $1.9 \mathrm{~mm}$. Considering the high level of random noise and error at both sites suggests that any transient deformation signal associated with short-period and/or short-duration motion will not be captured. None of the processed data shows nor does the data treated with a noise reduction strategy show any discernable short period or long period signals of deformation. The level of positioning noise for our station CLNT exceeds the likely deformation associated with the small explosive eruptions that are common at Santiaguito. 

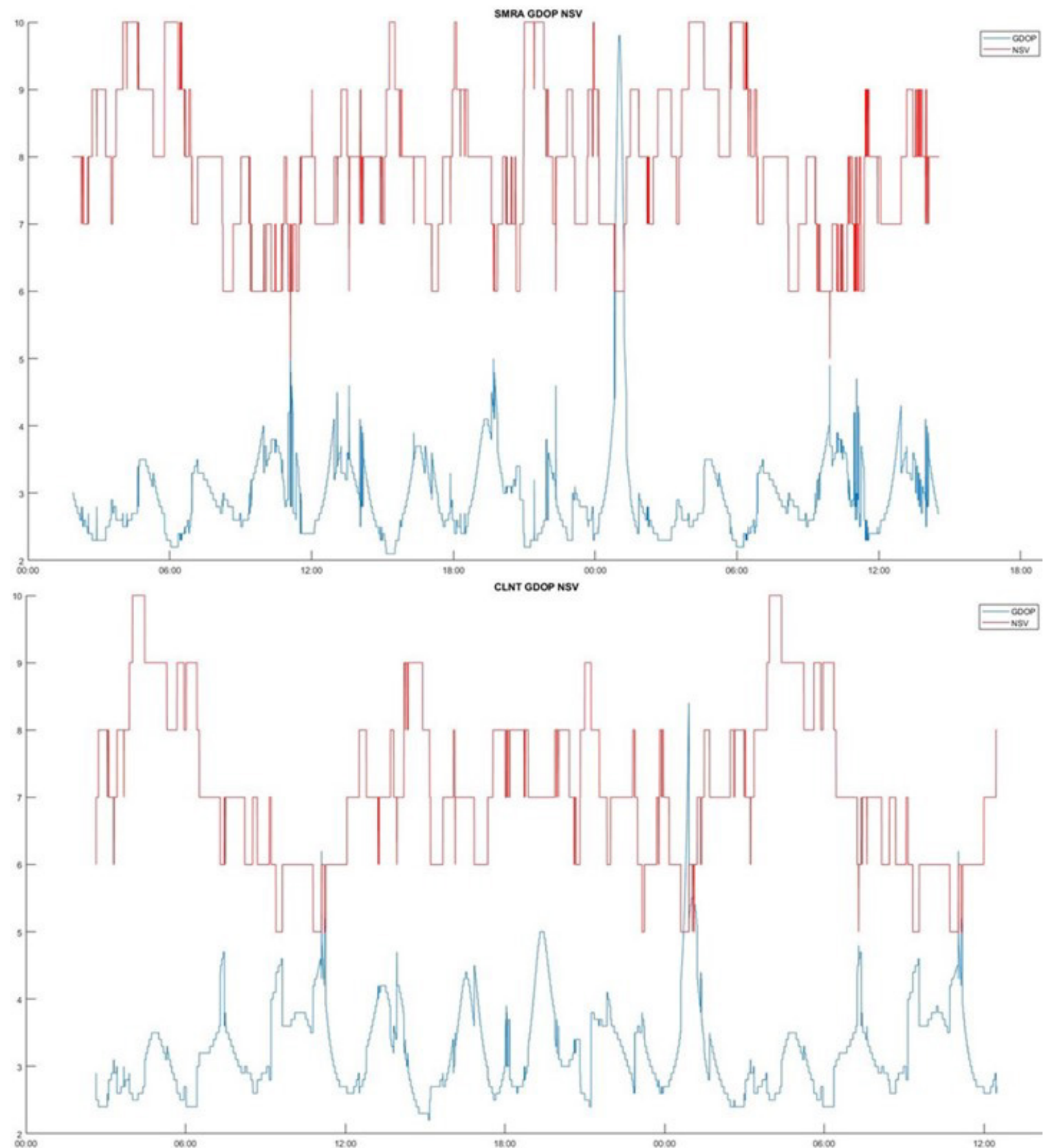

Figure 4.10 GDOP and number of visible satellites from stations SMRA (top) and CLNT (bottom). 



Figure 4.11 Number of satellites tracked and percentage of ambiguity resets at station CLNT. Top is from January 8. Bottom is from January 9. 
Tracked Satellites and Reset Ambiguities (2016-01-09 00:00:17.000 GPS)


Figure 4.12 Number of satellites tracked and percentage of ambiguity resets at station SMRA. Top is from January 8. Bottom is from January 9. 

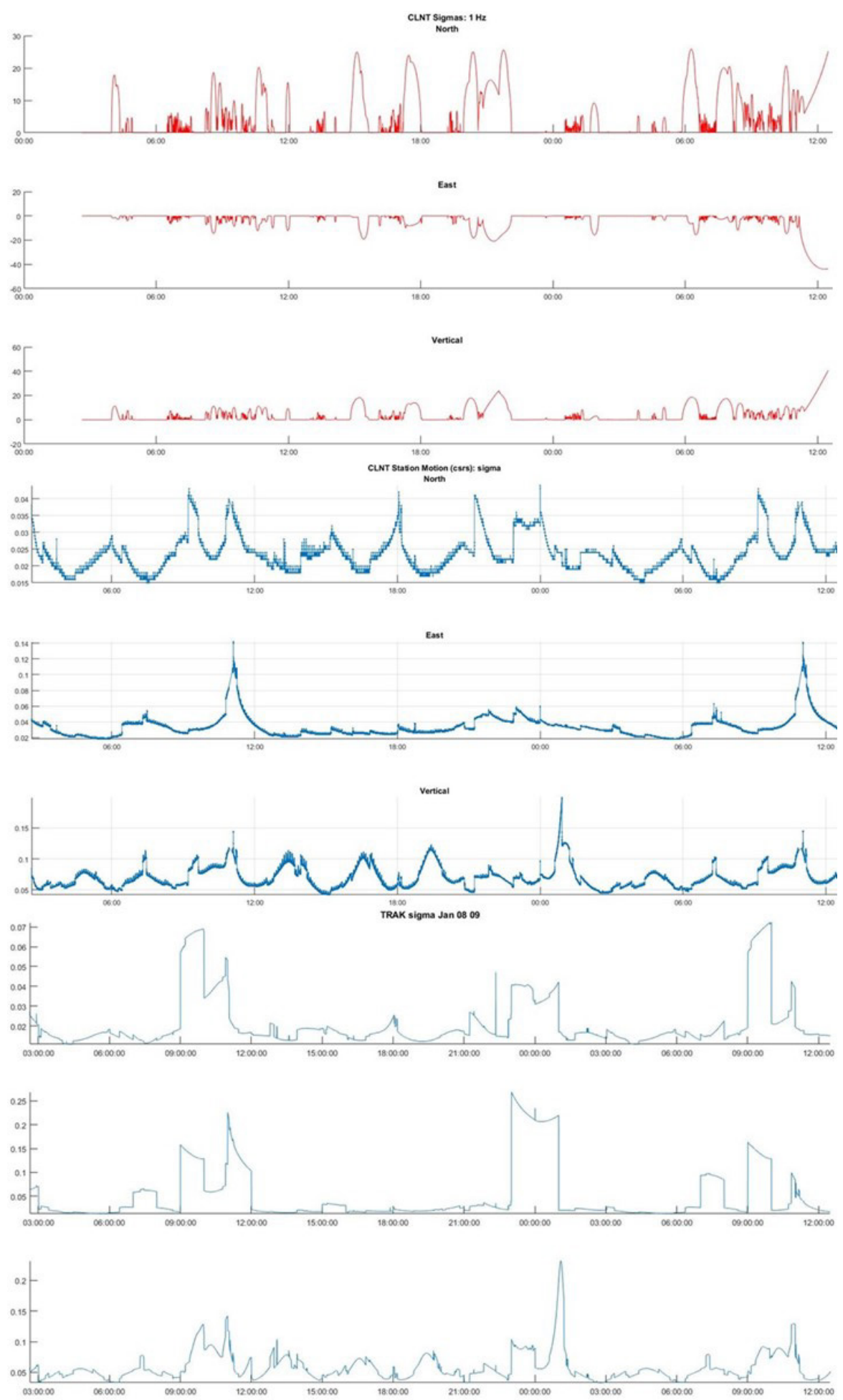

Figure 4.13 Standard deviations for directional components of each position estimates at station CLNT. Top in red north, east and height from APPS. Middle in blue north, east and height from CSRS-PPP. Bottom in green, north, east and height from TRACK. 


\subsection{Conclusion}

What have we learned from this experiment and its poor results? First, we need a longer observation window at the reference station and the rover station. This would allow for improvements in the application of the modified sidereal filtering technique by providing more orbital repeat paths. Second having additional rover stations would allow us to better assess multipath and determine which is systematic and which is unique to the individual receiver. Lastly, if observing volcano deformation prior to an eruption is our primary goal it may not be totally necessary to record data a rate faster than 15 seconds. At this rate it would should still be possible to observe long period deformation, assuming it is greater than the level of white noise, and would be less onerous for storage, telemetry (assuming it is being used as a monitoring instrument) and processing.

Santiaguito is an extremely active volcano and is considered one of the most reliable volcanoes in terms of research. We designed an experiment to observe short-term displacement or very long period deformation signals associated with magma movement and frequent explosive eruptions. GPS data were collected from January 8-9, 2016 and analyzed to investigate inflationary/deflationary displacements associated with these eruptions. Data were evaluated with Precise Point Positioning methodology using online processors APPS and CSRS-PPP, and kinematic processing using GAMIT/GLOBK/TRACK with a multipath filter to develop an appropriate analysis strategy. While our results show that we were able to reduce noise down to the centimeter level in a one-hour time window, we are unable to see any observable deformation signal. This likely indicates that any deformation signal is below our reported level of noise. In the future, the aim will be to extend observation duration for several days so that improved multipath analysis can be conducted with the goal of developing a more robust, real-time or near real-time deformation monitoring tool. 


\subsection{References}

Agnew, D. C. \& K. M. Larson (2007) Finding the repeat times of the GPS constellation. Gps Solutions, 11, 71-76.

Avallone, A., E. D'Anastasio, E. Serpelloni, D. Latorre, A. Cavaliere, C. D'Ambrosio, S. Del Mese, A. Massucci \& G. Cecere (2012) High-rate (1 Hz to $20 \mathrm{~Hz}$ ) GPS coseismic dynamic displacements carried out during the Emilia 2012 seismic sequence. Annals of Geophysics, 55.

Avallone, A., D. Latorre, E. Serpelloni, A. Cavaliere, A. Herrero, G. Cecere, N. D'Agostino, C. D'Ambrosio, R. Devoti \& R. Giuliani (2016) Coseismic displacement waveforms for the 2016 August $24 \mathrm{Mw} 6.0$ Amatrice earthquake (central Italy) carried out from High-Rate GPS data. Annals of Geophysics, 59.

Bertiger, W., S. D. Desai, B. Haines, N. Harvey, A. W. Moore, S. Owen \& J. P. Weiss (2010) Single receiver phase ambiguity resolution with GPS data. Journal of Geodesy, 84, 327-337.

Bilich, A. L. (2006) Improving the precision and accuracy of geodetic GPS: Applications to multipath and seismology.

Bluth, G. J. \& W. I. Rose (2004) Observations of eruptive activity at Santiaguito volcano, Guatemala. Journal of Volcanology and Geothermal research, 136, 297-302.

Bock, Y., D. Melgar \& B. W. Crowell (2011) Real-time strong-motion broadband displacements from collocated GPS and accelerometers. Bulletin of the Seismological Society of America, 101, 2904-2925.

Bock, Y., R. M. Nikolaidis, P. J. Jonge \& M. Bevis (2000) Instantaneous geodetic positioning at medium distances with the Global Positioning System. Journal of Geophysical Research: Solid Earth (1978-2012), 105, 28223-28253.

Bock, Y., L. Prawirodirdjo \& T. I. Melbourne (2004) Detection of arbitrarily large dynamic ground motions with a dense high-rate GPS network. Geophysical Research Letters, 31.

Cannavò, F., A. G. Camacho, P. J. González, M. Mattia, G. Puglisi \& J. Fernández (2015) Real time tracking of magmatic intrusions by means of ground deformation modeling during volcanic crises. Scientific reports, 5, 10970.

Cervelli, P., T. Fournier, J. Freymueller \& J. Power (2006) Ground deformation associated with the precursory unrest and early phases of the January 2006 eruption of Augustine Volcano, Alaska. Geophysical Research Letters, 33.

Choi, K., A. Bilich, K. M. Larson \& P. Axelrad (2004a) Modified sidereal filtering: Implications for high-rate GPS positioning. Geophysical research letters, 31.

Choi, K. H., A. Bilich, K. M. Larson \& P. Axelrad (2004b) Modified sidereal filtering: Implications for high-rate GPS positioning. GEOPHYSICAL RESEARCH LETTERS, 31, -.

Dzurisin, D. (2000) Volcano geodesy: challenges and opportunities for the 21 st century. Phil. Trans. R. Soc. Lond., A, 1547-1566.

Dzurisin, D. 2006. Volcano deformation: new geodetic monitoring techniques. Berlin: Springer.

Dzurisin, D., M. Lisowski \& C. W. Wicks Jr (2017) Semipermanent GPS (SPGPS) as a volcano monitoring tool: rationale, method, and applications. Journal of Volcanology and Geothermal Research, 344, 40-51. 
El-Mowafy, A. (2011) Analysis of web-based GNSS post-processing services for static and kinematic positioning using short data spans. Survey Review, 43, 535-549.

Genrich, J. F. \& Y. Bock (1992) Rapid resolution of crustal motion at short ranges with the Global Positioning System. Journal of Geophysical Research: Solid Earth, 97, 3261-3269.

Grapenthin, R., J. T. Freymueller \& A. M. Kaufman (2013) Geodetic observations during the 2009 eruption of Redoubt Volcano, Alaska. Journal of Volcanology and Geothermal Research, 259, 115-132.

Hofmann-Wellenhof, B., H. Lichtenegger \& J. Collins. 2012. Global positioning system: theory and practice. Springer Science \& Business Media.

Holland, A. P., I. M. Watson, J. C. Phillips, L. Caricchi \& M. P. Dalton (2011) Degassing processes during lava dome growth: Insights from Santiaguito lava dome, Guatemala. Journal of Volcanology and Geothermal Research, 202, 153-166.

Johnson, J. B., J. M. Lees, A. Gerst, D. Sahagian \& N. Varley (2008) Long-period earthquakes and co-eruptive dome inflation seen with particle image velocimetry. Nature, 456, 377.

Johnson, J. B., J. Lyons, B. J. Andrews \& J. Lees (2014) Explosive dome eruptions modulated by periodic gas-driven inflation. Geophysical Research Letters, 41, 66896697.

Lagios, E., V. Sakkas, F. Novali, A. Ferreti, B. Damiata \& V. J. Dietrich. 2018. Reviewing and Updating (1996-2012) Ground Deformation in Nisyros Volcano (Greece) Determined by GPS and SAR Interferometric Techniques (1996-2012). In Nisyros Volcano, 285-301. Springer.

Langley, R. B. (1999) Dilution of precision. GPS world, 10, 52-59.

Larson, K. M., A. Bilich \& P. Axelrad (2007) Improving the precision of high-rate GPS. Journal of Geophysical Research-Solid Earth, 112, -.

Larson, K. M., P. Bodin \& J. Gomberg (2003) Using 1-Hz GPS data to measure deformations caused by the Denali fault earthquake. Science, 300, 1421-1424.

Larson, K. M., S. Palo, C. Roesler, M. Mattia, V. Bruno, M. Coltelli, D. J. J. o. V. Fee \& G. Research (2017) Detection of plumes at Redoubt and Etna volcanoes using the GPS SNR method. 344, 26-39.

Larson, K. M., M. Poland \& A. Miklius (2010a) Volcano monitoring using GPS: Developing data analysis strategies based on the June 2007 Kîlauea Volcano intrusion and eruption. Journal of Geophysical Research: Solid Earth (1978-2012), 115.

Larson, K. M., M. Poland \& A. Miklius (2010b) Volcano monitoring using GPS: Developing data analysis strategies based on the June 2007 Killauea Volcano intrusion and eruption. Journal of Geophysical Research: Solid Earth, 115.

Larson, K. M. J. G. R. L. (2013) A new way to detect volcanic plumes. 40, 2657-2660. Lechner, H. N., C. DeMets, D. Hernandez \& W. Rose (2013) A pilot GPS study of Santa Ana Volcano (Ilamatepec) and Coatepeque caldera, El Salvador. Geological Society of America Special Papers, 498, 57-75.

Lechner, H. N., C. Wauthier, G. P. Waite \& R. Escobar-Wolf (2018) Magma storage and diking revealed by GPS and InSAR geodesy at Pacaya volcano, Guatemala. Bulletin of Volcanology, In Review.

Martin, I. (2013) GNSS precise point positioning: the enhancement with GLONASS. 
Mattia, M., M. Palano, M. Aloisi, V. Bruno \& Y. Bock (2008) High rate GPS data on active volcanoes: an application to the 2005-2006 Mt. Augustine (Alaska, USA) eruption. Terra Nova, 20, 134-140.

Mattia, M., M. Rossi, F. Guglielmino, M. Aloisi \& Y. Bock (2004) The shallow plumbing system of Stromboli Island as imaged from $1 \mathrm{~Hz}$ instantaneous GPS positions. Geophysical Research Letters, 31.

Mogi, K. (1958) Relations Between the Eruptions of Various Volcanoes and the Deformations of the Ground Surfaces around them. Bulletin of the Earthquake Resezarch Institute, 36, 99-134.

Owen, S., P. Segall, M. Lisowski, A. Miklius, M. Murray, M. Bevis \& J. Foster (2000) January 30, 1997 eruptive event on Kilauea Volcano, Hawaii, as monitored by continuous GPS. Geophysical Research Letters, 27, 2757-2760.

Patane, D., M. Mattia, G. Di Grazia, F. Cannavo, E. Giampiccolo, C. Musumeci, P. Montalto \& E. Boschi (2007) Insights into the dynamic processes of the 2007 Stromboli eruption and possible meteorological influences on the magmatic system. Geophysical Research Letters, 34.

Ragheb, A., S. Edwards \& P. J. Clarke (2009) Using filtered and semicontinuous high rate GPS for monitoring deformations. Journal of Surveying Engineering, 136, 72-79.

Rizos, C. \& S. Han. 1998. Status and trends for high precision GPS kinematic positioning. In Proceedings of the 9th Australasian Remote Sensing and Photogrammetry Conference. Citeseer.

Rose, W. I. (1987) Volcanic activity at Santiaguito volcano, 1976-1984. Geol. Soc. Amer., Spec. Pap., 17-27.

Sanderson, R. W., J. Johnson \& J. Lees (2010) Ultra-long period seismic signals and cyclic deflation coincident with eruptions at Santiaguito volcano, Guatemala. Journal of Volcanology and Geothermal Research, 198, 35-44.

Scott, J. A., T. A. Mather, D. M. Pyle, W. I. Rose \& G. Chigna (2012) The magmatic plumbing system beneath Santiaguito Volcano, Guatemala. Journal of Volcanology and Geothermal Research, 237, 54-68.

Segall, P., P. Cervelli, S. Owen, M. Lisowski \& A. Miklius (2001) Constraints on Dike Propagation from Continuous GPS Measurements. JOURNAL OF GEOPHYSICAL RESEARCH, 106, 19,301-19,317.

Zumberge, J., M. Heflin, D. Jefferson, M. Watkins \& F. Webb (1997) Precise point positioning for the efficient and robust analysis of GPS data from large networks. Journal of Geophysical Research: Solid Earth (1978-2012), 102, 5005-5017. 


\section{Chapter 5: Summary, synthesis, and conclusion}

\subsection{Introduction}

The research presented in this dissertation has approached volcanic hazards by examining two different components of the same (or similar) geophysical events. First, we examined the physical nature of Pacaya volcano from where the extreme events emanate. Second, we looked at the social factors that affect people's decision-making and behavior in response to an extreme geophysical event. The goal of this work is highlight the linkage between these two components and emphasize the importance of an interconnected, multidisciplinary approach to risk reduction at volcanoes in Guatemala. The main contributions of this work were improvements to our understanding of the magma system dynamics at Pacaya, and the first systematic investigation of evacuation behavior of a socially vulnerable population during a volcanic eruption.

\subsection{Approaching volcanic hazards}

Traditionally, natural hazards are defined as extreme natural events that threaten a specific space in time. This approach expresses hazards as elements within the physical world that are harmful to humans (Burton et al. 1968, Kates 1976). It presents risk as a probability that nature will adversely affect humans and their environment. Within this line of thinking, we define disasters as the result of cyclical progressions from early warning signs, alarm, crisis, evacuation, response and recovery; and a community that suffers from disaster has failed to mitigate the hazard appropriately (Alexander 1997). The concepts of magnitude and frequency are essential for the assessment of hazard, and the characteristics of the event define the impact it will have on people. Since the 1940s natural hazards research has been dominated by this behavioral paradigm that assesses risk to extreme events based on rational adjustment behavior for risk reduction. While this approach significantly improves our understanding of hazards and their triggers, and allows us to make recommendations for mitigation, it hinges on the expectation that information gleaned from science and technology will transfer to vulnerable people, and that they will adjust appropriately and rationally based on their perceived level of risk.

Broadly defined, vulnerability is the potential for loss or susceptibility to damage or injury (Wisner et al. 2004, Cutter 2012). It is a measure of the degree to which a system reacts adversely to the occurrence of a hazardous event (Timmerman 1981). The physical vulnerability of a place can be reduced through technical or engineered mitigation efforts such as disaster resistant buildings, changes in land-use, construction of hazard diversions or barriers, restoration of forests and wetlands, or other measures appropriate for the hazards considered (Cutter 2012). Vulnerability complicates the perception of risk especially when considering hazards to poor or marginalized populations, in places like including Guatemala and other developing nations. In these cases, a portion of the vulnerability is caused by the social system. Thus, when defining vulnerability we should also address the social causes of the inability to take effective measures against loss and 
the consequence of the impossibility or improbability of effective mitigation (Bogard 1988).

Therefore, social vulnerability can be defined as the product of social, economic, or political inequities that inhibit groups of people from adjusting appropriately to extreme events. It stems from the lack of basic provisions that we often attribute to quality of life, such as healthcare, safety and security, livability of a place, accessibility to lifelines (power, water, emergency response,) and political or fiscal capital (Cutter 2012). Social vulnerability reflects the characteristics of a person or group (in terms of their capacity) to anticipate, cope, resist and recover from an extreme natural event. It involves a combination of factors that determine the degree to which someone's life and livelihood are at risk by discrete and identifiable events in nature or society (Wisner et al. 2004). By emphasizing the weight of social and economic constraints on people's abilities and behavior, social vulnerability helps us to understand why some groups of people suffer more than others.

\subsection{Vulnerability in Guatemala}

Guatemala is vulnerable country. Physically it is vulnerable to a variety of extreme geologic and environmental phenomena such as earthquakes, hurricanes, landslides, and volcanic eruptions. However, it is also an extremely socially vulnerable country plagued with high crime, political corruption, chronic poverty, malnutrition, decrepit infrastructure, deficient public/social services, social and spatial segregation, pollution, and ecological deterioration (INE 2003, Tesliuc and Lindert 2004, World_Bank(a) 2009, Cabrera and Haase 2018). It is a lower-middle-income country with a GDP of $\$ 75.62$ billion USD, and a per capita GDP of approximately $\$ 4500$ USD (compared to the United States at. $\$ 19.3$ trillion and $\$ 59,531$, respectively), 56 percent poverty, little tax revenue (9.6 percent) and an undiversified economy (Tesliuc and Lindert 2004, World_Bank(a) 2009, World_Bank(b) 2017). The country's natural hazard mitigation strategy places greater emphasis on coping with risk after an event rather than proactively attempting to reduce risk (Tesliuc and Lindert 2004). Guatemala's pressing socioeconomic and political issues so outweigh and overshadow factors of geophysical vulnerability that effective changes to policy or emergency response strategies rarely occur. Given the high degree of physical and social vulnerability in Guatemala, when catastrophic events happen they have long-lasting effects on the poor, who often suffer the most.

The most egregious disproportionate disaster in Guatemalan history occurred after a 7.5 magnitude earthquake in February 1976. Nearly 25,000 people died in what is now referred to as the "class-quake" (Jonas 1976). Those most severely affected were poor and working class families who lived in poorly constructed, non-reinforced dwellings. For days and weeks after the quake, victims waited for basic aid from the government and disaster management authorities, which in many cases never arrived (Jonas 1976, Gawronski et al. 2013). During this event, all of the elements of vulnerability - 
geographic, geologic, social, and economic - crashed together at that moment in time and space to produce areas of disaster throughout poor, urban neighborhoods. The inequitable nature of the damage not only demonstrated that poor people are more susceptible to loss and suffering, but that the country as a whole lacks the capacity to anticipate, resist, cope and recover from extreme events.

The tragic loss of life and suffering of the Guatemalan people notwithstanding, an important takeaway point from this event was the lack of preparedness and the inability of the Guatemalan government to coordinate aid and relief to those most in need. The deficiency of an adequate response before, during, and after the earthquake was, and still is, a consequence of the social vulnerability that affects the entire country. Considering Guatemala's high exposure to extreme physical events, small economy, low per-capita GDP, extreme poverty and inequitable access and distribution of lifeline resources (healthcare, insurance, infrastructure, security) it is only a matter of time before another class-specific disaster strikes. As a geoscientist that has spent considerable time in Guatemala researching volcanoes, I have witnessed firsthand how the socio-economic situation and political culture inhibit the ability of emergency management agencies to implement an effective disaster management framework (identify, monitor, assess, inform, prepare, respond, and recover). This was evident most recently during the June 2018 eruption at Fuego, and the October 2015 El Cambray landslide (LaPorte 2018). While this dissertation has focused on volcanic hazards and behavioral response at Pacaya volcano, especially the 2010 eruption, the other events mentioned here illuminate the need for increased, multidisciplinary hazards research, policy recommendations, and disaster management strategies aimed at risk and vulnerability reduction.

\subsection{Vulnerability at Pacaya}

Pacaya volcano clearly represents a geophysical hazard to the people of Guatemala. It has been persistently active since 1961 and is one of Guatemala's most active volcanoes. Over the last 57 years, a network of eruptive vents produced the volume of the volcanic material that has formed the Mackenney cone within the collapse amphitheater of the ancestral Pacaya. The volcano has produced a number of moderate lava flows and explosive, tephra producing, eruptions (VEI II \& III) that have caused at least a dozen evacuations since 1961. The majority of these eruptions occurred from a central vent on the Mackenney cone with the bulk of the eruptive products dispersed and affecting communities to the south. The May 27, 2010 eruption drastically altered the morphology of the Mackenney, when a large fissure like structure formed on the northern flank from the summit to the base of the Mackenney cone. The Mackenney cone continues to grow asymmetrically from a series of explosive and effusive eruptions. This type of activity is common for Pacaya; however, the unconsolidated and unbalanced Mackenney cone should be deeply concerning to nearby communities, emergency management authorities, and volcano scientists in Guatemala. 
Clearly, Pacaya volcano represents a physical threat to nearby communities, and the 2010 eruption also highlighted the social vulnerability of the people living within those communities. The uncharacteristic nature of that eruption sent ash, tephra, and ballistics into communities to the north and caught many people uniformed and unprepared, leading to the improvised evacuation of roughly 2500 residents from northern communities. While this eruption, considered the largest since 1961, showed a pronounced increase in seismicity and eruptive activity prior, many residents in the communities most severely affected did not evacuate before or even after the eruption began. I contend that the agencies responsible for monitoring and communicating hazards lacked the resources necessary to detect geophysical signals that may have provided a clearer picture of the changes and a more accurate forecast indicating the direction and magnitude, which would have allowed for proactive warnings and evacuation efforts. Furthermore, those communities that were most vulnerable were made more so by their lack of resources, information, and capacity to effectively evacuate or adjust to the eruption. Again, we see an example of physical and social vulnerability colliding at one place in time to create near disastrous results.

\subsection{Physical dimensions of Pacaya hazards research}

In the examination of the physical dimensions of volcanic hazards from the perspective of the dominant approach, my research at Pacaya volcano (chapter 2) uses GPS measurements and InSAR data to observe surface deformation. Volcano scientist often apply geodetic data at active volcanoes to model the subsurface sources of deformation. It is commonly understood that most volcanoes produce some degree of surface displacement prior to an eruption (Dzurisin 2003). In fact, as a result of technological advances and improved observations and reporting, deformation has been observed at more than 220 volcanoes around the world (Biggs and Pritchard 2017). Detailed geodetic surveys allow us to track the ascent and extrusion of magma, which is of critical importance when issuing volcano related hazard warnings (Sparks 2003, Acocella and Neri 2009, Ebmeier et al. 2018).

My research uses data from a time-period spanning from 2009 through 2015 to model deformation sources for two eruptive time-periods at Pacaya. The GPS observations presented downward vertical and outward horizontal deformation greater than $25 \mathrm{~cm}$ at several locations around the volcano, while the InSAR data showed up to $15 \mathrm{~cm}$ of lineof-sight displacement. We assumed these observations to be indicative of at least two sources of deformation, as the down-and-out displacement signal is difficult to resolve with either a single point source or single dike source. Therefore, to visualize the internal dynamics of the magma storage system we inverted the available geodetic data to produce an analytical model for each time-period. Both our models suggest that vertical deformation is dominated by a deflating point source beneath the NW flank of the Mackenney cone and that the horizontal motion is likely the result of inflation of a shallow, subvertical dike seated high within the Mackenney cone. Furthermore, our models are consistent with the geologic features observed at Pacaya. First, the NW-SE 
linear alignment of past eruptive vents suggests that a dike feature may be propagating along the ancestral collapse scarp. Second, the deflationary signal likely represents two interconnected magma chambers at varying depths below the NW flank of the Mackenney cone. Lastly, an expanding dike high within the Mackenney cone is likely responsible for the fissure-like feature on the northern flank. If over-pressurized this could result in another north directed blast similar to or greater than that of 2010 and cause another massive sector collapse. The data and results presented in this research suggest that GPS and InSAR geodesy are functional tools to monitor Pacaya volcano and aid in the production of hazard warnings and evacuation notices during future eruptive crisis. While this technique has improved our ability to monitor Pacaya volcano for spatial and temporal changes (assuming regular observations) and permits us to produce analytical solutions for the sources of deformation, the questions still remain: "What deformation will lead to an eruption (or sector collapse)? How can this information be used to reduce risk to people living in those communities?"

\subsection{Social dimensions of Pacaya hazards research}

My research at Pacaya (chapter 3) uses quantitative social data to examine evacuation behavior during a volcanic crisis. We know that not everyone evacuates during a geophysical crisis and there is no shortage of research that tries to document and explain the "how" and "why." While many of these studies have revealed consistent patterns that help explain variations in behavior which can usually be accounted for by factors such as hazard exposure and level of risk, emergency management action, housing or shelter, perception of risk, and individual-specific variables many other variables still lack clarity. One set of variables that requires much more attention relates to factors associated with social vulnerability. The ultimate goal of studying evacuation behavior should be to produce a model that can predict magnitudes of change in evacuation behavior relative to simultaneous changes to one or multiple variables (Baker 1991).

Using a door-to-door survey, we collected data from residents in communities around Pacaya regarding factors of household evacuation-decision making during a volcanic eruption or the threat thereof. While we did not test for social vulnerability at an individual or household level, we did hold it as a constant within our sample population. Based on the socio-economic and political situation of the country of Guatemala, we assumed that our entire target population is socially vulnerable. In doing so, we found that evacuation behavior in 2010 and future evacuation intention are strongly influenced by perceptions of evacuation, perceptions of security, exposure to hazards, and past behavior.

Ultimately, we found that risk perception and protective action behavioral adjustments are not coupled as is predicted by those who approach hazards using the behavioral paradigm. Second we show that households around Pacaya place more emphasis on situational factors (age, community, damage, home vulnerability) and official warning messages than on environmental (fallout) or social cues (seeing people flee) when 
making the decision to evacuate or not. This is a reasonable conclusion considering a socially vulnerable population with limited access to critical resources (transportation, shelter, money). Third, we found that amount of damage experienced personally, and the perception of damage (severity of eruption) was a good predictor of evacuation behavior in 2010. However, the perception of the 2010 eruption alone has little to no influence of future evacuation intention. Lastly, we found that the severity of impact from 2010 eruption on one's community to be the strongest predictor of who did evacuate and who intends to evacuate in the future, while issues such as age and the perceived need to protect one's home and property were stronger predictors of past behavior than the perception of severity alone. These finding suggest that situational impediments such age or fear of looters had a negative impact on evacuation behavior, while warning messages had a positive impact. Although the models presented in this research cannot predict magnitudes of change, they do function to predict directional change in the probability of evacuation behavior, given changes in one variable at a time. Therefore, to affect future evacuation behavior in a positive way, in addition to forecasting an eruption and understanding the geophysical potential, emergency managers and civil authorities must also address the specific issues of social vulnerability mentioned above. When people perceive themselves as able, or have access to evacuation resources, or confidence in the security of their homes there is a greater probability of evacuation response during a future volcanic crisis at Pacaya.

\subsection{Synthesis and future work}

By examining the internal structure of Pacaya, we have improved the ability to forecast magma ascent that causes detectable crustal deformation and disturbances. These deformations can indicate the buildup of magma that could lead to another eruptive episode. Monitoring these changes provides scientists and hazard managers the opportunity to issue long-term and short-term warnings. Of course, significant issues and limitations still exist in assessing exact timing, magnitude, direction, and even if an actual eruption will occur. While precise and confident forecasts may only ever be available shortly or immediately before an eruption, their value in terms of warnings and evacuations should not minimized. Without adequate instrumentation and monitoring, certain aspects of volcanic eruptions will remain completely obscured and unpredictable and provide little if any opportunity for warnings, evacuations, or preemptive response. Of course, effective communication systems and evacuation strategies rely on more than just instrumentation and monitoring. At-risk communities must also be prepared, willing, and able to respond appropriately in the event of a volcanic crisis. In our examination of preparedness, behavior, intention and risk perception, we have drawn on aspects of people's past behavior and perceptions of past experience, including direct experience and vicarious experience (in relation to community of residence and damage within that community). Understanding what factors influenced past behavior gives us greater insight into future response. We can evaluate those components of the cycle that were effective and those that failed, where more emphasis needs to placed (monitoring, 
warnings, evacuation facilitation), and what recommendations can be made to monitoring agencies, emergency management institutions, and local communities.

Several different observations, surveys, and analyses can be applied at Pacaya or other volcanoes in Guatemala and around the world. In terms of understanding surface deformation and hazards monitoring, future work should focus of improving the spatial and temporal density of the GPS network with more frequent observations. Of particular interest would be the installation of GPS benchmarks on the western and eastern flanks of the Mackenney cone. This would allow for continued refinement of deformation sources models presented in this dissertation and long-term monitoring of slope displacement. These campaign-style observations would not necessarily be useful for short-term warnings, but the addition of two to three continuous, and telemetered, GPS stations could provide more timely information. These continuous data could be compared to the a priori deformation source models, allowing for interpretation of incoming geodetic data in real-time or near real-time that would greatly improve eruption forecasting and hazard warning communication.

Future work applied to evacuation decision making during a volcanic crisis could benefit from a variable oriented cross-case analysis. The research presented in chapter three examined evacuation decisions of a socially vulnerable population, however, we could gain further insight by examining behavior and decision-making of a population that is less, or not at all, socially vulnerable. This would allow us to compare and contrast variations and commonalities in the variable factors that are influential in decisions, outcomes, and behavioral response during volcanic crises. This research would be further improved by including multi-disciplinary expert elicitation. The inclusion of expert opinion would allow us to validate or dismiss some of the variables within our models. These two research methods in conjunction with one another could provide valuable insight into evacuation behavior during rare, extreme events.

\subsection{Conclusion}

In this dissertation, I have argued that there are two critical components needed to reduce volcanic hazards in Guatemala. One requires enhanced monitoring technology; the second requires reduced social vulnerability. Which one must come first is difficult to say, as the two are deeply interconnected and require economic capital and political will. I contend that both the dominant and radical approaches are equally important when addressing natural hazards. If we were to focus only on science and technology, we would overlook society's ability to respond; and if we focus only on fixing the root causes of social vulnerability, we would ignore the importance of technology to inform populations of changes to the environmental system.

Understanding and reducing both physical and social vulnerability can be achieved through multi-disciplinary research and policy. In this sense, this dissertation has contributed to the understanding and assessment of the physical hazard dynamics at 
Pacaya volcano and has addressed issues of risk perception and behavioral adjustments of a socially vulnerable population. In presenting this multidisciplinary approach to volcanic hazards, I have not only applied the traditional view (behavioral paradigm) through a robust examination of the physical nature of Pacaya, I have also delved into the realm of research often dominated by social scientists (structural paradigm) through an examination of behavioral response to eruption hazards. I have made an effort to account for the human systems as an integral part of the geographic place and how that system is affected by physical changes in the volcanic system. This integrated research aims for ultimate goal of optimum risk reduction solutions founded in the understanding of human response to geophysical events. 


\subsection{References}

Acocella, V. \& M. Neri (2009) Dike propagation in volcanic edifices: overview and possible developments. Tectonophysics, 471, 67-77.

Alexander, D. J. D. (1997) The study of natural disasters, 1977-97: Some reflections on a changing field of knowledge. 21, 284-304.

Baker, E. J. (1991) Hurricane evacuation behavior. International Journal of Mass Emergencies and Disasters, 9, 287-310.

Biggs, J. \& M. E. Pritchard (2017) Global volcano monitoring: what does it mean when volcanoes deform? Elements, 13, 17-22.

Bogard, W. C. (1988) Bringing social theory to hazards research: conditions and consequences of the mitigation of environmental hazards. Sociological Perspectives, 147-168.

Burton, I., R. W. Kates \& G. F. White. 1968. The human ecology of extreme geophysical events. Department of Geography, University of Toronto.

Cabrera, F. C. \& D. J. C. Haase (2018) Guatemala City: A socio-ecological profile. 72, 379-390.

Cutter, S. L. 2012. Hazards Vulnerability and Environmental Justice. Routledge.

Dzurisin, D. (2003) A comprehensive approach to monitoring volcano deformation as a window on the eruption cycle. Reviews of Geophysics, 41, 1001.

Ebmeier, S., B. Andrews, M. Araya, D. Arnold, J. Biggs, C. Cooper, E. Cottrell, M. Furtney, J. Hickey \& J. J. J. o. A. V. Jay (2018) Synthesis of global satellite observations of magmatic and volcanic deformation: implications for volcano monitoring \& the lateral extent of magmatic domains. 7, 2.

Gawronski, V. T., R. S. J. L. A. P. Olson \& Society (2013) Disasters as crisis triggers for critical junctures? The 1976 Guatemala case. 55, 133-149.

INE, I. N. d. E. G. 2003. Censo nacionales XI de población y VI de habitación 2002. In Instituto Nacional de Estadística.

Jonas, S. 1976. Class-quake in Guatmala. In Guatemala and Central America Report. Berkeley, CA: American Friends of Guatemala.

Kates, R. W. 1976. Experiencing the environment as hazard. In Experiencing the environment, 133-156. Springer.

LaPorte, D. W. 2018. Evaluating landslide risk management in Guatemala City through a study of risk perception and behavior changes. Colorado School of Mines. Arthur Lakes Library.

Sparks, R. (2003) Forecasting volcanic eruptions. Earth and Planetary Science Letters, 210, 1-15.

Tesliuc, E. D. \& K. Lindert. 2004. Risk and vulnerability in Guatemala: A quantitative and qualitative assessment. Social Protection, Labor Markets, Pensions, Social Assistance, World Bank.

Timmerman, P. (1981) Vulnerability resilience and collapse ofsociety. A Review ofModels and Possible Climatic Applications. Toronto, Canada: Institute for Environmental Studies, University of Toronto.

Wisner, B., P. Blaikie, T. Cannon \& I. Davis. 2004. At risk: natural hazards, people's vulnerability and disasters. Psychology Press. 
World_Bank(a). 2009. Guatemala Poverty Assessment: Good Performances and Low Levels. In Report No 43920-GT. Central America Department Poverty Reduction and Economic Management Unity.

World_Bank(b). 2017. World Development Indicators. 


\section{Appendix}

\subsection{Chapter 2 supplemental material}

Table 6-1 Station occupations in UTM coordinates with 1-sigma uncertainties output from GIPSY/OASIS software, version GOA6.3 with precise clock and orbit determinations processed using International Terrestrial Reference Frame 2008 (ITRF08)

\begin{tabular}{|c|c|c|c|c|c|c|c|}
\hline BVIS & Date & Easting (m) & Northing (m) & Height (m) & $\sigma \mathrm{E}(\mathrm{m})$ & $\sigma \mathrm{N}(\mathrm{m})$ & $\sigma \mathrm{H}(\mathrm{m})$ \\
\hline 1 & $1 / 19 / 2009$ & 756513.852 & 1590836.544 & 1703.339 & 0.001 & 0.003 & 0.004 \\
\hline 2 & $1 / 26 / 2011$ & 756513.786 & 1590836.546 & 1703.299 & 0.001 & 0.003 & 0.004 \\
\hline 3 & $9 / 21 / 2011$ & 756513.784 & 1590836.550 & 1703.371 & 0.001 & 0.003 & 0.005 \\
\hline 4 & $11 / 30 / 2011$ & 756513.784 & 1590836.548 & 1703.383 & 0.001 & 0.003 & 0.005 \\
\hline 5 & $1 / 9 / 2012$ & 756513.780 & 1590836.546 & 1703.380 & 0.001 & 0.003 & 0.005 \\
\hline 6 & $4 / 11 / 2012$ & 756513.778 & 1590836.557 & 1703.387 & 0.002 & 0.003 & 0.005 \\
\hline 7 & $8 / 29 / 2012$ & & 1590836.553 & 1703.370 & 0.001 & 0.003 & 0.004 \\
\hline 8 & $12 / 2 / 2012$ & & 1590836.559 & 1703.362 & 0.001 & 0.003 & 0.004 \\
\hline 9 & $1 / 11 / 2013$ & & 1590836.558 & 1703.388 & 0.001 & 0.003 & 0.004 \\
\hline 10 & $3 / 28 / 2013$ & & 1590836.567 & 1703.371 & 0.002 & 0.004 & 0.007 \\
\hline 11 & $11 / 13 / 2014$ & 756513.767 & 1590836.563 & 1703.291 & 0.002 & 0.005 & 0.008 \\
\hline 12 & $1 / 16 / 2015$ & 756513.766 & 1590836.565 & 1703.274 & 0.002 & 0.005 & 0.007 \\
\hline CHNO & Date & Easting (m) & Northing (m) & Height (m) & $\sigma \mathrm{E}(\mathrm{m})$ & $\sigma \mathrm{N}(\mathrm{m})$ & $\sigma \mathrm{H}(\mathrm{m})$ \\
\hline 1 & $1 / 23 / 2009$ & 758104.265 & 1592161.670 & 2225.725 & 0.001 & 0.003 & 0.004 \\
\hline 2 & $1 / 20 / 2011$ & 758104.206 & 1592161.417 & 2225.541 & 0.001 & 0.003 & 0.004 \\
\hline 3 & 9/20/2011 & 758104.204 & 1592161.408 & 2225.540 & 0.002 & 0.004 & 0.006 \\
\hline 4 & $12 / 3 / 2011$ & 758104.199 & 1592161.410 & 2225.568 & 0.002 & 0.004 & 0.006 \\
\hline 5 & $1 / 7 / 2012$ & 758104.202 & 1592161.414 & 2225.567 & 0.001 & 0.004 & 0.005 \\
\hline 6 & $4 / 12 / 2012$ & 758104.206 & 1592161.412 & 2225.609 & 0.002 & 0.004 & 0.006 \\
\hline 7 & $8 / 28 / 2012$ & 758104.207 & 1592161.405 & 2225.553 & 0.001 & 0.003 & 0.004 \\
\hline 8 & $11 / 30 / 2012$ & 758104.196 & 1592161.400 & 2225.561 & 0.001 & 0.003 & 0.005 \\
\hline 9 & $1 / 12 / 2013$ & 758104.189 & 1592161.399 & 2225.552 & 0.001 & 0.004 & 0.006 \\
\hline 10 & $3 / 29 / 2013$ & 758104.187 & 1592161.404 & 2225.571 & 0.002 & 0.004 & 0.006 \\
\hline 11 & $11 / 15 / 2014$ & 758104.203 & 1592161.414 & 2225.441 & 0.002 & 0.007 & 0.010 \\
\hline 12 & $1 / 15 / 2015$ & 758104.203 & 1592161.415 & & 0.002 & 0.004 & 0.006 \\
\hline CHQO & Date & Easting (m) & Northing (m) & Height (m) & $\sigma E(m)$ & $\sigma \mathrm{N}(\mathrm{m})$ & $\sigma \mathrm{H}(\mathrm{m})$ \\
\hline 1 & $1 / 23 / 2009$ & 759424.416 & 1592156.205 & 2360.460 & 0.001 & 0.002 & 0.004 \\
\hline 2 & $1 / 21 / 2011$ & 759424.418 & 1592156.208 & 2360.450 & 0.001 & 0.002 & 0.004 \\
\hline 3 & 9/20/2011 & 759424.408 & 1592156.213 & 2360.467 & 0.003 & 0.005 & 0.008 \\
\hline 4 & $12 / 2 / 2011$ & 759424.417 & 1592156.214 & 2360.462 & 0.002 & 0.004 & 0.006 \\
\hline
\end{tabular}

116 


\begin{tabular}{|c|c|c|c|c|c|c|c|}
\hline 5 & $1 / 8 / 2012$ & 759424.415 & 1592156.211 & 2360.481 & 0.002 & 0.005 & 0.007 \\
\hline 6 & $8 / 27 / 2012$ & 759424.417 & 1592156.218 & 2360.481 & 0.002 & 0.003 & 0.005 \\
\hline 7 & $12 / 1 / 2012$ & 759424.407 & 1592156.213 & 2360.485 & 0.001 & 0.003 & 0.005 \\
\hline 8 & $1 / 12 / 2013$ & 759424.405 & 1592156.214 & 2360.477 & 0.001 & 0.003 & 0.006 \\
\hline 9 & $3 / 29 / 2013$ & 759424.402 & 1592156.216 & 2360.497 & 0.002 & 0.004 & 0.006 \\
\hline 10 & $11 / 14 / 2014$ & 759424.423 & 1592156.236 & 2360.447 & 0.002 & 0.005 & 0.008 \\
\hline 11 & $1 / 10 / 2015$ & 759424.423 & 1592156.239 & 2360.427 & 0.002 & 0.005 & 0.007 \\
\hline CHUP & Date & Easting $(\mathrm{m})$ & Northing $(\mathrm{m})$ & Height $(\mathrm{m})$ & $\sigma \mathrm{E}(\mathrm{m})$ & $\sigma \mathrm{N}(\mathrm{m})$ & $\sigma \mathrm{H}(\mathrm{m})$ \\
\hline 1 & $1 / 20 / 2009$ & 758376.716 & 1588823.806 & 1516.312 & 0.001 & 0.002 & 0.004 \\
\hline 2 & $1 / 25 / 2011$ & 758376.696 & 1588823.779 & 1516.291 & 0.001 & 0.003 & 0.005 \\
\hline 3 & $9 / 22 / 2011$ & 758376.693 & 1588823.788 & 1516.319 & 0.002 & 0.003 & 0.005 \\
\hline 4 & $12 / 4 / 2011$ & 758376.696 & 1588823.791 & 1516.338 & 0.001 & 0.003 & 0.005 \\
\hline 5 & $1 / 10 / 2012$ & 758376.688 & 1588823.784 & 1516.325 & 0.001 & 0.003 & 0.005 \\
\hline 6 & $4 / 10 / 2012$ & 6.702 & 1588823.799 & 1516.317 & 0.002 & 0.003 & 0.005 \\
\hline 7 & $8 / 26 / 2012$ & 758376.692 & 1588823.796 & 1516.342 & 0.001 & 0.003 & 0.006 \\
\hline 8 & $11 / 29 / 2012$ & 758376.686 & 1588823.795 & 1516.273 & 0.001 & 0.003 & 0.005 \\
\hline 9 & $1 / 13 / 2013$ & 758376.684 & 1588823.789 & 1516.357 & 0.001 & 0.003 & 0.005 \\
\hline 10 & $3 / 28 / 2013$ & .688 & 1588823.790 & 1516.340 & 0.002 & 0.004 & 0.006 \\
\hline 11 & $11 / 12 / 2014$ & 758376.675 & 1588823.804 & 1516.247 & 0.002 & 0.004 & 0.006 \\
\hline 12 & $1 / 11 / 2015$ & 758376.681 & 1588823.797 & 1516.296 & 0.002 & 0.005 & 0.008 \\
\hline CRAK & Date & Easting $(\mathrm{m})$ & Northing (m) & Height $(\mathrm{m})$ & $\sigma \mathrm{E}(\mathrm{m})$ & $\sigma \mathrm{N}(\mathrm{m})$ & $\sigma \mathrm{H}(\mathrm{m})$ \\
\hline 1 & $8 / 28 / 2012$ & 783 & 1591644.707 & 2390.627 & 0.002 & 0.005 & 0.006 \\
\hline 2 & $11 / 30 / 2012$ & 758 & 1591 & 2390.568 & 0.002 & 0.006 & 0.008 \\
\hline 3 & $1 / 12 / 2013$ & 758445.734 & 1591 & 2390.602 & 0.002 & 0.006 & 0.008 \\
\hline 4 & $3 / 29 / 2013$ & 758445.731 & 1591644.724 & 2390.573 & 0.002 & 0.007 & 0.010 \\
\hline LBLK & Date & Easting $(\mathrm{m})$ & Northing (m) & Height $(\mathrm{m})$ & $\sigma \mathrm{E}(\mathrm{m})$ & $\sigma \mathrm{N}(\mathrm{m})$ & $\sigma \mathrm{H}(\mathrm{m})$ \\
\hline 1 & $1 / 20 / 2009$ & 757357.414 & 1588971.778 & 1399.092 & 0.001 & 0.002 & 0.004 \\
\hline 2 & $1 / 22 / 2011$ & 757357.308 & 1588971.564 & 1398.902 & 0.001 & 0.003 & 0.004 \\
\hline 3 & $9 / 21 / 2011$ & 757357.303 & 1588971.563 & 1398.947 & 0.002 & 0.004 & 0.006 \\
\hline 4 & $12 / 6 / 2011$ & 757357.312 & 1588971.564 & 1398.870 & 0.002 & 0.004 & 0.006 \\
\hline 5 & $1 / 6$ & 757357.296 & 1588971.555 & 1398.944 & 0.001 & 0.003 & 0.004 \\
\hline 6 & $4 / 11$ & 757357.299 & 1588971.558 & 1398.938 & 0.002 & 0.004 & 0.008 \\
\hline 7 & $8 / 29 / 2012$ & 757357.303 & 1588971.558 & 61 & 0.002 & 0.003 & 0.006 \\
\hline 8 & $12 / 2 / 2012$ & 757357.288 & 1588971.548 & 1398.967 & 0.001 & 0.003 & 0.005 \\
\hline 9 & $1 / 11 / 2013$ & 757357.296 & 1588971.558 & 1398.918 & 0.001 & 0.003 & 0.006 \\
\hline 10 & $3 / 28 / 2013$ & 757357.294 & 1588971.556 & 1398.934 & 0.002 & 0.004 & 0.006 \\
\hline 11 & $11 / 13 / 2014$ & 757357.279 & 1588971.555 & 1398.871 & 0.002 & 0.005 & 0.007 \\
\hline 12 & $1 / 20 / 2015$ & 757357.282 & 1588971.550 & 1398.883 & 0.002 & 0.004 & 0.007 \\
\hline LVES & Date & Easting $(\mathrm{m})$ & Northing (m) & Height (m) & $\sigma \mathrm{E}(\mathrm{m})$ & $\sigma \mathrm{N}(\mathrm{m})$ & $\sigma \mathrm{H}(\mathrm{m})$ \\
\hline
\end{tabular}




\begin{tabular}{|r|r|r|r|r|r|r|r|}
\cline { 1 - 1 }$n$ & $9 / 24 / 2011$ & 759124.815 & 1591548.414 & 2385.319 & 0.002 & 0.004 & 0.005 \\
\hline 2 & $12 / 2 / 2011$ & 759124.838 & 1591548.422 & 2385.315 & 0.001 & 0.004 & 0.006 \\
\hline 3 & $1 / 8 / 2012$ & 759124.844 & 1591548.422 & 2385.307 & 0.002 & 0.004 & 0.006 \\
\hline 4 & $8 / 27 / 2012$ & 759124.849 & 1591548.437 & 2385.285 & 0.002 & 0.004 & 0.005 \\
\hline 5 & $12 / 1 / 2012$ & 759124.860 & 1591548.433 & 2385.271 & 0.002 & 0.004 & 0.006 \\
\hline 6 & $1 / 12 / 2013$ & 759124.860 & 1591548.435 & 2385.257 & 0.001 & 0.004 & 0.006 \\
\hline 7 & $3 / 29 / 2013$ & 759124.867 & 1591548.435 & 2385.266 & 0.002 & 0.004 & 0.006 \\
\hline 8 & $11 / 14 / 2014$ & 759125.116 & 1591548.552 & 2385.144 & 0.002 & 0.007 & 0.010 \\
\hline 9 & $1 / 10 / 2015$ & 759125.122 & 1591548.561 & 2385.122 & 0.002 & 0.005 & 0.007 \\
\hline
\end{tabular}

Table 6-2 Acquisition dates for interferograms used in this study.

\begin{tabular}{|l|l|}
\hline Acquisition 1 & Acquisition 2 \\
\hline 26-Mar-13 & 24-Jul-13 \\
\hline 24-Jul-13 & $17-A u g-13$ \\
\hline 17-Aug-13 & $10-$ Sep-13 \\
\hline 10-Sep-13 & $4-$ Oct-13 \\
\hline 4-Oct-13 & 21-Nov-13 \\
\hline 21-Nov-13 & $15-$ Dec-13 \\
\hline 15-Dec-13 & 8-Jan-14 \\
\hline 8-Jan-14 & $21-M a r-14$ \\
\hline 21-Mar-14 & $14-A p r-14$ \\
\hline 14-Apr-14 & 8-May-14 \\
\hline 8-May-14 & 1-Jun-14 \\
\hline 1-Jun-14 & 25-Jun-14 \\
\hline 25-Jun-14 & $19-J u l-14$ \\
\hline 19-Jul-14 & $12-A u g-14$ \\
\hline 12-Aug-14 & 5-Sep-14 \\
\hline 5-Sep-14 & 29-Sep-14 \\
\hline 29-Sep-14 & $16-N o v-14$ \\
\hline
\end{tabular}



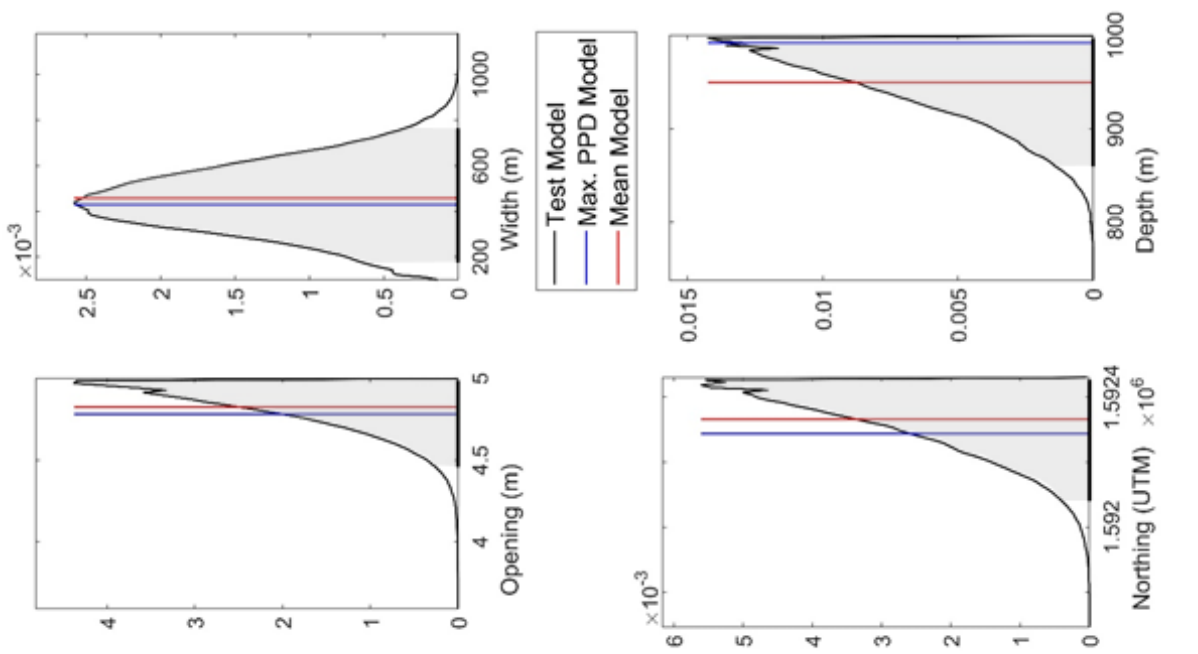

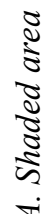
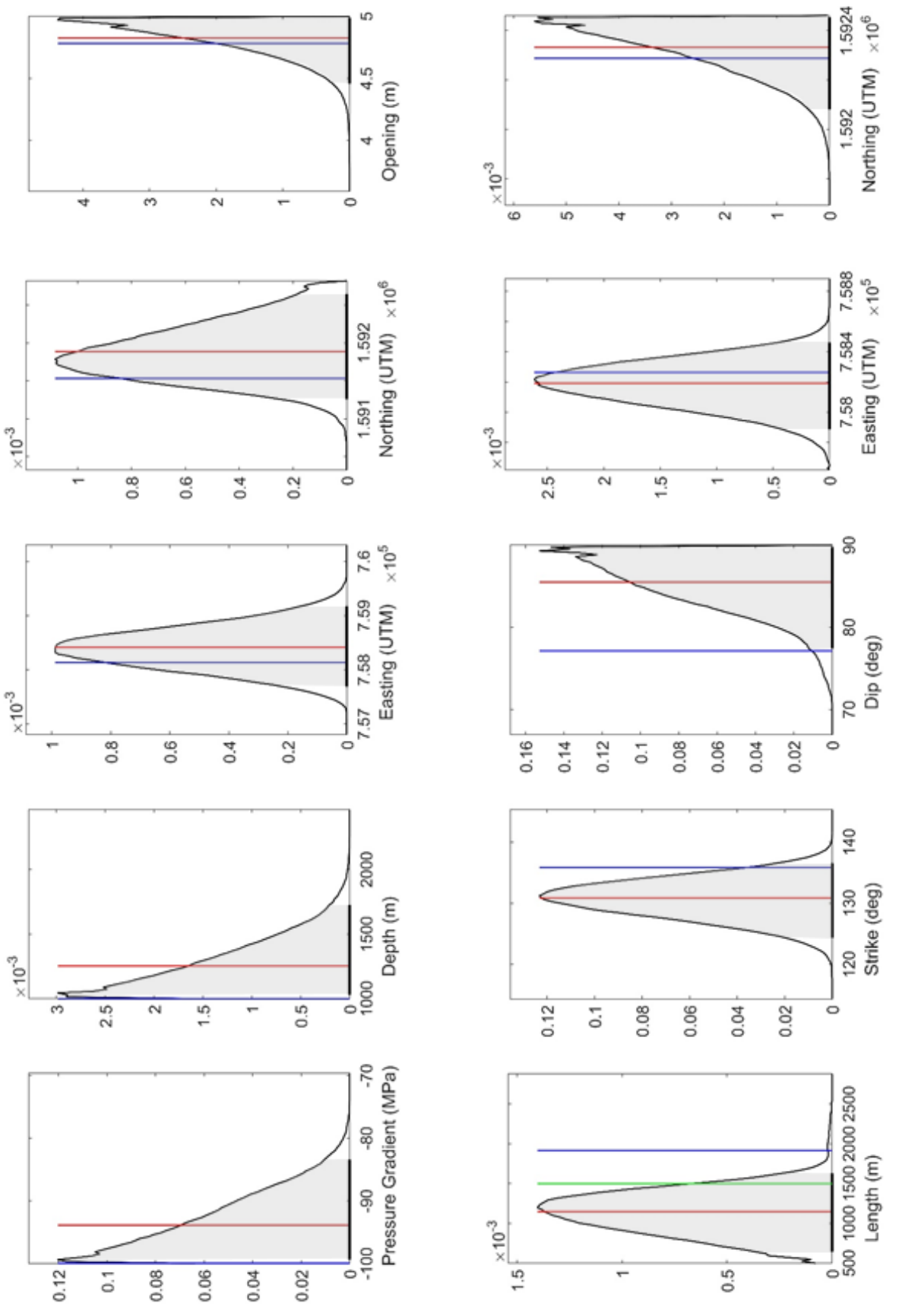





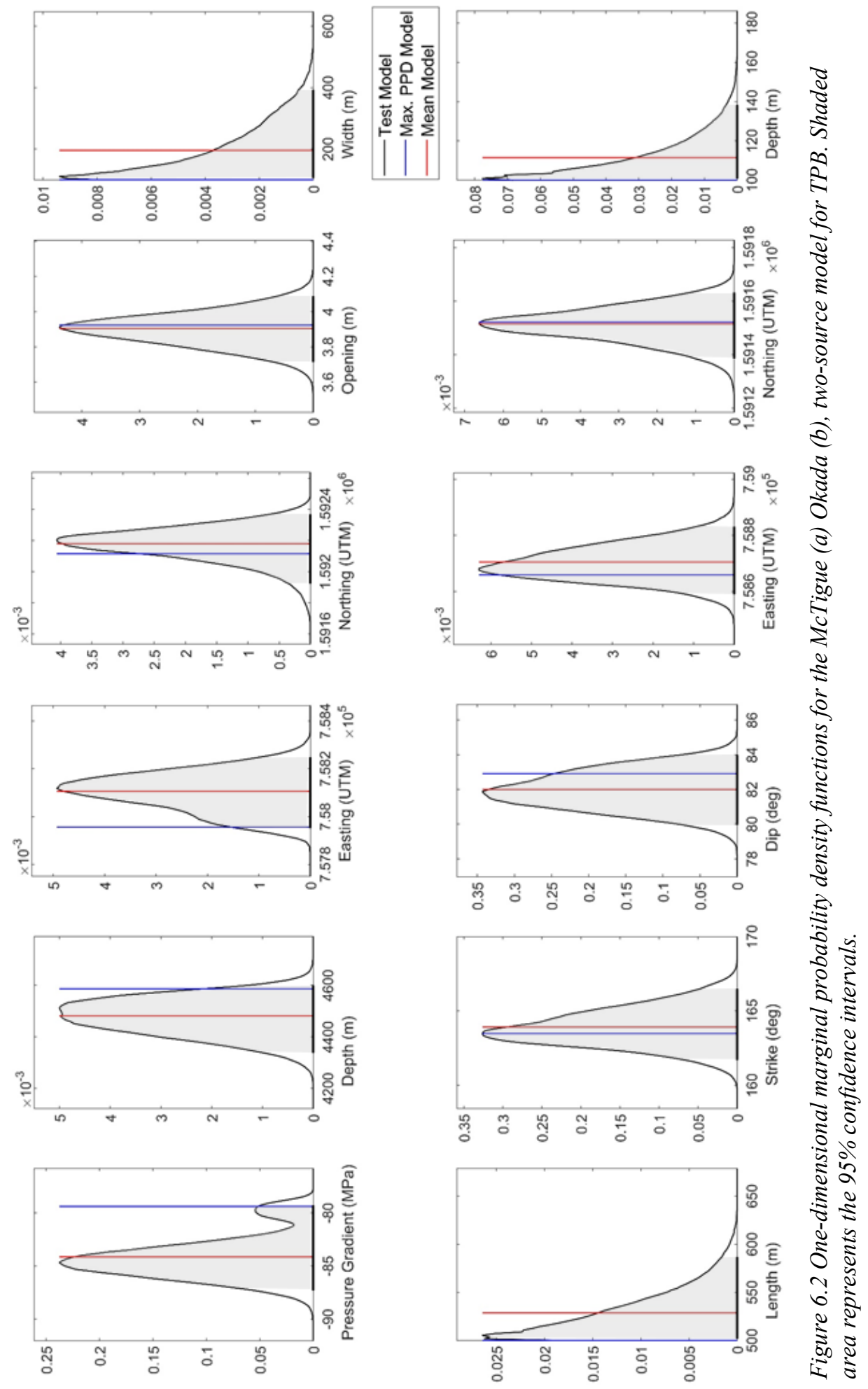







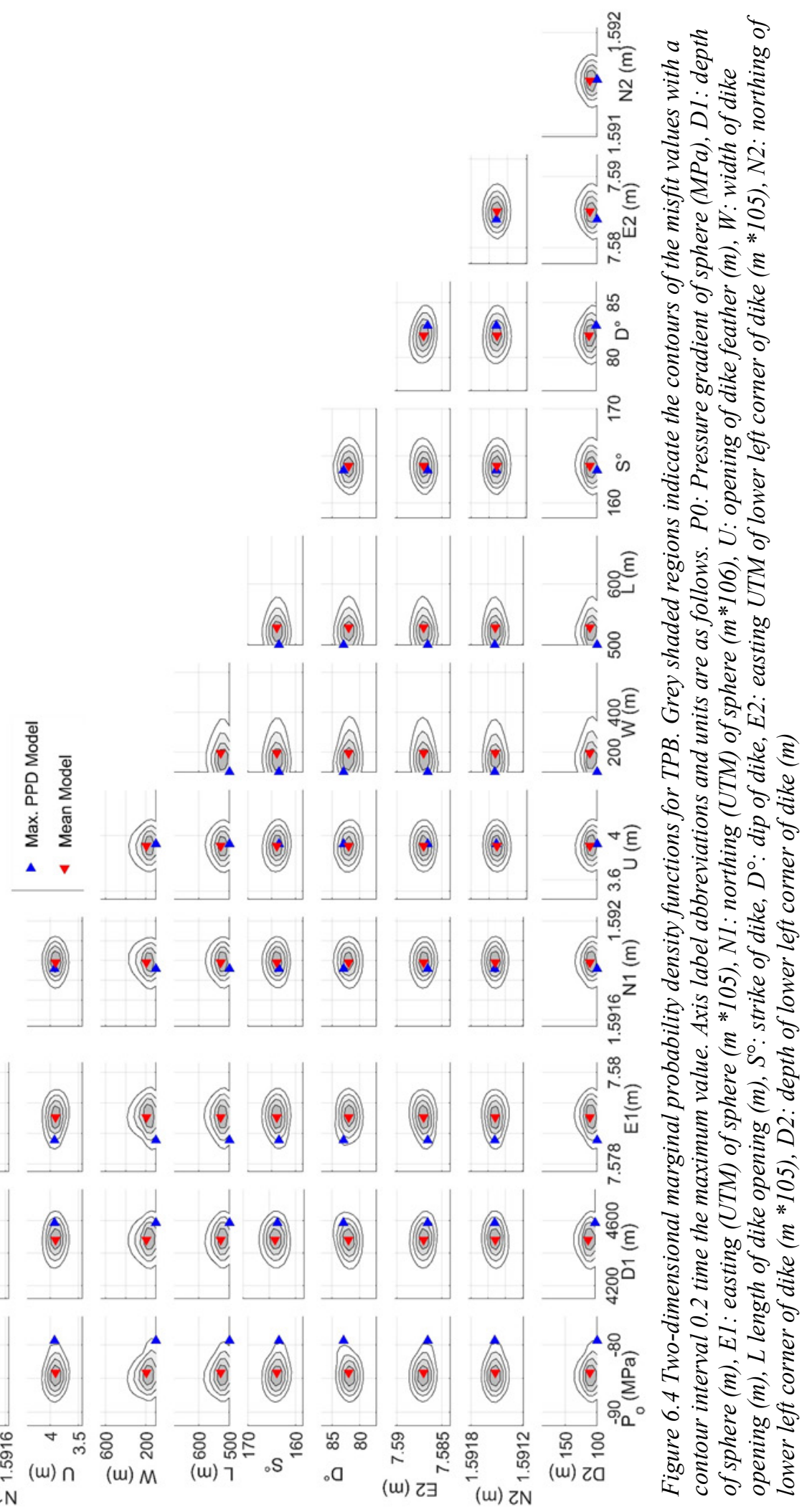






Figure 6.5 Map view of our modeled spherical dike sources for both TPA and TPB compared to those modeled by Wnuk and Wauthier (2017). Grey features represent the models from this study. Red features represent the model presented by Wnuk and Wauthier. Red rectangles indicate $95 \%$ confidence areas. Green rectangles with double black line indicate $95 \%$ confidence areas for time-period A. Blue rectangles with hash outline represent $95 \%$ confidence areas for time-period B. Confidence areas for dike features modeled in this work represent $X$ and $Y$ position of lower left corner. 


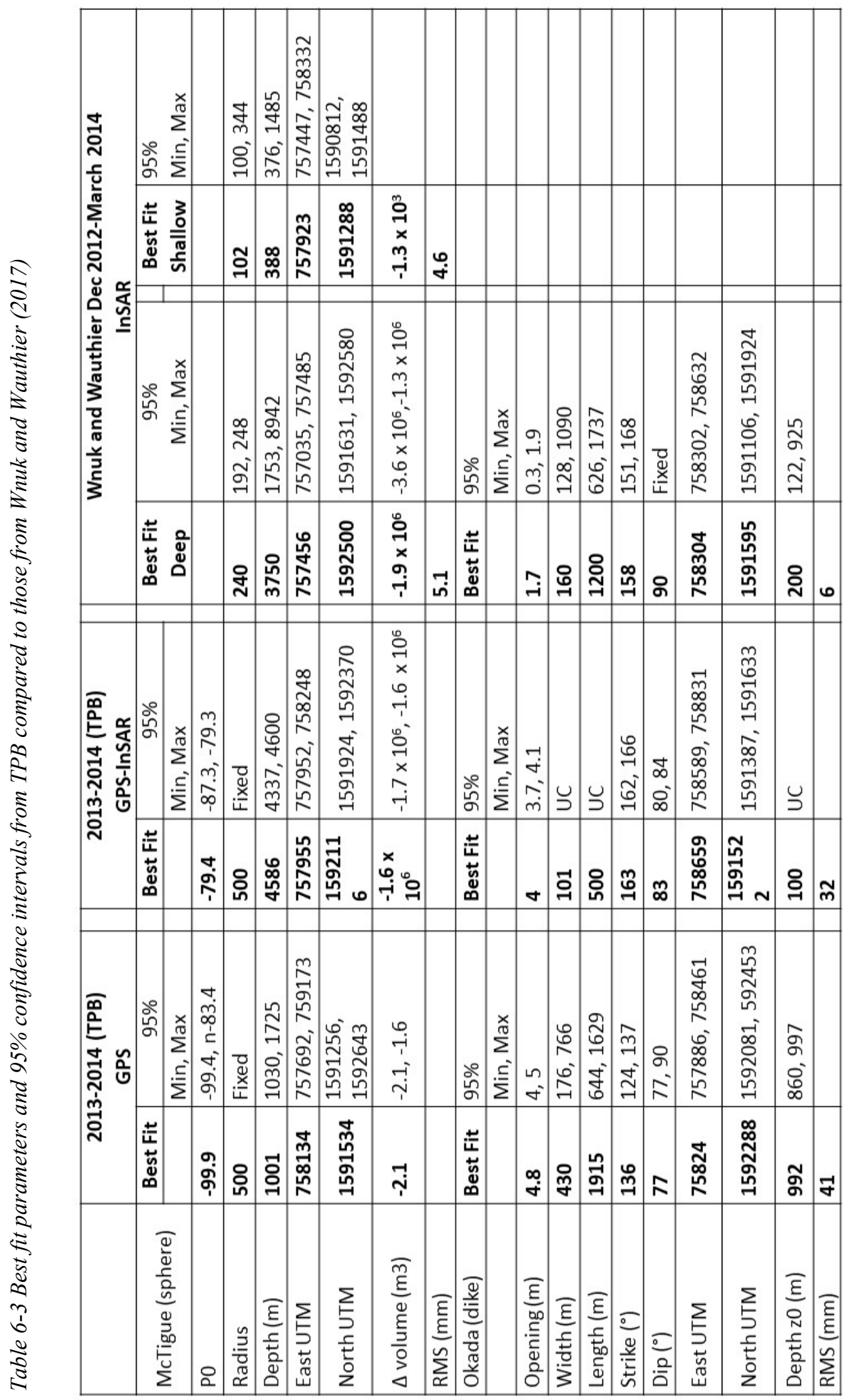




\subsection{Chapter 3 supplemental material}

\subsubsection{Survey in Spanish}

Encuesta sobre las crisis volcánicas en el volcán Pacaya

Toda la información que Usted proveerá en las respuestas a las siguientes preguntas será anónima. La información será utilizada únicamente con fines de investigación y la identidad de los encuestados nunca será revelada a otras personas. Usted puede sentirse libre para no responder a cualquier de las preguntas o terminar la entrevista en cualquier momento.

Nombre de Comunidad

Nombre de entrevistador

Fecha

Genero del voluntario(a): $\mathrm{M} \square$

$\mathrm{Fu}$

Tipo de casa: Madera $\square$ Lamina $\square$ Bloque/concreto $\square$ Adobe $\square$ Mud/Straw $\square$ Otro

Tipo de techo: Madera $\square$ Lamina $\square$ Concreto $\square$ Palma/paja $\square$ Cerámico $\square$ Otro $\square$

Tienen electricidad: Si $\square$ No $\square$ No se $\square$

¿Quién o quienes toma las decisiones importantes en su

casa? Por ejemplo Madre, Padre, abuela, o toda la familia

1 juntas

¿Se siente cómodo contestando preguntas sobre

2 decisiones de la casa?

$\square$ No $\quad \square \mathrm{Si}$

Así "NO" pregunte así hay algún tiempo a volver para

hablar con el líder de la casa. Así no, dígales "Gracias"

3 ¿Cuántos años tiene?

¿En que

trabaja o a

que se $\quad$ en el $\quad \square$ Ama de $\quad \square \quad \square$ No trabaja ni

4 dedica?

campo

casa Estudiante

estudia

5 ¿Otra ocupación (indique cual)?

¿Cuál es su fuente de ingreso

6 primario?

¿Nivel de

7 educación

completado? $\quad \square$ Primaria $\square$ Basicos Diversificado $\square$ Universidad

8 Estado Civil $\square$ Soltero(a) $\square$ Casado(a) Unido(a)

$9 \quad$ ¿Cuántos hijos tiene? Más de 18 Menos de 18

¿Cuantas personas viven en esta

10 casa?

Más de 18 Menos de 18

Se encontraba usted o cualquier miembro

de su casa aquí durante la erupción en el

11

2010 del volcán Pacaya?

$\square$ No

$\square \mathrm{Si} \quad \square$ NoSe

Si "NO" pase a la pregunta \#22

¿Cuantos miembros de su familia vivían

en su casa durante la erupción de

2010?

Más de 18

Menos de 18 


\begin{tabular}{|l|l|l|}
\hline \multicolumn{2}{|l|}{$\begin{array}{l}\text { 13 } \\
14\end{array}$} & $\begin{array}{l}\text { Vio o escuchó un mensaje de alerta oficial (Por ejemplo } \\
\text { INSIVUMEH, CONRED o PNC, etc.) }\end{array}$ \\
\hline 15 & & Sabía Usted sobre las albergues emergencia? \\
\hline \multirow{2}{*}{16} & & $\begin{array}{l}\text { Usted o algún miembro de su casa fueron evacuados durante la } \\
\text { erupción en el } 2010 \text { del volcán Pacaya? }\end{array}$ \\
\cline { 2 - 3 } & a & \begin{tabular}{l} 
¿Cuantos miembros de su casa que fueron evacuados? \\
\cline { 2 - 3 }
\end{tabular} \\
& b & $\begin{array}{l}\text { ¿Cuantos miembros de su casa se quedaron en la casa durante la } \\
\text { erupción? }\end{array}$ \\
\end{tabular}

\begin{tabular}{|l|l|}
\hline 17 & $\begin{array}{l}\text { ¿De las personas que fueron evacuadas durante la erupción } \\
\text { alguna paso una o más noches en un albergue de emergencia? }\end{array}$ \\
\hline 18 & $\begin{array}{l}\text { ¿Las personas que evacuaron, salieron antes o durante la } \\
\text { erupción? }\end{array}$ \\
\hline 19 & $\begin{array}{l}\text { ¿Si hubiera una nueva erupción como la del 2010, evacuaría o } \\
\text { no? }\end{array}$ \\
\hline
\end{tabular}

\begin{tabular}{l}
$\begin{array}{l}\text { Por favor califique las siguientes afirmaciones según una escala de } 1 \\
\text { a 5, en cual } 1 \text { significa NADA/NINGUNA y } 5 \text { significa MUCHISIMO }\end{array}$ \\
\hline 20 \\
\hline
\end{tabular}




\begin{tabular}{|c|c|}
\hline & $\begin{array}{l}\text { ¿Cuál es la importancia de los siguientes factores en su } \\
\text { decisión de evacuar o no? }\end{array}$ \\
\hline a & $\begin{array}{l}\text { Ver o escuchar un mensaje de alerta oficial (Por ejemplo } \\
\text { INSIVUMEH, CONRED o PNC, etc.) }\end{array}$ \\
\hline b & $\begin{array}{l}\text { Escuchar el mensaje de alerta de parte de amigos, vecinos } \\
\text { o familiares }\end{array}$ \\
\hline c & $\begin{array}{l}\text { Escuchar un mensaje de alerta de parte de un miembro de } \\
\text { la Iglesia }\end{array}$ \\
\hline d & $\begin{array}{l}\text { Escuchar un mensaje de alerta de parte de líderes } \\
\text { comunitarios (por ejemplo del COCODE) }\end{array}$ \\
\hline e & $\begin{array}{l}\text { Ver o escuchar un mensaje de alerta en las noticias (por } \\
\text { ejemplo, televisión, radio, periódico, etc.) }\end{array}$ \\
\hline f & $\begin{array}{l}\text { Escuchar un mensaje de alerta por parte de la } \\
\text { municipalidad }\end{array}$ \\
\hline $\mathrm{g}$ & $\begin{array}{l}\text { Cuando comienzan a caer cenizas, arena, piedras u otros } \\
\text { materiales volcánicos }\end{array}$ \\
\hline $\mathrm{h}$ & Ver amigos, familiares y vecinos evacuar \\
\hline i & Sentirse seguro en su casa \\
\hline j & Temor de los ladrones al abandonar su casa \\
\hline k & $\begin{array}{l}\text { La necesidad a proteger nuestra casa de las cenizas, arena, } \\
\text { etc. }\end{array}$ \\
\hline I & La necesidad a cuidar de las siembras o animales \\
\hline $\mathrm{m}$ & Los medios para evacuar \\
\hline $\mathrm{n}$ & Acceso a transporte \\
\hline o & Un lugar seguro a llegar (albergue de emergencia, etc.) \\
\hline$p$ & Su salud o sus habilidades físicamente \\
\hline$q$ & ¿Alguna otra razón que influyó en su decisión? \\
\hline 22 & $\begin{array}{l}\text { Está usted de acuerdo o en desacuerdo con las siguientes } \\
\text { declaraciones }\end{array}$ \\
\hline a & $\begin{array}{l}\text { El volcán Pacaya dará señales claras de que va a tener una } \\
\text { erupción de gran magnitud como la del } 2010 \text { o más } \\
\text { grande, antes de entrar en erupción }\end{array}$ \\
\hline b & $\begin{array}{l}\text { Erupciones grandes como la del volcán Pacaya en } 2010 \text { se } \\
\text { están volviendo más frecuentes }\end{array}$ \\
\hline d & $\begin{array}{l}\text { La erupción del } 2010 \text { de Pacaya es la más grande que el } \\
\text { volcán ha tenido }\end{array}$ \\
\hline c & $\begin{array}{l}\text { El volcán Pacaya tendrá otra erupción de gran magnitud } \\
\text { como la del } 2010 \text { o más grande durante su vida }\end{array}$ \\
\hline
\end{tabular}




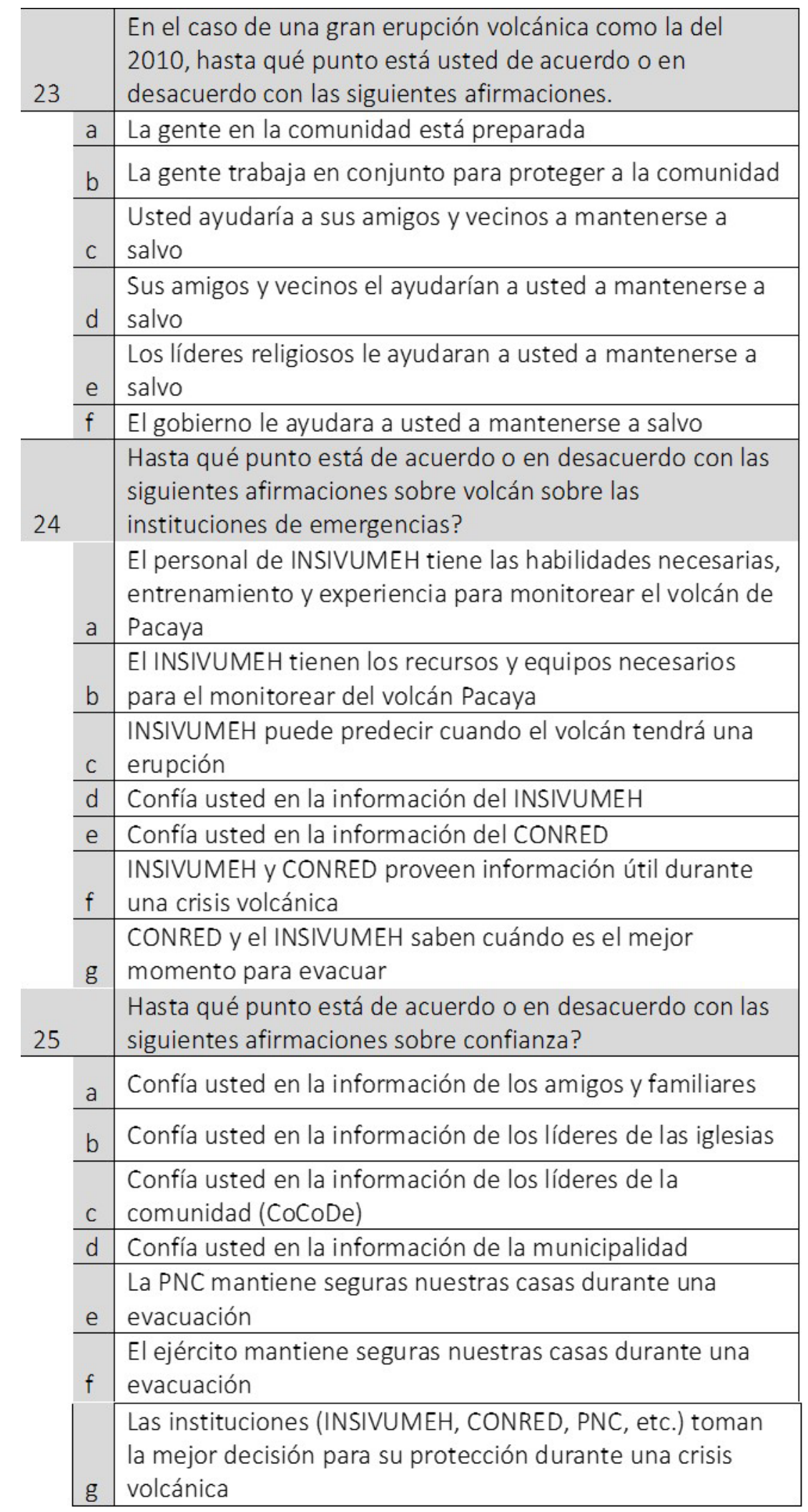




\begin{tabular}{|c|c|}
\hline 26 & En el caso de otra gran erupción similar a $2010 \ldots$ \\
\hline a & Estará listo para evacuar \\
\hline$b$ & Estará preparado para proteger su casa \\
\hline 27 & $\begin{array}{l}\text { En su opinión, ¿Qué tan de acuerdo o en desacuerdo esta } \\
\text { con las siguientes afirmaciones sobre de la preparación } \\
\text { durante otra gran erupción como la de } 2010 \text { ? }\end{array}$ \\
\hline a & Puede mantenerse a salvo \\
\hline $\mathrm{b}$ & Puede mantener a su familia a salvo \\
\hline $\mathrm{C}$ & Puede evacuar de manera segura a tiempo \\
\hline $\mathrm{d}$ & Sabe usted a dónde ir \\
\hline $\mathrm{e}$ & Se puede llegar a un lugar seguro. \\
\hline 28 & $\begin{array}{l}\text { En su opinión, ¿Qué tan de acuerdo o en desacuerdo está } \\
\text { con las siguientes afirmaciones acerca de las evacuaciones } \\
\text { en el futuro si hay otra gran erupción como la de la de } \\
2010\end{array}$ \\
\hline a & $\begin{array}{l}\text { Va a evacuar si hay un mensaje de alerta del INSIVUMEH o } \\
\text { CONRED, incluso si el volcán no parece estar en erupción }\end{array}$ \\
\hline$b$ & $\begin{array}{l}\text { Va a evacuar durante otra gran erupción, incluso si usted } \\
\text { no recibe un mensaje de alerta del INSIVUMEH o CONRED }\end{array}$ \\
\hline C & $\begin{array}{l}\text { Usted será capaz de evacuar. Por ejemplo tendrá tiempo } \\
\text { suficient, transporte, refugio, apoyo, etc. para salir. }\end{array}$ \\
\hline d & $\begin{array}{l}\text { La evacuación es la mejor manera de mantenerse a salvo } \\
\text { durante una erupción volcánica grande }\end{array}$ \\
\hline $\mathrm{e}$ & $\begin{array}{l}\text { Usted no planea evacuar durante otra gran erupción } \\
\text { volcánica }\end{array}$ \\
\hline 29 & $\begin{array}{l}\text { Usted obtiene información sobre qué hacer durante las } \\
\text { emergencias volcánicas de: }\end{array}$ \\
\hline a & Televisión \\
\hline$b$ & Radio \\
\hline $\mathrm{c}$ & Periódico \\
\hline $\mathrm{d}$ & Teléfono móvil \\
\hline $\mathrm{e}$ & Internet \\
\hline f & Medios sociales (Twitter, Facebook, etc.) \\
\hline $\mathrm{g}$ & ¿Algún otra fuente de información que no está en la lista? \\
\hline
\end{tabular}




\subsubsection{Survey in English}

\section{Survey about volcanic crises at Pacaya volcano}

All of the information you provide in the following answers will be anonymous. The information will be used solely for this research and the identity of the respondents will never be revealed to any other persons. You can feel free not to respond to any question or end this interview at any moment.

Name of community

Name of interviewer

Date

Gender of volunteer: $\mathrm{M} \square \quad \mathrm{F} \square$

Type of house: Wood $\square$ Sheet metal $\square$ Block/Concrete $\square$ Adobe $\square$ Mud/Straw $\square$ Other $\square$ Type of roof: Wood $\square$ Sheet metal $\square$ Concrete $\square$ Palm leaf $\square$ Ceramic $\square$ Other $\square$

Do they have electricity: Yes $\square$ No $\square$ D/K $\square$

Who or whom makes the important decisions in this

household (e.g. mother, father, grandmother, or

1 everyone together)?

Do you feel comfortable answering question about

2 household decisions?

If "NO" ask if there is another time we can return to speak with the head of the household. If no, tell them thankyou

3 What is your age

What kind of work do you

4 do?

$\square$ work in the

$\square$ Home No $\square \mathrm{Si}$

5 Other occupation (indicate which))? What is your primary source of

6 income?

7 Level of education completed

$\square$ Primary maker

Student

No work or field/agriculture (n)

school

8 Marital status $\square$ Single

Basic $\square$ Secondary University

9 How many children do you have? How many people live in this

house? $\square$ Married/Partnered Where you or any member of your household Older than $18 \quad$ Younger than 18 living in this community during the 2010 eruption of Pacaya?

\section{If "No" move to question 23}

How many members of your family were living here during the 2010 


\begin{tabular}{|c|c|}
\hline 13 & Did you see or hear an official warning message? \\
\hline 14 & Did you know about the emergency shelters? \\
\hline 15 & Was transportation available for evacuation? \\
\hline 16 & $\begin{array}{l}\text { Did you or any member of your household evacuate during the } 2010 \text { eruption } \\
\text { of Pacaya volcano? }\end{array}$ \\
\hline \multirow{2}{*}{$\begin{array}{l}\text { a) } \\
\text { b) }\end{array}$} & How many members of your household were evacuated \\
\hline & How many members of your household stayed in place during the eruption \\
\hline 17 & $\begin{array}{l}\text { Of those who evacuated did anyone spend one or more nights in an } \\
\text { emergency shelter during the eruption? }\end{array}$ \\
\hline 18 & Did you and your family evacuate before the eruption began? \\
\hline \multirow[t]{2}{*}{19} & If there was another eruption like that in 2010 , would you evacuate or not? \\
\hline & $\begin{array}{l}\text { Please identify the degree to which you agree or disagree with the following } \\
\text { statements using a scale of } 1 \text { to } 5 \text { in which } 1 \text { signifies none/not-at-all and } 5 \\
\text { signifies totally/very much. }\end{array}$ \\
\hline \multirow{5}{*}{$\begin{array}{l}20 \\
\text { a) } \\
\text { b) } \\
\text { c) } \\
\text { d) }\end{array}$} & During the 2010 eruption how much did you experience the following? \\
\hline & Damage to your home or property \\
\hline & Damage to your milpa, finca or animals \\
\hline & Injury to you or a member of your household \\
\hline & Theft from robbers \\
\hline 21 & $\begin{array}{l}\text { On a scale of } 1 \text { to } 5,1 \text { being none and } 5 \text { being very much: How important are } \\
\text { the following factors in your decision to evacuate? }\end{array}$ \\
\hline \multirow{2}{*}{ a) } & $\begin{array}{l}\text { Hearing or seeing an official warning message (e.g. INSIVUMEH, CONRED or } \\
\text { PNC, etc) }\end{array}$ \\
\hline & Hearing an warning message from friends and family \\
\hline \multirow{3}{*}{$\begin{array}{l}\text { c) } \\
\text { d) } \\
\text { e) }\end{array}$} & Hearing a warning message from church leaders \\
\hline & Hearing a warning message from community leaders (e.g. CoCoDe). \\
\hline & Hearing or seeing a warning message on the news (e.g. TV, radio, paper, etc) \\
\hline & Hearing a warning message from elected officials \\
\hline & When volcanic ash, bombs or tephra begins to fall \\
\hline \multirow{2}{*}{$\begin{array}{l}\text { h) } \\
\text { i) }\end{array}$} & Seeing friends, family and neighbors evacuating \\
\hline & Feeling of safety in your house \\
\hline \multirow{2}{*}{ j) } & The fear of robbers to leave your house \\
\hline & The need to protect your home from ash, tephra, etc \\
\hline \multirow{2}{*}{$\begin{array}{l}\text { l) } \\
\mathrm{m})\end{array}$} & The need to protect your plants and animals \\
\hline & The means to evacuate \\
\hline n) & Access to transportation \\
\hline \multirow{2}{*}{$\begin{array}{l}\text { o) } \\
\text { p) }\end{array}$} & A safe place to go (shelter) \\
\hline & Your health or physical abilities \\
\hline
\end{tabular}


22 To what extent do you agree or disagree with the following statements Pacaya volcano will give clear signals that it is going to have a large eruption

a) like the one in $\mathbf{2 0 1 0}$ or bigger before the eruption begins Large eruptions like the one in $\mathbf{2 0 1 0}$ at Pacaya volcano are becoming more

b) frequent

c) The eruption in 2010 is the first time Pacaya has had a large eruption. Pacaya volcano will have another large eruption like the one in 2010 or bigger

d) before you die In the event of a large volcanic eruption like the one in 2010, to what extent

23 do you agree or disagree with the following statements

a) The people in this community are prepared

b) The people in this community work together to protect the community

c) You would help your friends and neighbors stay safe in their home

d) Your friends and neighbors would help you stay safe in your home

e) Church leaders will help you stay safe in your home

f) The government will help you stay safe in your home

24 To what extent do you agree or disagree with the following statements The people at INSIVUMEH have the necessary skills, training and experience to

a) monitor the volcano Pacaya The people at INSIVUMEH have the necessary skills, training and experience to

b) monitor the volcano Pacaya INSIVUMEH has the necessary resources and equipment to monitor the

c) volcano Pacaya

d) INSIVUMEH can predict when the volcano will erupt

e) This household trusts the information from INSIVUMEH

f) This household trusts the information from CONRED

g) INSIVUMEH and CONRED provide useful information during a volcanic crisis

h) CONRED and INSIVUMEH know when it is the best time to evacuate

25 To what extent do you agree or disagree with the following statements

a) This household trusts information from friends, family

b) This household trusts information from church leaders

c) This household trusts information from community leaders (CoCoDe)

d) This household trust information from the municipal leaders

e) The PNC does a good job protecting us and our property during an evacuation

f) The army does a good job protecting us and our property during an evacuation Emergency managers (eg INSIVUMEH, CONRED, PNC) make the best decision

g) for your safety during a volcanic crisis 


\begin{tabular}{|c|c|}
\hline 26 & $\begin{array}{l}\text { To what extent do you agree or disagree with the following statements: In the } \\
\text { event of another large eruption similar to } 2010 \ldots\end{array}$ \\
\hline \multirow{2}{*}{$\begin{array}{l}\text { a) } \\
\text { b) }\end{array}$} & You will be ready to evacuate. \\
\hline & You will be ready to protect you home \\
\hline 27 & $\begin{array}{l}\text { In your opinion, how much do you agree or disagree with the following } \\
\text { statements about preparedness during another large eruption like the one in } \\
2010 \text { ? }\end{array}$ \\
\hline \multirow{4}{*}{$\begin{array}{l}\text { a) } \\
\text { b) } \\
\text { c) } \\
\text { d) } \\
\text { e) }\end{array}$} & You can keep yourself safe \\
\hline & You can keep your family safe \\
\hline & You can evacuate safely in time \\
\hline & $\begin{array}{l}\text { You will know where to go } \\
\text { Will you be able to get somewhere safe } \\
\text { In your opinion, how much do you agree or disagree with the following } \\
\text { statements about evacuations in future if there is another large eruption like } \\
\text { the one the one } 2010 \text {. }\end{array}$ \\
\hline a) & $\begin{array}{l}\text { You will evacuate if there is a warning message from INSIVUMEH or CONRED } \\
\text { even if the volcano does not appear to be erupting }\end{array}$ \\
\hline b) & $\begin{array}{l}\text { You will evacuate during another large eruption even if you do not receive a } \\
\text { warning message from INSIVUMEH or CONRED }\end{array}$ \\
\hline c) & You will be able to evacuate (e.g. time, transport, shelter, support, etc) \\
\hline d) & Evacuation is the best way to stay safe during a volcanic eruption \\
\hline e) & You do not plan evacuate during another large volcanic eruption \\
\hline 29 & You obtain information about volcanic emergencies from: \\
\hline a) & TV \\
\hline b) & Radio \\
\hline c) & News paper \\
\hline d) & Cell Phone \\
\hline e) & Internet \\
\hline f) & Social Media (twitter, Facebook, etc) \\
\hline g) & Did I miss any other groups of information on this list? \\
\hline
\end{tabular}

